Aus der Klinik für Psychiatrie und Psychotherapie

(Prof. Dr. med. J. Wiltfang)

der Medizinischen Fakultät der Universität Göttingen

\title{
Arzneimittelsicherheit in der Psychiatrie: Leberwerterhöhungen unter der Therapie mit Antipsychotika
}

\section{INAUGURAL-DISSERTATION \\ zur Erlangung des Doktorgrades der Medizinischen Fakultät der \\ Georg-August-Universität zu Göttingen}

vorgelegt von

Yannick Jörn Rudolph

aus

Kassel

Göttingen 2017 
Dekan:

Referent:

Ko-Referent:

Drittreferent:

Promotor-Vertretung:
Prof. Dr. Heyo K. Kroemer

Prof. Dr. Detlef Degner

Prof. Dr. Mladen Tzvetkov

PD Dr. Ahmad Amanzada

Prof. Dr. Thomas Meyer

Datum der mündlichen Prüfung: 24.01.2019 
Hiermit erkläre ich, die Dissertation mit dem Titel "Arzneimittelsicherheit in der Psychiatrie: Leberwerterhöhungen unter der Therapie mit Antipsychotika" eigenständig angefertigt und keine anderen als die von mir angegebenen Quellen und Hilfsmittel verwendet zu haben.

Göttingen, den 
Seite

Abbildungsverzeichnis ............................................................................................ III

Tabellenverzeichnis .............................................................................................. IV

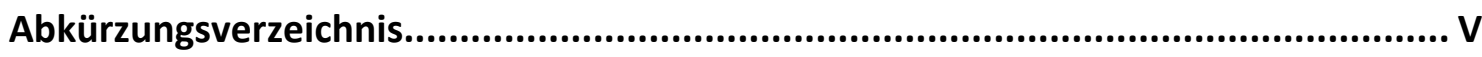

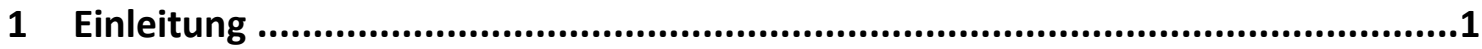

1.1 Historische Entwicklung der Antipsychotikatherapie............................................. 1

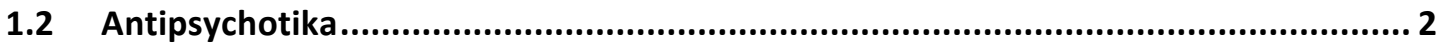

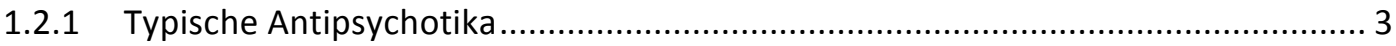

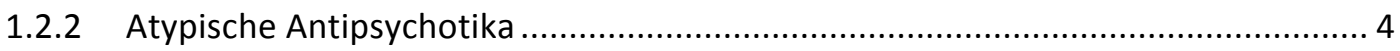

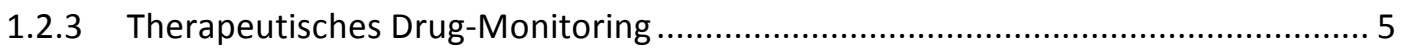

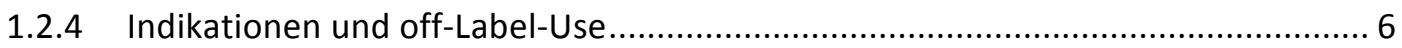

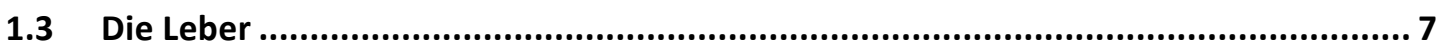

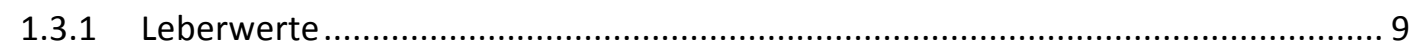

1.3.1.1 Alanin-Aminotransferase (ALT) und Aspartat-Aminotransferase (AST) .....................10

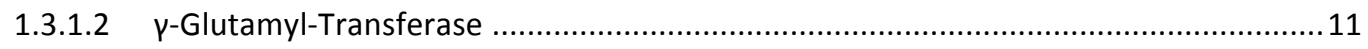

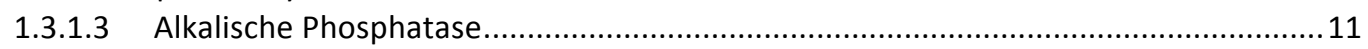

1.4 Pharmakokinetik und Pharmakodynamik ............................................................. 12

1.5 Biotransformation von Medikamenten in der Leber ........................................... 13

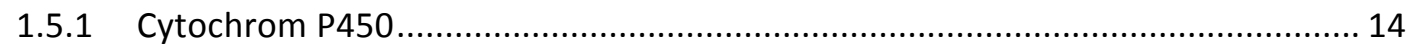

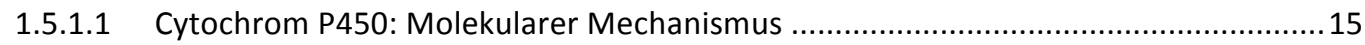

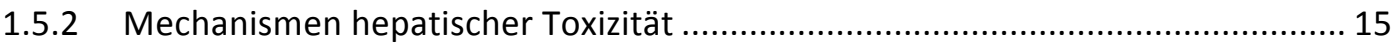

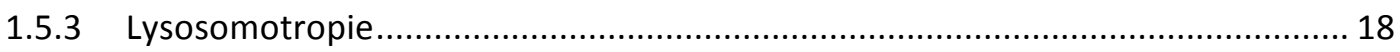

1.6 Schizophrenie: Pathophysiologie und Wirkungsmechanismus der Antipsychotika . 20

1.7 Klassifikation der unerwünschten Arzneimittelwirkungen .................................. 22

1.8 Bisherige Erkenntnisse zu Leberwerterhöhung unter Antipsychotikatherapie ........ 23

1.9 Zielsetzung der Untersuchung............................................................................... 24

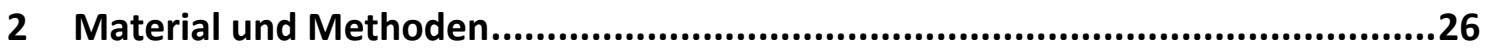

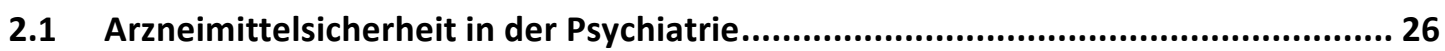

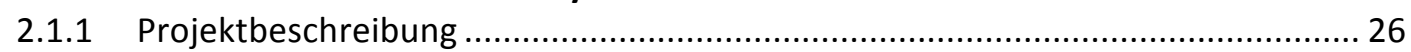

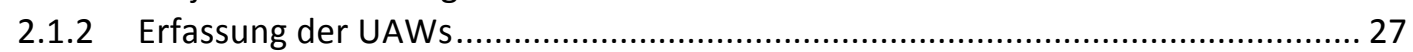

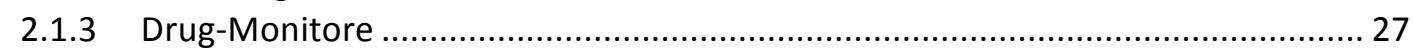

2.1.4 Alleinanschuldigung vs. Kombinationsanschuldigung...................................... 28

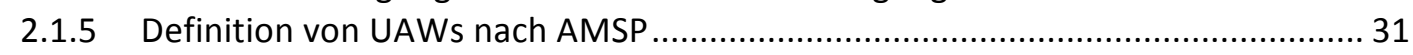

2.1.6 Kriterien für die Leberwerterhöhung als „schwere“ UAW ................................... 31

2.1.7 Erfassungsbogen für schwere UAWs nach AMSP .............................................. 31

2.1.8 Erfassung der Gesamtpopulation anhand von Stichtagserhebungen .................... 32

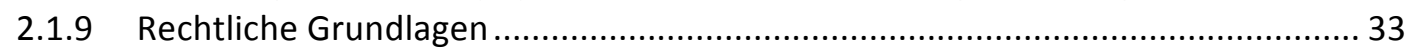

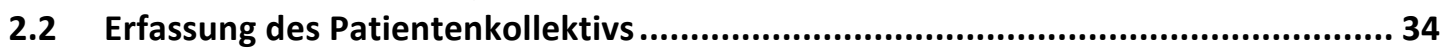

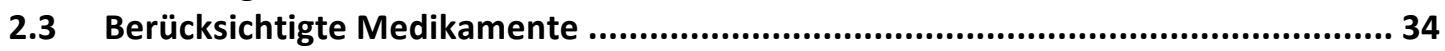

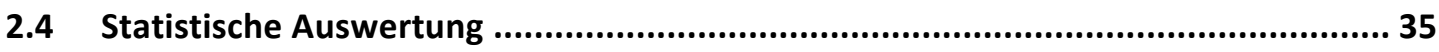

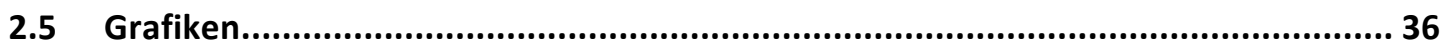

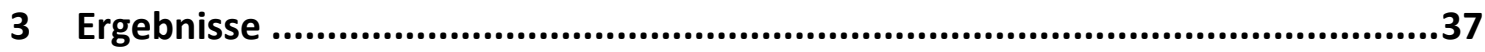

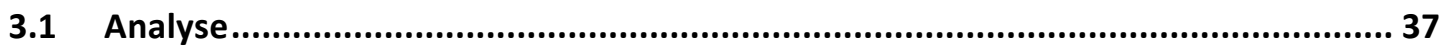

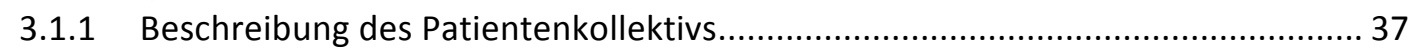

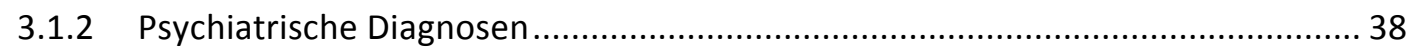

3.1.3 Somatische Diagnosen und Risikofaktoren bezüglich des Auftretens einer UAW 40 


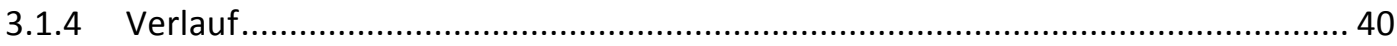

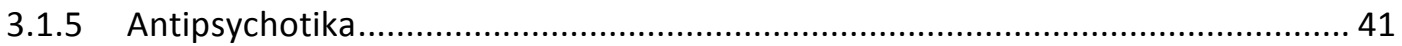

3.1.6 Präexposition und Reexposition ............................................................... 50

3.1.7 Laborparameter ............................................................................... 51

3.1.8 Geschätzte Inzidenzen der Leberwerterhöhung in drei Altersgruppen............... 52

3.1.9 Entwicklung in der Antipsychotikatherapie von 1994 bis 2012 ......................... 53

3.1.10 Dauer der Therapie bis zum Auftreten der UAW .......................................... 55

3.2 Signifikanztests / Unterschiede.................................................................... 57

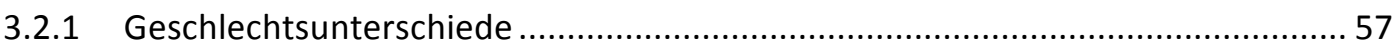

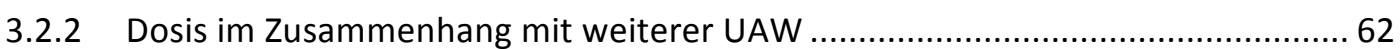

3.3 Kasuistik: Leberversagen............................................................................. 62

3.3.1 Fall 1: Leberversagen mit anschließender Lebertransplantation........................ 62

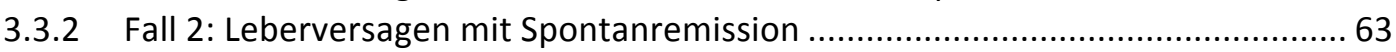

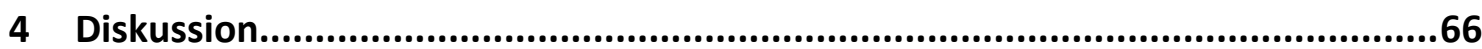

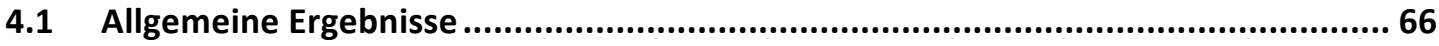

4.2 Der Einfluss von Risikofaktoren auf die Leberwerterhöhung ............................... 68

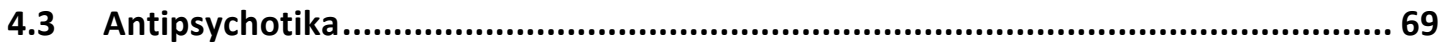

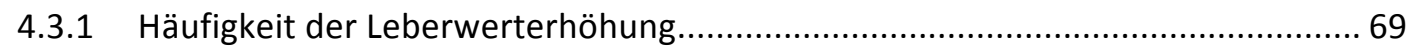

4.3.2 Zusammenhang von Dosis und Leberwerterhöhung ..................................... 70

4.3.3 Dauer der Therapie bis zum Auftreten der UAW ......................................... 71

4.4 Polypharmazie .................................................................................. 71

4.5 Geschlechtsunterschiede ................................................................... 73

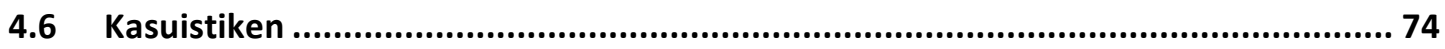

4.7 Limitierungen der Studie........................................................................ 76

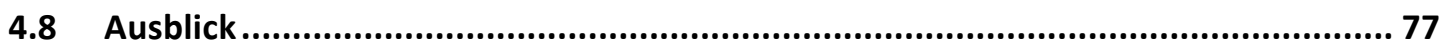

5 Zusammenfassung ..................................................................................78

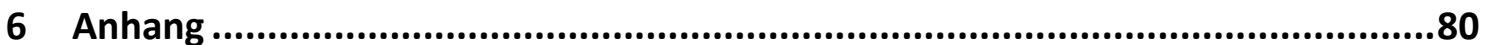

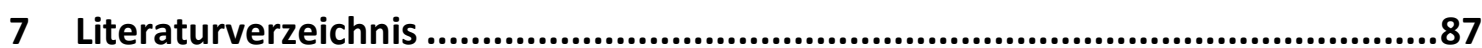




\section{ABBILDUNGSVERZEICHNIS}

ABBILDUNG 1: STRUKTURFORMELN VON PHENOTHIAZINEN UND THIOXANTHENEN .............................................. 4

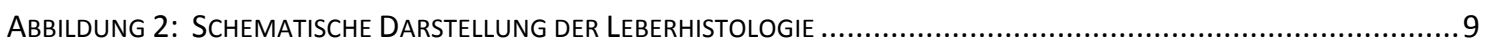

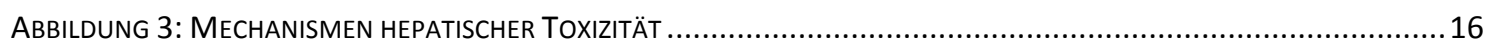

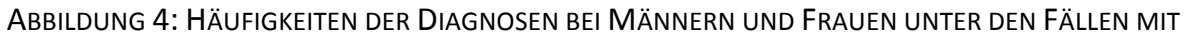

LEBERWERTERHÖHUNGEN

ABbildung 5: ANZAHL deR KOMBINATIONSANSCHULDIGUNGEN: ANTIPSYCHOtIKA, ANTIDEPRESSIVA, MOOD STABILIZER

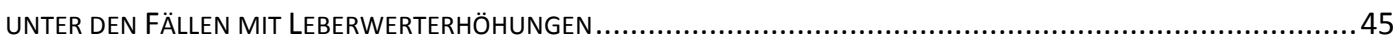

AbBILdUNg 6: LeBERWERTERHÖHUNGEN IN \% DER ÜBERWACHTEN PATIENTEN DES JEWEILIGEN ANTIPSYCHOTIKUMS .........49 Abbildung 7: Prozentualer Anteil der Verschiedenen Leberwerterhöhungen (AST, ALT, rGT) AN DEN FÄlLen Mit LEBERWERTERHÖHUNGEN BEI DEN JEWEILIGEN ANTIPSYCHOTIKA .................................................... 50

ABBILDUNG 8: ERMITTELTE INZIDENZ DER LEBERWERTERHÖHUNG UNTER DEN ALTERSGRUPPEN (IN JAHREN)...................53

ABBILDUNG 9: ENTWICKLUNGEN IN DER ANTIPSYCHOTIKATHERAPIE VON 1994 BIS 2012 ......................................54

ABBILDUNG 10: ERMITTELTE INZIDENZ DER SCHWEREN LEBERWERTERHÖHUNG ÜBER DIE GESCHLECHTER UND

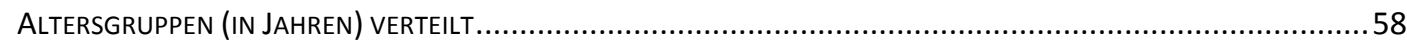

ABBILDUNG 11: ANTEIL DER LEBERWERTERHÖHUNGEN OBERHALB DES FÜNFFACHEN REFERENZWERTES AN ALLEN GEMESSENEN WERTEN 


\section{TABELLENVERZEICHNIS}

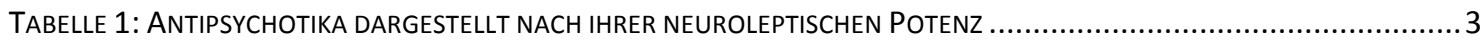

TABELLE 2: ZUGELASSENE INDIKATIONEN DER ANTIPSYCHOTIKA .................................................................... 7

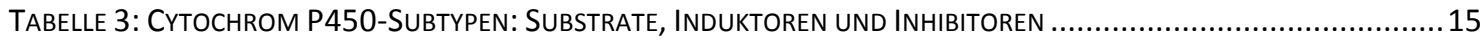

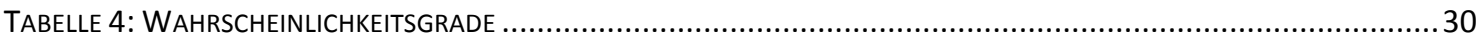

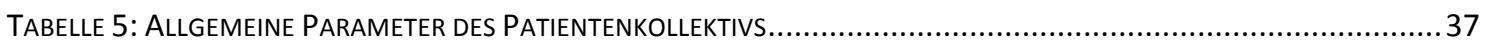

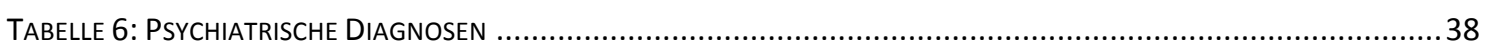

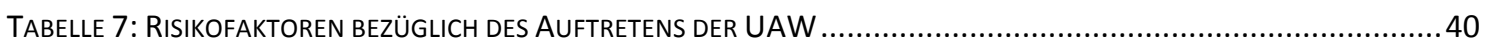

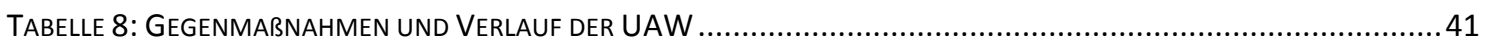

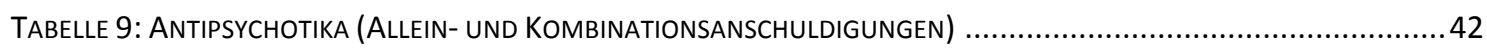

TABELle 10: ANTIPSYCHOTIKA (KombinATIONSANSCHULDIGUNGEN BEZÜGLICH DES AUFTRETENS DER

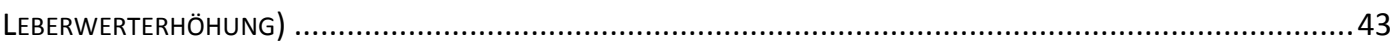

TABELLE 11: HÄUfIGKEITEN DER KOMBINATIONSANSCHULDIGUNGEN BEZÜGLICH DES AUFTRETENS EINER SCHWEREN

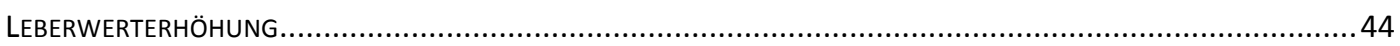

TABELLE 12: Dosis DER ANTIPSYCHOTIKA BEI DEN FÄLLEN MIT LEBERWERTERHÖHUNGEN ...........................................46

TABELLE 13: UNTERSCHIEDE IN DER DOSIS DER ANTIPSYCHOTIKA ZWISCHEN DEN FÄLLEN MIT LEBERWERTERHÖHUNG UND DER

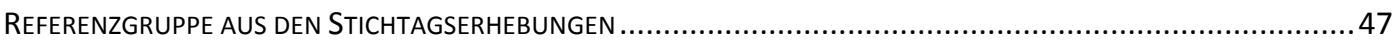

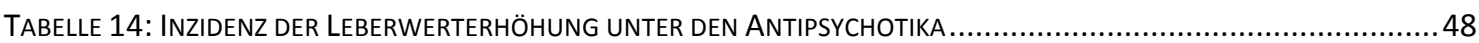

TABELLE 15: PRÄEXPOSITION UND REEXPOSITION MIT DEM JEWEILIGEN ANTIPSYCHOTIKUM .........................................51

TABELLE 16: HÄUFIGKEITEN DER LABORWERTE OBERHALB DES FÜNFFACHEN REFERENZWERTES UNTER DEN FÄLLEN MIT

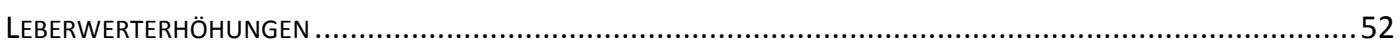

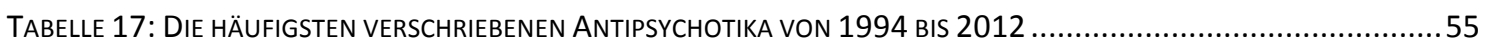

TABELLE 18: DAUER DER THERAPIE BIS ZUM AUfTRETEN DER UAW ................................................................5

TABELLE 19: GeSCHLECHTSUNTERSCHIEDE: RISIKOFAKTOREN UND SOMATISCHE DIAGNOSEN ..................................5

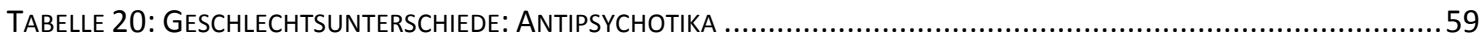

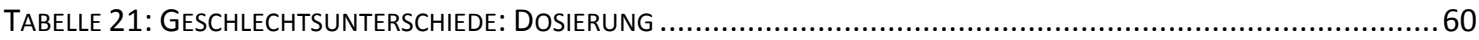

TABELLE 22: GESCHLECHTSUNTERSCHIEDE HINSICHTLICH DER LABORWERTE OBERHALB DES FÜNFFACHEN REFERENZWERTES 61

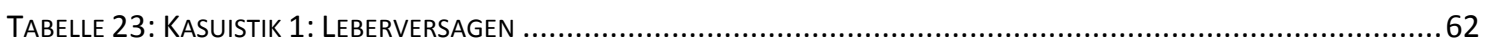

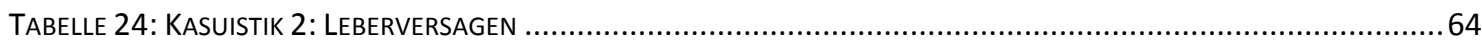




\section{ABKÜRZUNGSVERZEICHNIS}

5HT-Rezeptor

A.

ALT

ALT $>5 x$

AMSP

AP

AST

AST $>5 x$

ATP

ATY-AP

BfArM

BMI

cAMP

$\mathrm{CHE}$

CPZ

CYP

D-Rezeptor

EPMS

GLDH

H1-Rezeptor

$\mathrm{LDH}$

LWE

NADP

Ref-Gruppe

TDM

TYP-AP

TYP-HS

UAW
5-Hydroxytryptamin-Rezeptor (Serotonin-Rezeptor)

Arteria

Alanin-Aminotransferase

laborchemisch um mehr als das Fünffache des oberen

Referenzwertes erhöhte Alanin-Aminotransferase

Arzneimittelsicherheit in der Psychiatrie

Alkalische Phosphatase

Aspartat-Aminotransferase

laborchemisch um mehr als das Fünffache des oberen

Referenzwertes erhöhte Aspartat-Aminotransferase

Adenosintriphosphat

Atypisches Antipsychotikum

Bundesinstitut für Arzneimittel und Medizinprodukte

Body-Mass-Index

zyklisches Adenosinmonophosphat

Cholinesterase

Chlorpromazin

Cytochrom P450

Dopamin-Rezeptor (1 bis 5)

extrapyramidalmotorische Störungen

Glutamatdehydrogenase

Histamin-1-Rezeptor

Laktatdehydrogenase

Leberwerterhöhung

Nicotinamidadenindinukleotidphosphat

Referenzgruppe

Therapeutisches Drug-Monitoring

Typisches Antipsychotikum mit antipsychotischer Wirkung

Typisches Antipsychotikum mit hypnotisch-sedierender

Wirkung

Unerwünschte Arzneimittelwirkung 


$\begin{array}{ll}\text { UV } & \text { Ultraviolet } \\ \text { V. } & \text { Vena } \\ \text { VS } & \text { Versus } \\ \text { W-Grad } & \text { Wahrscheinlichkeitsgrad } \\ \text { VGT } & \text { Y-Glutamyltransferase } \\ \text { YGT>5x } & \text { laborchemisch um mehr als das Fünffache des oberen } \\ & \text { Referenzwertes erhöhte } \text { y-Glutamyltransferase }\end{array}$




\section{EINLEITUNG}

\subsection{Historische Entwicklung der Antipsychotikatherapie}

Nachdem in den 20er Jahren des letzten Jahrhunderts die Schizophrenie erstmals mit einer durch Insulin und im weiteren Verlauf elektrisch getriggerten Krampftherapie behandelt wurde, kam 1952 mit Chlorpromazin das erste Antipsychotikum auf den Markt, welches gezielt die psychotische Symptomatik medikamentös behandeln konnte. Nur wenige Jahre später (1958) folgte die Markteinführung von Haloperidol (Schott und Tölle 2006).

Das Therapiespektrum wurde im Verlauf um weitere, sogenannte „typische“ Antipsychotika ergänzt, die allesamt das Risiko bargen, extrapyramidalmotorische Störungen als unerwünschte Arzneimittelwirkung (= UAW) hervorzurufen (Hollister 1968). 1972 kam Clozapin als erstes atypisches Antipsychtotikum auf dem Markt, wies jedoch eine fatale UAW auf. Bei einigen Patienten in Finnland kam es im Rahmen der Therapie zu einer lebensbedrohlichen Agranulozytose mit zum Teil letalen Verläufen (Idänpään-Heikkilä et al. 1977).

In den folgenden Jahren erhielten beispielsweise Olanzapin, Quetiapin und Risperidon als weitere atypische Antipsychotika ihre Zulassung. Von der Therapie mit typischen Präparaten wurde zunehmend auf den Einsatz von atypischen Antipsychotika übergegangen (Grohmann et al. 2004a). Jedoch stellte sich heraus, dass die atypischen Antipsychotika unter anderem zahlreiche metabolische UAWs verursachten, wie beispielsweise Diabetes mellitus und Gewichtszunahme (Melkersson und Dahl 2012). Als neue Substanz der atypischen Antipsychotika ist Aripiprazol der erste Partialagonist am D2- und 5HT1A-Rezeptor mit gleichzeitig antagonistischer Wirkung am 5HT2A-Rezeptor (Burris et al. 2002), der auf dem Markt erschien und darüber hinaus auch im Vergleich zu Olanzapin deutlich seltener zu Gewichtszunahmen als unerwünschte Arzneimittelwirkung führte (McQuade et al. 2004). 


\subsection{Antipsychotika}

Antipsychotika lassen sich in typische (oder auch Antipsychotika der ersten Generation) und atypische Antipsychotika (Antipsychotika der zweiten Generation) unterteilen. Atypische Antipsychotika wirken sowohl gegen die positive als auch die negative Symptomatik bei Schizophrenien. Wobei Clozapin als Prototyp des atypisches Antipsychotikum im ursprünglichen Sinne bezeichnet werden kann, da es praktisch keine extrapyramidalmotorischen Störungen verursacht. Andere Antipsychotika, die ebenfalls den Atypika zugerechnet werden, sind sehr wohl bei höherer Dosierung in der Lage, extrapyramidalmotorische Störungen zu verursachen (Knable et al. 1997). Die atypische Wirkung lässt sich anhand des schnellen Abdissoziierens von den D2-Rezptoren erklären. Eine lang andauernde und feste Bindung zu den D2-Rezeptoren verursacht in der Regel die extrapyramidalmotorischen Störungen (Kapur und Seeman 2001).

Weiterhin lassen sich die Antipsychotika in hoch-, mittel- und niederpotent anhand ihrer neuroleptischen Potenz untergliedern. Die neuroleptische Potenz lässt sich in Chlorpromazin (CPZ)-Äquivalent angeben. Chlorpromazin kam als erstes Antipsychotikum zur Anwendung und erhält ein CPZ-Äquivalent von 1. Weitere Antipsychotika werden anhand ihrer neuroleptischen Potenz in Relation betrachtet. Ein Antipsychotikum mit einem CPZ-Äquivalent von 2 ist entsprechend doppelt so potent wie Chlorpromazin. Antipsychotika mit einem CPZ-Äquivalent kleiner als 1 werden als niedrigpotent beschrieben, solche mit einem Wert zwischen 1 und 10 als mittelpotent und jene mit einem CPZ-Äquivalent über 10 als hochpotent. Eine hohe neuroleptische Potenz steht in direktem Zusammenhang mit einer hohen Affinität des Neuroleptikums zu dem D2-Rezeptor und der damit verbundenen antipsychotischen Wirkung. Niederpotente Antipsychotika wirken hingegen eher sedierend, aber kaum antipsychotisch, da sie affiner an Histamin- oder Serotonin-Rezeptoren binden (Benkert et al. 2010). 
Tabelle 1: Antipsychotika dargestellt nach ihrer neuroleptischen Potenz

\begin{tabular}{|l|r|l|r|l|r|}
\hline Hochpotent & \multicolumn{1}{|l|}{ CPZ-Ä } & Mittelpotent & \multicolumn{1}{l|}{ CPZ-Ä } & Niederpotent & \multicolumn{1}{|l|}{ CPZ-Ä } \\
\hline Benperidol & 75 & Clozapin & 1 & Amisulprid & 0,2 \\
\hline Bromperidol & 50 & Melperon & 1 & Chlorprothixen & 0,8 \\
\hline Flupentixol & 50 & Perazin & 1 & Levomepromazin & 0,5 \\
\hline Haloperidol & 50 & Quetiapin & 1 & Pipamperon & 0,8 \\
\hline Olanzapin & 50 & Zuclopenthixol & 5 & Promethazin & 0,5 \\
\hline Risperidon & 50 & & & Prothipendyl & 0,7 \\
\hline Aripiprazol & 15 & & & & \\
\hline
\end{tabular}

Modifiziert nach Bandelow et al. (2011, S. 95 - 96), ergänzt auf Grundlage der Aufführrungen aus Riederer und Laux (2010), CPZ-Ä = Chlorpromazin-Äquivalent

\subsubsection{Typische Antipsychotika}

\section{Phenothiazine:}

Die Phenothiazine bestehen aus einem Kohlenstoff-Trizyklus mit zwei Substituenten, die je nach Medikament variieren. Der zentrale Zyklus des Phenothiazins besteht aus sechs Atomen mit einem Schwefelatom an Position 5 und einem Stickstoffatom an Position 10 (siehe Abbildung 1). Anhand der Substituenten lassen sich die Phenothiazine in drei Unterklassen unterteilen.

a) Aliphatische Seitenkette:

Die Eigenschaft dieser Substanzgruppe ist die hohe antagonistische Potenz gegen muskarinerge, $\mathrm{H} 1$ - und $\alpha 1$-Rezeptoren mit stark sedierender Wirkung. Ein Wirkstoff dieser Substanzklasse ist Chlorpromazin.

b) Piperidin-Seitenkette:

Die Phenothiazine mit einer Piperidin-Seitenkette als Substituent wirken stark antimuskarinerg und gering antidopaminderg, wodurch sich die verminderte Entstehung von extrapyramidalmotorischen Störungen erklären lässt. Ein Präparat dieser Klasse ist das Thioridazin.

c) Piparazin-Seitenkette:

Diese Substanzklasse bindet stärker an D2-Rezeptoren, jedoch geringer an $\alpha 1-$, Muskarin- und H1-Rezeptoren. Hierzu zählen Fluphenazin und Perphenazin (Schatzberg und Nemeroff 2009). 


\section{Thioxanthene:}

Die Thioxanthene sind von der Grundstruktur sehr ähnlich wie die Phenothiazine aufgebaut, haben jedoch an Position $10 \mathrm{im}$ Trizyklus ein Kohlenstoffatom anstatt des Stickstoffatoms (siehe Abbildung 1). Anhand ihrer Substrate, die denen der Phenothiazine gleichen, lassen sich ihre Wirkweisen analog ableiten.

a) Aliphatische Seitenkette:

Präparat: Chlorprothixen

b) Piperazin-Seitenkette:

Präparate: Flupentixol, Zuclopentixol (Gründer 2011)

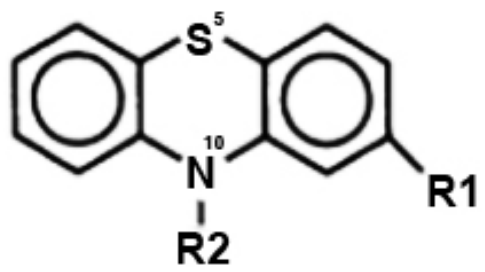

Phenothiazin

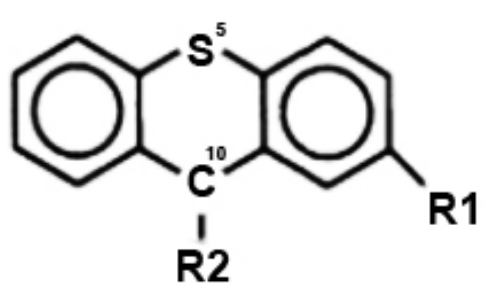

Thioxanthen

Abbildung 1: Strukturformeln von Phenothiazinen und Thioxanthenen Modifiziert nach Minchin und Csernansky (1996, S. 7), R1 und R2 markieren die Bereiche, an denen die Substituenten binden, anhand derer sich die Antipsychotikagruppen und deren jeweilige Antipsychotika unterscheiden.

\section{Butyrophenone:}

Vertreter dieser Substanzklasse wirken vor allem an D2-Rezeptoren und sind damit stark antipsychotisch und wirken nur sehr gering an anderen Rezeptoren. Hierzu zählen Haloperidol und Droperidol (Schatzberg und Nemeroff 2009).

\subsubsection{Atypische Antipsychotika}

Die atypischen Antipsychotika lassen sich unter anderem unterteilen in Dibenzepine und substituierte Benzamide.

Die Dibenzepine sind gering bis mittelgradig affin zu D2-Rezeptoren, wirken jedoch stark vegetativ über ihre Antagonisierung an $\mathrm{H} 1-$, Muskarin- und 
a1-Rezeptoren. Beispiele dieser Substanzklasse sind Clozapin, Olanzapin, Quetiapin und Zotepin.

Substituierte Benzamide weisen eine hohe antagonistische Wirkung an D2- und D3-Rezeptoren auf und können wegen ihrer hydrophilen Eigenschaften nur schwer die Blut-Hirn-Schranke passieren. Sie können somit zu einem großen Teil unverändert renal eliminiert werden und haben somit eine geringe Bioverfügbarkeit. Ein Antipsychotikum dieser Substanzklasse ist Amisulprid (Gründer 2011).

\subsubsection{Therapeutisches Drug-Monitoring}

Das therapeutische Drug-Monitoring (TDM) dient der Ermittlung der Plasmakonzentration des zu untersuchenden Medikaments. So kann anhand von definierten Referenzwerten überprüft werden, ob der Plasmaspiegel hoch genug ist, um im therapeutischen Rahmen wirksam zu sein. Allen voran kommt das therapeutische Drug-Monitoring im Falle schlechter Compliance, bei älteren Patienten, bei Ultra-Rapid-Metabolizers oder Poor-Metabolizers und bei Leberschäden zum Einsatz, um unerwünschte Arzneimittelwirkungen zu vermeiden, den therapeutischen Effekt zu erzielen und die Lebensqualität zu bewahren (Balant-Gorgia und Balant 1995). Der Plasmaspiegel ist ein Anhaltspunkt dafür, wie stark das Medikament seine therapeutische Wirkung entfalten kann (Eilers 1995). Darüber hinaus bietet das TDM auch die Möglichkeit anhand der Plasmakonzentration zu prüfen, ob die Gabe einer Komedikation die Metabolisierung des Medikamentes beeinflusst (BalantGorgia und Balant 1995). Beispielsweise konnte in einer Studie für Olanzapin nachgewiesen werden, dass ab einem Blutplasmaspiegel von mehr als 9,2 ng/ml eine Reduktion der schizophrenen Symptomatik signifikant häufiger als bei geringerer Konzentration festzustellen war (Perry et al. 1997). Für die Psychiatrie hat die Arbeitsgemeinschaft für Neuropsychopharmakologie und Pharmakopsychiatrie (AGNP) für zahlreiche in der Klinik angewandte Substanzen Richtwerte und Empfehlungen zum optimalen Drug-Monitoring veröffentlicht. Anhand derer soll in der Klinik die Entscheidung leichter Fallen, wie und in welchem Rahmen therapeutisches Drug-Monitoring durchgeführt werden sollte (Hiemke 2016). 


\subsubsection{Indikationen und off-Label-Use}

Antipsychotika sind klinisch indiziert bei Schizophrenien, schizoaffektiven, bipolaren, psychotisch affektiven (in Kombination mit Antidepressiva) und neurologischen Störungen, wie beispielsweise medikamenteninduzierten psychotischen Symptomen in der Parkinsontherapie. Als möglicherweise wirksam gilt der Einsatz bei Persönlichkeits-, Zwangs- oder Angststörungen, organischen Psychosen, Schmerzsyndromen und der nicht-psychotischen Depression (Benkert et al. 2012). Die typischen Antipsychotika sind bei der Schizophrenie vor allem gegen die Positivsymptomatik wirksam. Eine zusätzliche partielle Wirksamkeit gegen eine „Negativsymptomatik“ zeigen stärker die atypischen Antipsychotika. Unwirksam sind diese Substanzen jedoch gegen die mit einer Schizophrenie meist einhergehenden kognitiven Störungen (Gründer 2011). Clozapin war in Studien im Rahmen der Negativsymptomatik einer Schizophrenie oder der schizoaffektiven Störung auch suizidpräventiv wirksam (Meltzer HY et al. 2003). Die Indikationen der für diese wissenschaftliche Arbeit relevanten Antipsychotika sind in Tabelle 2 aufgeführt. Allerdings werden Antipsychotika auch häufig über die von dem zuständigen Institut BfArM zugelassenen Indikationen hinaus off-Label eingesetzt (Alexander et al. 2011). Nach einem Urteil des Bundessozialgerichtes vom 19.03.2003 sind off-Label-Behandlungen über die gesetzliche Krankenversicherung abrechenbar, wenn es keine Behandlungsalternative gibt, die zu behandelnde Erkrankung schwer ist und die aktuelle Studienlage einen Therapieerfolg in Aussicht stellt (Schimmelpfeng-Schütte 2004). 
Tabelle 2: Zugelassene Indikationen der Antipsychotika

\begin{tabular}{|c|c|}
\hline Antipsychotikum & Indikation \\
\hline Amisulprid & $\begin{array}{l}\text { Akute und chronisch schizophrene Störungen, primäre } \\
\text { Negativsymptomatik }\end{array}$ \\
\hline Aripiprazol & Schizophrenie, manische Episoden \\
\hline Benperidol & $\begin{array}{l}\text { Akute psychotische Syndrome, Delir, exogene Psychosen, } \\
\text { Katatonie, psychomotorische Erregungszustände, Manie, } \\
\text { Rezidivprophylaxe bei chronischen Psychosen }\end{array}$ \\
\hline Bromperidol & Kein Vorteil im Vergleich zu Haloperidol, daher verzichtbar \\
\hline Chlorprothixen & $\begin{array}{l}\text { Psychomotorische Unruhe bei psychotischen Syndromen, } \\
\text { maniforme Syndrome }\end{array}$ \\
\hline Clozapin & $\begin{array}{l}\text { Akute und chronische Schizophrenie, Psychosen bei M. Parkinson } \\
\text { und Lewy-Body-Demenz }\end{array}$ \\
\hline Flupentixol & Schizophrenie \\
\hline Haloperidol & $\begin{array}{l}\text { Akute psychotische Syndrome, katatone Syndrome, Delir, exogene } \\
\text { Psychosen, chronische Psychosen, Manie, psychomotorische } \\
\text { Erregungszustände, Dyskinesien und Tic-Störungen (niedrige } \\
\text { Dosierung), Kombinationstherapie bei Schmerzen, Erbrechen, } \\
\text { Stottern, Angstsyndrome, autistische Störungen }\end{array}$ \\
\hline Levomepromazin & $\begin{array}{l}\text { Erregungszustände bei psychotischen und maniformen Störungen, } \\
\text { Kombinationstherapie bei Schmerzen }\end{array}$ \\
\hline Melperon & $\begin{array}{l}\text { Schlafstörungen, Verwirrtheitszustände, Psychoneurosen, } \\
\text { Erregungszustände, Oligophrenie, organische Demenz, } \\
\text { alkoholinduzierte Störungen }\end{array}$ \\
\hline Olanzapin & $\begin{array}{l}\text { Schizophrenie, Manie, Phasenprophylaxe bei bipolarer Störungen } \\
\text { (sofern Ansprechen bei manischer Phase) }\end{array}$ \\
\hline Perazin & $\begin{array}{l}\text { Akute psychotische Syndrome, maniforme Syndrome, } \\
\text { Erregungszustände, katatone Syndrome, chronische Psychosen }\end{array}$ \\
\hline Pipamperon & $\begin{array}{l}\text { Psychomotorische Erregung, Aggressivität, Schlafstörungen, } \\
\text { Verwirrtheitszustände, Affektverarmung, Affektlabilität }\end{array}$ \\
\hline Promethazin* & $\begin{array}{l}\text { Schlafstörungen, Unruhe und Erregungszustände bei } \\
\text { psychiatrischen Erkrankungen }\end{array}$ \\
\hline Prothipendyl & Komedikation bei schweren Einschlafstörungen \\
\hline Quetiapin & $\begin{array}{l}\text { Schizophrenie, manische Episoden bei bipolaren Störungen, } \\
\text { schwere Depression bei bipolarer Störung, Prävention bei } \\
\text { bipolaren Störungen, Komedikation bei Depression }\end{array}$ \\
\hline Risperidon & $\begin{array}{l}\text { Chronisch schizophrene Psychosen, manische Episoden bei } \\
\text { bipolaren Störungen, Aggression bei M. Alzheimer bei Risiko der } \\
\text { Eigen- oder Fremdgefährdung, Aggression und Verhaltensstörung } \\
\text { bei Kindern ab } 5 \text { Jahren mit mentaler Retardierung }\end{array}$ \\
\hline Zuclopenthixol & $\begin{array}{l}\text { Schizophrenie, Manie, Erregungszustände bei geistiger } \\
\text { Behinderung, Verwirrtheitszustände bei Demenz }\end{array}$ \\
\hline
\end{tabular}

Erstellt auf der Grundlage der Aufführungen von Benkert et al. (2010), *wird nach Benkert et al. als Hypnotikum klassifiziert

\subsection{Die Leber}

Bei der Leber handelt es sich um ein intraperitoneal gelegenes Organ. Sie ist von der Glisson-Kapsel umgeben und lässt sich in vier makroskopisch sichtbare Lappen untergliedern. Diese Lappen werden weiterhin in acht Lebersegmente unterteilt, die anhand des Verlaufs der portalen Trias voneinander unterschieden werden. 
Die Leber nimmt hinsichtlich ihrer Blutversorgung eine besondere Stellung im Organsystem des Körpers ein. So drainiert sie über die Vena portae hepatis das Blut aus dem portalen Kreislauf und hat so eine entgiftende Funktion. Arteriell wird sie über die Arteria hepatica propria aus dem Truncus coeliacus versorgt. Das Blut fließt letztlich über drei Lebervenen ab in die Vena cava inferior (Tillmann 2010).

Histologisch und physiologisch lässt sich die Leber in anatomische und funktionelle Untereinheiten gliedern. So stellt das Leberläppchen eine sechseckige Baueinheit dar, die die Hepatozyten, Sinusioide und eine Zentralvene enthält. In den Ecken des Sechseckes verläuft im bindegewebigen Raum die so genannte "Glisson-Trias“, bestehend aus einem Ast der A. hepatica propria, einem Ast der V. portae und einem interlobulären Gallengang. Aus der Arterie und der Vene verläuft in den Sinusuoiden Mischblut von peripher nach zentral in die entsprechende Zentralvene. Parallel zu den Sinusoiden verlaufen die Hepatozyten, die wiederum mit dem Bereich, wo Hepatozyt an Hepatozyt grenzt die Gallenkanälchen bilden, die antiparallel zu den Sinusoiden verlaufend die von den Hepatozyten produzierte Galle abtransportieren (Wachtler 2005). Die Wand der Sinusoide wird durch Endothelzellen, Kupffer-Zellen und ItoZellen begrenzt (Widmann et al. 1972). Die Endothelzellen bilden mit einem diskontinuierlichen, nicht durch ein Diaphragma verschlossenes, Endothel ein sehr durchlässiges Netz ohne zugehörige Basallamina (Ogawa et al. 1973).

Die funktionelle Untereinheit der Leber ist der Leberazinus, der mikroskopisch durch zwei periportal gelegene Glisson-Trias und eine Zentralvene dreieckig begrenzt wird. Anhand des Azinus lässt sich die Sauerstoffversorgung des Leberläppchens besser erklären. Von der Zentralvene aus gesehen am periphersten liegt die Zone 1, die am besten oxygeniert wird. Zone 3, die der Zentralvene anliegt, wird entsprechend am schlechtesten mit Sauerstoff versorgt (Welsch und Sobotta 2006; Sherlock und Dooley 2008) (siehe Abbildung 2).

Die Hepatozyten nehmen als funktionelle Zellen der Leber wichtige Rollen in endokrinen Vorgängen, Gallenproduktion, Säure-Base-Regulation, Biotransformation und vielen weiteren für den Körper wichtigen Vorgängen ein 
(Beckh 2010). Eine besondere Relevanz kommt hinsichtlich dieser Arbeit der Biotransformation von Medikamenten über unterschiedliche Cytochrom P450-Subtypen zu (siehe 1.5.1).

Weiterhin gibt es in der Leber die sogenannten Kupffer-Zellen, die als Makrophagen immunologische Funktionen der Leber übernehmen (Widmann et al. 1972; Bilzer et al. 2006)

Im Disse-Raum liegen die Ito-Zellen (oder auch Stern-Zellen), die mittels ihrer kontraktilen Ausläufer den Blutfluss in den Sinusoiden regulieren können. Darüber hinaus können sie Vitamin A speichern, sind zustätzlich auch verantwortlich für die vermehrte Bildung von extrazellulärer Matrix im Rahmen der Leberzirrhose (Hautekeete und Geerts 1997).

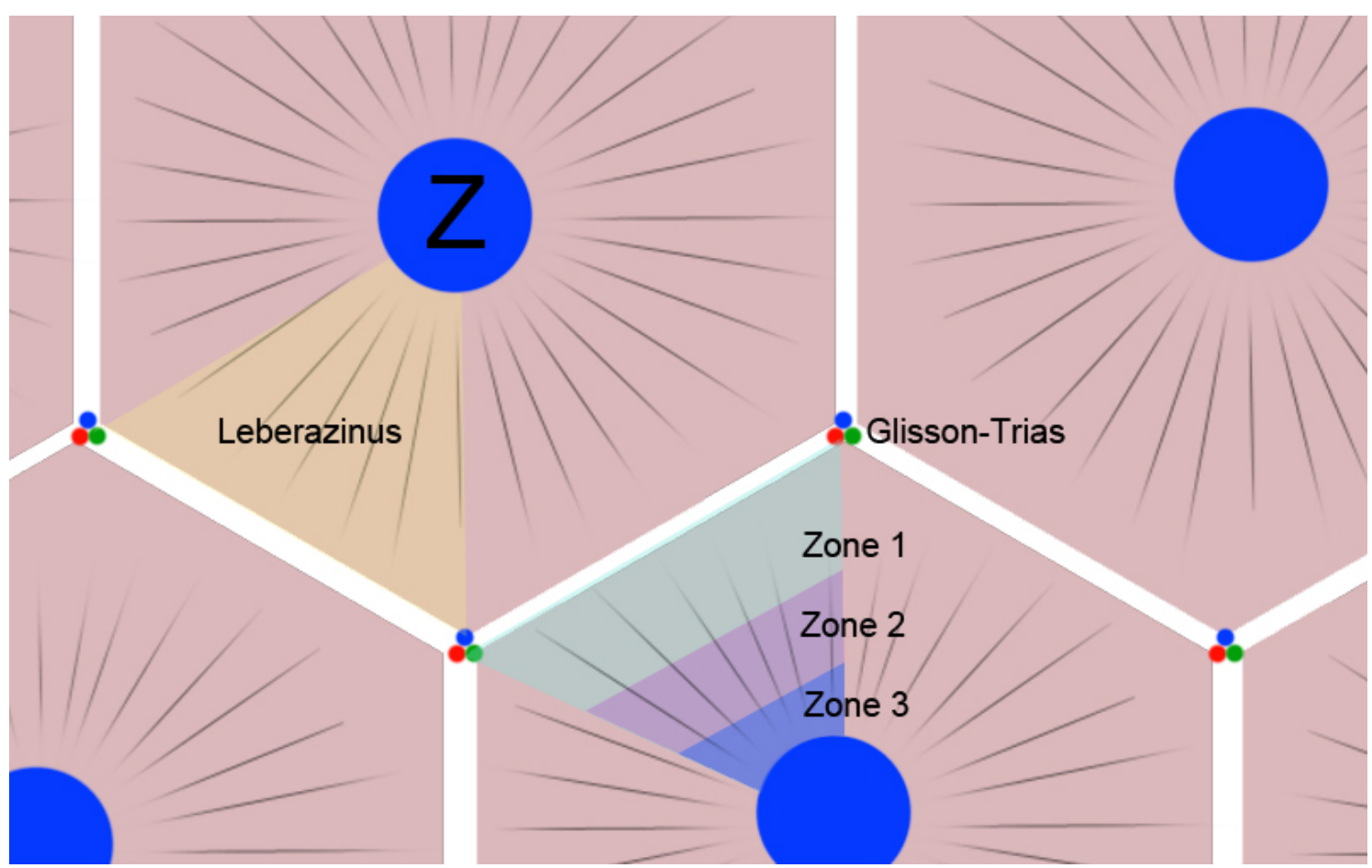

Abbildung 2: Schematische Darstellung der Leberhistologie

Z = Zentralvene; Glisson-Trias: Rot = Ast der A. hepatica, Blau = Ast der V. portae, Grün = interlobulärer Gallengang

\subsubsection{Leberwerte}

Bei den im Blut gemessenen Leberwerten handelt es sich überwiegend um Enzyme, die aufgrund von Zelluntergang oder vermehrter Sekretion bei exogener Stimulation ins Blut übergehen. Zu den Werten, die laborchemisch häufig bestimmt werden, um die Leber auf ihre Funktionalität zu überprüfen, 
zählen Alanin-Aminotransferase (ALT), Aspartat-Aminotransferase (AST), Alkalische Phosphatase (AP), y-Glutamyltransferase (yGT) und Bilirubin. Dabei dienen ALT und AST vor allem dem Nachweis eines hepatozellulären Schadens, wohingegen AP und yGT bei einer Cholestase ansteigen. Bei Bilirubin handelt es sich um ein Abbauprodukt des Hämoglobins. Bevor Bilirubin in der Leber konjugiert wird, bezeichnet man es als indirektes oder unkonjugiertes Bilirubin, welches unter anderem bei Hämolyse ansteigt, aber auch bei Einstellung der Leberfunktion und folglich verringerter Aufnahme des unkonjugierten Bilirbins ansteigen kann. Direktes oder auch konjugiertes Bilirubin ist im Blut vermehrt zu finden, wenn der Gallenabfluss gestört oder die hepatozelluläre Gallenexkretion verringert ist (Gressner und Arndt 2013). Im Folgenden werden die vier Leberwerte, die nach den Kriterien der „Arzneimittelsicherheit in der Psychiatrie" (siehe 2.1.6) relevant sind, noch einmal genauer erläutert.

\subsubsection{Alanin-Aminotransferase (ALT) und Aspartat-Aminotransferase (AST)}

ALT und AST zählen zu der Gruppe der Aminotransferasen, die dafür sorgen, dass der Malat-Aspartat-Shuttle der Mitochondrienmembran aufrechterhalten werden kann und so das aus der Gylkolyse, die im Zytosol stattfindet, gewonnene $\mathrm{NADPH}+\mathrm{H}^{+}$den Mitochondrien zur ATP-Synthese zuzuführen (Heinrich et al. 2012). Die beiden Enzyme katalysieren die folgenden Reaktionen:

- ALT: L-Alanin $+\alpha$-Ketoglutarat $\rightleftharpoons$ Pyruvat + L-Glutamat

- AST: L-Aspartat $+\alpha$-Ketoglutarat $\rightleftharpoons$ Oxalacetat + L-Glutamat (Han et al. 2011)

Die ALT liegt zu $80 \%$ im Zytosol der Hepatozyten vor, zu $20 \%$ in den Mitochondrien. Bei der AST ist das Verhältnis genau andersherum $(80 \% \mathrm{im}$ Mitochondrium, $20 \%$ im Zytosol) (Bruhn 2008) und sie ist weitaus weniger leberspezifisch, da sie ebenfalls in hoher Aktivität in den Herz- und Skelettmuskelzellen vorkommt (Kuntz und Kuntz 2009). Anhand der Verteilung in der Leber lässt sich der de Ritis-Quotient erklrären. Der de Ritis-Quotient gibt das Verhältnis von AST zu ALT gemessen im Blut an. Ein de Ritis-Quotient $<1$ spricht eher für einen geringen Leberschaden, da die AST aus den Mitochondrien noch in nicht so starkem Maße freigesetzt 
wurde. Dieses Bild findet sich bei einer Virushepatitis (De Ritis et al. 1957; De Ritis et al. 1965). Ein Wert > 1 spricht für einen sehr hohen Blutplasmaspiegel der AST, was für einen starken hepatozellulären Schaden, eine Nekrose, spricht (Lauer 2009). Die Halbwertszeit der AST im Blut liegt bei 12 bis 14 Stunden und die der ALT bei 50 Stunden (Thomas 1998).

\subsubsection{2 y-Glutamyl-Transferase}

Die $\mathrm{Y}$-Glutamyl-Trasnferase ( $\mathrm{YGT}$ ) ist in der Membran zahlreicher Zellen des Organismus lokalisiert und hat ein nach extrazellulär gerichtetes katalytisches Zentrum, ihre Halbwertszeit im Blut liegt laborchemisch bei drei bis vier Tagen (Thomas 1998). Sie befindet sich außerhalb der Leber und den Gallenkanälen noch in der Niere, dem Pankreas, dem Thymus, den Nebenhoden und im Gehirn. Sie transferiert dem Namen nach GlutamylReste auf verschiedene Proteine und sorgt für den Abbau von Glutathion (Kuntz und Kuntz 2009). Die yGT ist in der Kombination mit der alkalischen Phosphatase ein sehr gut geeigneter laborchemischer Marker für chronischen Leberschaden. Ihr reaktiver Anstieg im Blut korreliert mit dem Anstieg der alkalischen Phosphatase und spricht vor allem für eine Cholestase (Whitfield et al. 1972). Abgesehen davon, dass die yGT für einen hepatobiliären Schaden ein sehr sensitiver Marker ist, findet sich die Erhöhung der yGT physiologisch in der frühen Kindheit oder bei pathologischen Prozessen wie Diabetes mellitus, chronischem Alkoholkonsum, der Leberzirrhose, Herz- und Prankreaserkrankungen (Penn und Worthington 1983). Darüber hinaus wurde auch ein signifikanter Zusammenhang zwischen yGT und dem metabolischen Syndrom festgestellt, der vermuten lässt, dass eine Erhöhung der yGT auch durch das metabolische Syndrom bedingt sein kann (Rantala et al. 2000). Es zeigte sich, dass die YGT ein sehr sensitiver Marker zur Unterscheidung zwischen Knochen- und Lebererkrankungen ist, da hier bei erhöhter AP die yGT bei Lebererkrankungen häufiger ebenfalls erhöht ist (Lum und Gambino 1972).

\subsubsection{Alkalische Phosphatase}

Es werden mehrere Isoenzyme der alkalischen Phosphatase beschrieben, weshalb auch ein Rückschluss auf ein einziges Organ bei der Bestimmung der alkalischen Phosphatase nicht möglich ist. So wird die alkalische 
Phosphatase im Knochen, in der Leber, in der Niere und in der Plazenta synthetisiert (Moss 1982; Van Hoof und De Broe 1994). Ein erhöhter Wert kann so in der Wachstumsphase bei erhöhter Osteoblastenaktivität oder bei verschiedenen Knochenerkrankungen, wie beispielweise dem Morbus Paget, messbar sein (Warnes 1972).

In Studien stieg die alkalische Phosphatase vor allem bei Verschluss des Gallenganges im Rahmen einer daraus folgenden Cholestase reaktiv an (Kaplan und Righetti 1970). Eine erhöhte AP findet sich auch häufig bei Patienten mit Leberzirrhose (Warnes et al. 1977). Ihre Halbwertszeit im Blut ist mit drei bis sieben Tagen im Vergleich zu den vorher beschriebenen Parametern relativ lang (Thomas 1998).

\subsection{Pharmakokinetik und Pharmakodynamik}

Die Pharmakokinetik beschreibt die Schritte, die ein Medikament von der Aufnahme bis zur Ausscheidung durchläuft. Die Pharmakodynamik bezieht sich auf die Effekte des Medikamentes auf den Körper, wodurch sich die gewünschten und unerwünschten Arzneimittelwirkungen beschreiben lassen. Wie ein Medikament im Körper aufgenommen und verarbeitet wird, ist von seiner Fähigkeit, Membranen zu durchdringen, der Blutflussrate in verschiedenen Geweben und dem Transport im Plasma und der Aufnahme in das Gewebe abhängig (Daniel 2003).

Die Pharmakokinetik wird in verschiedene Schritte unterteilt. Die Freisetzung (engl.: Liberation) steht an erster Stelle, gefolgt von der Absorption, der Verteilung (engl: Distribution), dem Metabolismus und letztlich der Ausscheidung (engl.: Excretion). Die molekularen Eigenschaften des Medikamentes sind dabei entscheidend, wie gut oder schlecht es absorbiert, wie stark verteilt, wie schnell metabolisiert und ausgeschieden wird. Die einzelnen Schritte werden in dem sogenannten LADME-Schema $(\mathrm{L}=$ Liberation, $\mathrm{A}=$ Absorption, $\mathrm{D}=$ Distribution, $\mathrm{M}=$ Metabolism, $\mathrm{E}=\mathrm{Ex}-$ cretion) zusammengefasst (Schmidt 2007).

Ein Maß für die Fähigkeit des Gewebes, Medikamente aufzunehmen, ist das Verteilungsvolumen $V_{D}$, welches den proportionalen Anteil der applizierten Menge des Medikamentes zur Blutplasmakonzentration des Medikamentes angibt (Mörike und Eichelbaum 2000). Direkt verbunden damit ist die 
Halbwertszeit eines Medikamentes, die angibt, nach welcher Zeit die Hälfte der maximalen Konzentration des Medikamentes noch im Plasma vorzufinden ist (Meier et al. 1974). Entscheidend für die Wirksamkeit eines Medikamentes ist der so genannte first-pass Effekt, der den Anteil des applizierten Medikamentes beschreibt, der durch fehlende Resorption oder durch Inaktivierung in der Leber und im Darm seine Wirkung nicht entfalten kann und ausgeschieden wird (Thummel et al. 1997). Ein Maß für die Elimination des Medikamentes aus dem Körper ist die Clearance, die angibt, wie schnell das Plasma von einem bestimmten Stoff renal befreit wird (Dost 1949). Darüber hinaus wird auch eine Clearence für den gesamten Körper beschrieben, die als Maß für die hepatische Eliminierung herangezogen werden kann (Perrier und Gibaldi 1974).

\subsection{Biotransformation von Medikamenten in der Leber}

Als Biotransformation wird der Vorgang bezeichnet, der die Umwandlung von endogenen und auch von exogenen Stoffen wie Medikamenten in wasserlösliche Abbauprodukte katalysiert. Dieser Prozess findet zum großen Teil in der Leber statt, kann aber auch in der Lunge oder den Nieren ablaufen (De Kanter et al. 2002). Aufgrund der fachlichen Spezifizierung dieser Arbeit auf die Leberschädigung, wird im Folgenden nur die Biotransformation in der Leber dargestellt.

Aufgenommene Medikamente werden in der Leber entweder in Phase 1oder Phase 2-Reaktionen in ein hydrophiles Abbauprodukt metabolisiert, um anschließend mit der Galle oder über die Niere ausgeschieden zu werden. Dabei werden in der Phase 1-Reaktion lipophile Substanzen reduziert, oxidiert oder hydrolysiert. Die Oxidierung erfolgt überwiegend mittels des Enzyms Cytochrom P450 (siehe 1.5.1), welches in der Membran des glatten Endoplasmatischen Retikulums gelegen ist (lyanagi 2007). In der Phase 2Reaktion wird das Medikament mittels Konjugation hydrophiler, bis es renal oder über die Galle eliminiert werden kann. Hierbei wird der Stoff mit einer körpereigenen Substanz verbunden. Beispiele für diese körpereigenen Substanzen sind Glucuronsäure, Glycin, Glutathion und Methyl- oder Acetatgruppen (Prior und Baker 2003). 
Ein Vertreter der Enzyme der Phase 2- Reaktion ist die UDP-Glucuronosyltransferase, welche ebenfalls in der Membran des glatten endoplasmatischen Retikulums gelegen ist. Sie konjugiert das Substrat mittels Anlagerung von Glucuronsäure (lyanagi 2007).

\subsubsection{Cytochrom P450}

Cytochrom P450 ist ein in der Lipiddoppelschicht der Membran des glatten endopasmatischen Retikulums und in geringerer Anzahl in der Membran der Mitochondrien gelegenes Enzym der Klasse der Monooxygenasen, welches aus etwa 500 Aminosäuren besteht und mindestens 40 unterschiedliche Reaktionen katalysieren kann (Michalets 1998). Mehr als ein Viertel der über die Leber metabolisierten Medikamente wird über Cytochrom P450 abgebaut (Zanger et al. 2008). Der Mensch weist 57 Gene zur Kodierung der Cytrochrom P450 - Subtypen auf (Guengerich 2013). Jedoch sind Studien zufolge nur 27 davon in der Lage funktionsfähige Cytochrome zu kodieren (Nelson et al. 2004). Die Zahl 450 im Namen bezieht sich auf das Absorptionsmaximum des Häms im Cytochrom unter UV-Licht bei $450 \mathrm{~nm}$, wenn es Kohlenmonoxid gebunden hat (Klingenberg 1958; Omura und Sato 1962). Es wurden zahlreiche Polymorphismen von Cytochrom P450 Enzymen beschrieben, die individuell bei jedem Menschen anders ausfallen können (Pollock 1994). Dies führt dazu, dass einige Patienten als Poor Metabolizers oder Extensive Metabolizers bezüglich eines Medikamentes bezeichnet werden, was bedeutet, dass Poor Metabolizers bestimmte Pharmaka deutlich langsamer abbauen als Extensive Metabolizers (Kagimoto et al. 1990). Die unterschiedlichen Cytochrom P450-Subtypen wie beispielsweise CYP2D6, CYP3A4 oder CYP2C19 können anhand ihrer Substrate, Induktoren und Inhibitoren klassifiziert werden. CYP3A4/5/7 sind mit etwa $30 \%$ die häufigsten Cytochromsubtyen in der Leber (Pelkonen et al. 1998). Zu den Hauptvertretern der Cytochrome, welche für die Metabolisierung von Medikamenten verantwortlich sind, zählen die CYP3A-, CYP2D6-, CYP1A2- und CYP2C-Untergruppen (Michalets 1998). 


\subsubsection{Cytochrom P450: Molekularer Mechanismus}

Die katalytische Reaktion unter Cytochrom P450 durchläuft einen Zyklus, an dessen Ende das wieder voll funktionsfähige Cytochrom verbleibt und das Substrat in einen hydrophileren Stoff metabolisiert wurde. Initial bildet das oxygenierte dreiwertige Eisen im Häm einen Komplex mit dem Substrat. Durch ein Elektron von NADPH wird dieser Komplex anschließend reduziert. Dabei wird aus dem im Häm gebundenen dreiwertigen ein zweiwertiges Eisenatom. Durch die Anlagerung von molekularem Sauerstoff und der Übertragung eines weiteren Elektrons von NADPH resultiert am Ende ein konjugiertes Substrat, welches von dem oxygenierten Häm des Cytochroms abdissoziieren kann. Als Nebenprodukt entsteht Wasser (Hasler et al. 1999). In Tabelle 3 sind die verschiendenen Cytochrom-Subtypen sowie die Antipsychotika, durch die sie metaboliosiert werden, und ergänzend dazu die für diese Arbeit relevanten Induktoren und Inhibitoren aufgeführt.

Basierend auf diesen Kenntnissen lassen sich mögliche Interaktionen und das Auftreten von UAWs herleiten.

Tabelle 3: Cytochrom P450-Subtypen: Substrate, Induktoren und Inhibitoren

\begin{tabular}{|l|l|l|l|}
\hline Cytochrom & Substrat & Induktor & Inhibitor \\
\hline CYP1A2 & Clozapin, Olanzapin & Carbamazepin & Perazin \\
\hline CYP2C9 & Perazin & Carbamazepin & Valproat \\
\hline CYP2C19 & Clozapin & & Omeprazol \\
\hline CYP2D6 & $\begin{array}{l}\text { Aripiprazol, Haloperidol, } \\
\text { Levomepromazin, } \\
\text { Risperidon, } \\
\text { Zuclopentixol, } \\
\text { Flupentixol }\end{array}$ & & $\begin{array}{l}\text { Chlorprothixen, } \\
\text { Melperon }\end{array}$ \\
\hline CYP3A4/5/7 & $\begin{array}{l}\text { Aripiprazol, Bromperidol, } \\
\text { Clozapin, Haloperidol, } \\
\text { Perazin, Quetiapin, } \\
\text { Risperidon, }\end{array}$ & & \\
& Carbamazepin & \\
\hline
\end{tabular}

Modifiziert nach Benkert et al. (2010, S 687 - 689): Aufgeführt sind die für diese Arbeit relevanten Antispychotika sowie Induktoren und Inhibitoren (kursiv einige relevante Nicht-Antipsychotika).

\subsubsection{Mechanismen hepatischer Toxizität}

Bei der Leberschädiung ist zwischen hepatozellulärer, cholestatischer und immunulogischer Toxizität zu differenzieren. Dabei werden entweder über reaktive Metabolite des Medikaments oder eben jenem selbst die Leberzelle 
direkt geschädigt oder eine Immunreaktion hervorgerufen. Der daraus resultierende Leberschaden imponiert als Hepatitis (Kaplowitz 2004).

In Abbildung 3 sind die verschiedenen Mechanismen medikamentöser Leberschädigung dargestellt.

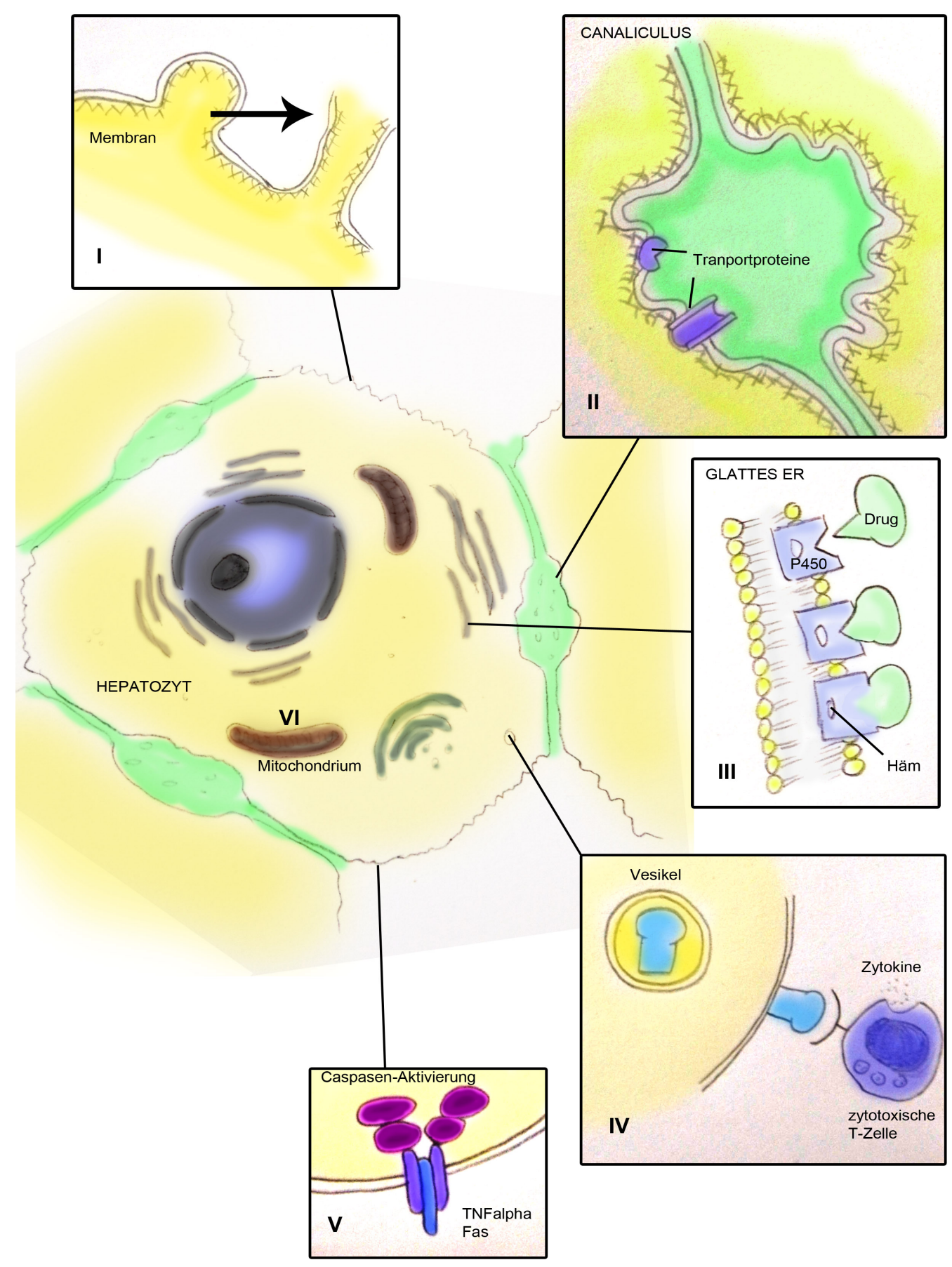

Abbildung 3: Mechanismen hepatischer Toxizität modifiziert nach Lee $(2003, S 477)$ 
Bei Reaktionen aktiver Metabolite eines Medikamentes mit Cytochrom P450 kann es zu kovalenten Bindungen zwischen Medikament und intrazellulären Proteinen kommen, die eine Zerstörung des intrazellulären lonengleichgewichts, der ATP-Funktion und von zellstabilisierenden Aktinfilamenten zur Folge hat (I). Es kommt zur Zellschwellung, Aufreißen der Membran und letztlich einem Zelluntergang (Lee 2003). Darüber hinaus kann es auch zur kovalenten Bindung zwischen dem Medikament und den Cytochrom P450-Enzymen kommen, was zur Folge hat, dass die kovalente Verbindung als Hapten in einem Vesikel zur Zelloberfläche transportiert und dort zytotoxischen T-Zellen präsentiert wird. Diese können mit anderen Zytokinen daraufhin die Zytolyse induzieren (III+IV) (Robin et al. 1997). Medikamente können über TNFa-Rezeptoren und Fas-Liganden die Apoptose durch Aktivierung intrazellulärer Caspasen induzieren (V) (Reed 2001). Manche Medikamente verfügen über die Fähigkeit, mitochondriale Funktionen wie die ß-Oxidation und Enzyme der Atmungskette zu hemmen. Durch den gehemmten Abbau akkumulieren freie Fettsäuren und es kann zum Ausfall der Atmungskette kommen. Daraufhin steigt der Laktatgehalt und es entstehen reaktive Sauerstoffmetabolite, die die mitochondriale DNA zerstören können (Pessayre et al. 1999). Über die Zerstörung der mitochondrialen Membran kann Cytochrom $\mathrm{C}$ freigesetzt werden, welches direkt Caspasen, die die Apoptose einleiten, aktivieren kann (VI) (Gu und Manautou 2012).

Über die Zerstörung von Aktinfilamenten - wie in Reaktion (I) - und durch die Blockade von in der Zellmembran der Hepatozyten gelegenen Transportern und Kanälen können Medikamente die Gallenexkretion verhindern (II). Die toxischen Gallensäuren können so sekundär einen hepatotoxischen Schaden anrichten, wenn sie in den Hepatozyten akkumulieren (Pauli-Magnus und Meier 2006).

Zur Quantifizierung des Leberschadens eignet sich sehr gut die laborchemische Untersuchung des Blutes. Die Transaminasen AST und ALT sind gute Marker für einen Leberschaden, geben jedoch keinen genauen Hinweis auf die Funktionalität der Leber. Dafür sind die Bestimmung von Albumin und der Prothrombinzeit, beziehungsweise dem INR, besser geeignet, da Albumin und Gerinnungsfaktoren von den Hepatozyten 
synthetisiert werden. Ebenso sind direktes und indirektes Bilirubin geeignete Marker für die exkretorische Leberfunktion, da hier erkennbar ist, wie gut die Leber in der Lage ist, Bilirubin zu konjugieren und in die Galle zu überführen (Navarro und Senior 2006).

Zur Klassifizierung eines erhöhten Risikos zur Entwicklung eines akuten Leberversagens bei medikamentös induziertem Leberschaden hat sich der sogenannte "Hy's Law" als ein diagnostischer Leitfaden in der Praxis bewährt, wonach die ALT mindestens das Dreifache des oberen Referenzwertes überschreiten muss, mit einem Bilirubinanstieg (über das Zweifache des oberen Referenzwertes) ohne gleichzeitigen Anstieg der alkalischen Phosphatase. Jederzeit muss darüber hinaus aber auch eine andere Ursache wie Hepatitis oder ein alkoholinduzierter Leberschaden ausgeschlossen werden (Temple 2006).

Eine aktuelle Studie zeigte, dass die Inzidenz von erhöhten Leberwerten unter unbestimmter medikamentöser Therapie weitaus größer zu sein scheint, als in der Literatur angegeben. So wurden in einer Apotheke bei randomisierten Probanden AST und ALT bestimmt und es fanden sich erhöhte Werte bei $16,4 \%$ der weiblichen und 13,3\% der männlichen Probanden. Desweiteren wurden potentielle Risikofaktoren untersucht, wobei sich unter den Fällen mit Leberwerterhöhung deutlich mehr Patienten mit chronischer Lebererkrankung, potentiell lebertoxischer Medikamenteneinnahme, chronischer Niereninsuffizienz und Diabetes mellitus befanden als in der Kohorte ohne erhöhte Leberwerte (Jüngst et al. 2016).

Weiterhin wurde festgestellt, dass hepatotoxische Leberschäden mit klinischem Ikterus ein höheres Mortalitätsrisiko aufweisen als cholestatische Leberschäden (Andrade et al. 2005).

\subsubsection{Lysosomotropie}

Neben den Interaktionen auf der Ebene der Cytochrome der Leber wurde auch der Mechanismus des Lysosomotropie beschrieben.

Basische lipophile Medikamente werden aufgrund ihrer fettlöslichen Eigenschaften sehr leicht in die Zelle aufgenommen. Sie können an Plasmaproteine wie Albumin gebunden im Blut transportiert und in die entsprechenden Organe aufgenommen werden. Dieser Vorgang erfolgt 
überwiegend mittels Diffusion durch die Plasmamembran der Zellen. Innerhalb der Zelle diffundieren basische lipophile Substanzen aufgrund ihrer Azidophilie häufig in Lysosomen. Diese befinden sich in großer Anzahl in der Lunge, der Leber, den Nieren, der Milz, den Leukozyten und den Makrophagen. Die lipophilen Substanzen können in den Lysosomen protoniert werden, was die Rückdiffusion ins Zytosol verhindert (Macintyre und Cutler 1988).

Studien am Mausmodell zeigten, dass bei Akkumulation von Basen in den Lysosomen der $\mathrm{pH}$ in diesen ansteigt und die weitere Aufnahme von basischen Substanzen verringert wird. Weitere basisch lipophile Substanzen oder ein nicht weiter aufzunehmender Überschuss desselben Medikaments sammeln sich nun in Zellmembranen, an Phospholipiden und im Zytosol an (Ohkuma und Poole 1978; Vestal et al. 1980). Wenn die Kapazität der Lysosomen der Leber überlastet ist, dringen die lipophilen basischen Substanzen vermehrt in Gewebe ein, die mit einer geringeren Anzahl an Lysosomen ausgestattet sind. Wenn diese gut durchblutet sind, wie beispielsweise das Herz oder das Gehirn, werden dort die Medikamente in stärkerem Maße angeschwemmt (Fayek et al. 2001; Mackin 2008). Daraus lässt sich schlussfolgern, dass bei vermehrter Akkumulation von basischen, lipophilen Pharmaka in Lysosomen, die Konzentration im Zytosol, den Membranen und letztlich im Blut steigt und zu unerwünschten Arzneimittelwirkungen führen kann. Ein Beispiel ist das Auftreten von extrapyramidalmotorischen Störungen als unerwünschte Arzneimittelwirkung von vor allem typischen Antipsychotika: So zeigte eine Studie, dass bei einer Blockade von über $60 \%$ der zerebralen D2-Rezeptoren extrapyramidalmotorische Störungen auftreten können (Knable et al. 1997; Miller et al. 2008), möglicherweise auch als Folge zu hoher Plasmaspiegel im Rahmen der Überladung von Lysosomen. Interaktionen von Perazin mit verschiedenen Antidepressiva wurden bereits am Tiermodell untersucht und zeigten einen Medikamentenkonzentrationsanstieg in lysosomärmeren Organen wie dem Gehirn und dem Herzen als Folge der Kombinationstherapie (Daniel und Wójcikowski 1999). 


\subsection{Schizophrenie: Pathophysiologie und Wirkungsmechanismus der Antipsychotika}

Um zu verstehen, wie Antipsychotika wirken und etwaige unerwünschte Arzneimittelwirkungen entstehen, ist es wichtig, die Schizophrenie in ihrer Pathophysiologie und die involvierten Rezeptoren genauer darzustellen.

Die Beschreibungen der schizophrenen Symptomatiken lassen sich in der Literatur weit in die Vergangenheit zurückverfolgen und es befassten sich unterschiedliche Wissenschaftler mit der Klassifizierung und Diagnose jener Krankheit. Emil Kraepelin prägte dabei 1893 den Begriff der dementia praecox als Abgrenzung zum manisch-depressiven Irresein. Der eigentliche Begriff der Schizophrenie geht auf die Beschreibungen Eugen Bleulers im Jahre 1908 zurück (Adityanjee et al. 1999).

Kurt Schneider schaffte 1938 mit der Defintion von Symptomen ersten und zweiten Ranges einen Leitfaden zur Diagnosestellung einer Schizophrenie, sofern eine organische Ursache ausgeschlossen werden kann. Zu den Symtomen ersten Ranges zählen Ich-Störungen, akustische Halluzinationen in Form von Stimmen, das Gefühl des Gemachten und Wahnwahrnehmungen. Den Symtomen zweiten Ranges werden Akoasmen, Zönästhesien, jegliche Halluzinationen der anderen Sinnesmodalitäten und Veränderungen des Affektes zugerechnet, wobei sie zur eigentlichen Diagnosestellung eine untergeordnetere Rolle spielen (Schneider 2007). Auftretende Halluzinationen bei der Gabe von Amphetaminen und die Wirkungsweise der Antipsychotika an dopaminergen Rezeptoren sorgten dafür, dass eine erhöhte oder inadäquate Aktivität dopaminerger Neurone als pathophysiologischer Mechanismus der Schizophrenie in Betracht gezogen wurde (Crow et al. 1977). Tatsächlich konnte auch nachgewiesen werden, dass schizophrene Patienten im Vergleich zu Gesunden eine erhöhte Konzentration von Dopamin im synaptischen Spalt striärer Neurone aufweisen (Heinz 2000). Neueren Erkenntnissen zufolge scheinen allerdings auch Abweichungen in physiologischen Prozessen der Neurotransmitter Glutamat, GABA, Acetylcholin und Serotonin eine Rolle in der Entstehung einer Schizophrenie zu spielen (Brisch et al. 2014). Bei der Schizophrenie lässt sich weiterhin die Positiv- von der Negativsymptomatik unterscheiden. Unter der Positivsymtomatik werden unter anderem Halluzinationen, formale 
Denkstörungen und bizarres Verhalten verstanden, während der Negativsymtomatik Antriebsminderung, Sprachverarmung und Anhedonie zugerechnet werden. Es können Symptome nur des positiven, nur des negativen Symtomenkomplexes oder auch parallel vorliegen (Andreasen und Olsen 1982).

Studien zufolge wird die Positivsymtomatik der Schizophrenie in Verbindung mit einer erhöhten Aktivität dopaminerger Neurone im limbischen System gebracht. Die Negativsymptomatik (Affektverflachung, Denkverlangsamung, etc.) lässt sich anhand einer verminderten Aktivität des dopaminergen Systems im präfrontalen Kortex erklären (Lynch 1992).

Es wurden vier Systeme beschrieben, in denen Antipsychotika auf der dopaminergen Ebene wirken (Stahl 2003):

1. Nigrostriatales System

2. Tuberoinfundibuläres System

3. Mesokortikales System

4. Mesolimbisches System

Zu den dopaminergen Rezeptoren zählen die D1- bis D5-Rezeptoren, wobei D1- und D5-Rezeptoren intrazellulär cAMP erhöhen und D2-, D3- und D4-Rezeptoren die Konzentration von intrazellulärem cAMP erniedrigen (Horacek et al. 2006). Die schizophrene Symptomatik wird vor allem durch die erhöhte Aktivität von D2- und D4-Rezeptoren hervorgerufen (Janković et al. 1996). D1- und D5- Rezeptoren findet man in hoher Dichte im präfrontalen Kortex, D2-, D3- und D4-Rezeptoren hingegen im Striatum (Lidow et al. 1991).

Atypische Antipsychotika wirken zusätzlich noch auf der Ebene der Serotonin-Rezeptoren (5-HT = 5-Hydroxytryptamin). Serotonin hemmt im nigrostriatalen System die Freisetzung von Dopamin. Wird dieser Mechanismus nun über an Serotoninrezeptoren wirksamen Antipsychotika gehemmt, wird vermehrt Dopamin in den synaptischen Spalt im nigrostriatalen System freigesetzt. Da die atypischen Antipsychotika aber gleichzeitig auch an den D2-Rezeptoren antagonistisch wirken, wird über das vermehrte Dopamin das Abdissoziieren des Antipsychotikum vom D2-Rezeptor ermöglicht, was vermutlich das verringerte Auftreten von EPMS erklären könnte (Stahl 2003). 
Über den Antagonismus an zerebralen Histamin-Rezeptoren (H1) kann eine sedative Wirkung erzielt werden. Die Blockade dieser Rezeptoren korreliert aber auch mit einer Gewichtszunahme als unerwünschte Arzeimittelwirkung (Kroeze et al. 2003; Matsui-Sakata et al. 2005). In Experimentem mit 5-HT2C-Rezeptor defizienten Mäusen konnte ein Übergewicht durch vermehrte Nahrungsaufnahme aufgrund abnormalem Fressverhaltens beobachtet werden (Tecott et al. 1995).

Als weitere unerwünschte Arzneimittelwirkungen wurde das vermehrte Auftreten von Diabetes mellitus bei der Blockade von Histamin- $(\mathrm{H} 1)$ und Serotoninrezeptoren (5-HT2C) beschrieben (Matsui-Sakata et al. 2005).

Antipsychotika können auch über ihre anticholinerge Wirkung an cholinergen Rezeptoren sowohl zentrale als auch periphere unerwünschte Arzneimittelwirkungen wie beispielweise Hypersalivation und Obstipation verursachen (Lieberman 2004).

\subsection{Klassifikation der unerwünschten Arzneimittelwirkungen}

Bezüglich der unerwünschten Arzneimittelwirkungen wurden sechs verschiedene Klassen der UAWs definiert (Edwards und Aronson 2000), wobei für diese Arbeit vor allem die dosisabhängigen Typ A-Reaktionen und die dosisunabhängigen immunologischen oder idiosynkratischen Typ B-Reaktionen von Relevanz sind. Idiosynkratische Arzneimittelwirkungen sind ingesamt über die Häufigkeit der Gabe eines Medikamentes ein sehr seltenes Ereignis und waren bisher in tierexperimentellen Studien nicht reproduzierbar (Li 2002). Sie zeigten über die Dosisunabhängigkeit hinaus auch keinen Zusammenhang zur Dauer der Therapie (Park et al. 1992). Typ A-Reaktionen sind bekannt, sind in tierexperimentellen Studien reproduzierbar und die UAW ist einer bestimmten pharmakologischen Eigenschaft des Medikamentes zuzuschreiben. Diese Reaktion ist vorhersehbar. Darüber hinaus konnte gezeigt werden, dass Typ B-Reaktionen mit einer viel größeren Mortalität als Typ A-Reaktionen vergesellschaftet sind (Edwards und Aronson 2000). 


\subsection{Bisherige Erkenntnisse zu Leberwerterhöhung unter Antipsychotikatherapie}

Leberwerterhöhungen wurden schon bei der Therapie mit Chlorpromazin in den 50er Jahren des letzten Jahrhunderts beschrieben (Hollister 1957; Dujovne und Zimmerman 1969), wobei besonders ein cholestatischer Schaden beschrieben wurde (Akerboom et al. 1991).

Weiterhin wurden bei Phenothiazinen, denen Chlorpromazin angehört, cholestatische Ikteren beschrieben (Regal et al. 1987). Hepatotoxische Schäden konnten bei der Gabe von Thioxanthenen nachgewiesen werden (Abernathy und Zimmerman 1975).

In der Literatur wurden zahlreiche Fälle von Leberwerterhöhungen unter der Therapie mit atypischen Antipsychotika beschrieben (El Hajj et al. 2004; Tello et al. 2005; Ozcanli et al. 2006; Wright und Vandenberg 2007). Fallberichte beschrieben hohe Transaminasenanstiege bei Olanzapin (Ozcanli et al. 2006) und cholestatische Schäden bei Risperidon (Llinares Tello et al. 2005) sowie der aufeinanderfolgenden Therapie von Risperidon und anschließend Quetiapin (Wright und Vandenberg 2007). Bei Quetiapin wurden einige Fälle mit medikamentös induzierten Leberschäden dokumentiert, von denen zwei regenerierten (Shpaner et al. 2008; Al Mutairi et al. 2012) und ein Fall letal verlief (El Hajj et al. 2004). Bei Clozapin war die Inzidenz der Leberwerterhöhung in einer klinischen Studie mehr als doppelt so hoch wie unter Haloperidol. Für Clozapin konnte das männliche Geschlecht und ein hoher Clozapin-Plasmaspiegel als Risiko für eine Leberwerterhöhung identifiziert werden (Hummer et al. 1997). Jedoch zeigten zwei Fallberichte auch, dass Clozapin nach einer Leberwerterhöhung vorsichtig unter Aufsicht und bei nachgewiesenem Erfolg der Therapie wieder eindosiert und in der Therapie fortgeführt werden konnte, ohne dass es zu einem erneuten Leberschaden kam (Eggert et al. 1994; Erdogan et al. 2004).

Die Häufigkeit von transienten Leberwerterhöhungen über den einfachen oberen Referenzwert hinaus ist nicht selten. So konnte bei der Therapie mit Olanzapin (26,9 \% der Fälle) und Risperidon (14,2 \%) in einer Studie eine Erhöhung der Transaminasen über den oberen Referenzwert hinaus beschrieben werden (Pae et al. 2005). Eine andere Studie kam zu dem 
Ergebnis, dass bei etwa $27 \%$ der mit Olanzapin, Risperidon oder Quetiapin behandelten Patienten mit einer asymptomatischen Erhöhung von ALT, AST, yGT oder Serum-Bilirubin zu rechnen war (Atasoy et al. 2007).

Darüber hinaus zeigte eine Studie in sechs von 23 Fällen Leberwerterhöhungen unter der Therapie mit Amisulprid, Risperidon, Olanzapin und Clozapin auf (Mouradian-Stamatiadis et al. 2002). Olanzapin führte häufiger zu transienten Leberwerterhöhungen als Risperidon und verursachte vermehrt eine Gewichtszunahme (Perlis et al. 2006). In einer Studie konnte gezeigt werden, dass bei jenen Patienten, die unter der Antipsychotikatherapie mehr als $7 \%$ ihres Ausgangsgewichtes zugenommen haben, auch deutlich höherere Transaminasenanstiege im Blut zu verzeichnen waren (Rettenbacher et al. 2006). Gewichtszunahmen konnten besonders bei Olanzapin und Clozapin beschrieben werden (Kraus et al. 1999), wobei Clozapin den größten gewichtssteigernden Effekt im Vergleich zwischen den verschiedenen Antipsychotika aufweist (Allison et al. 1999).

In einer retrospektiven Studie untersuchten Greil et al. (2013) mit den Daten der AMSP die Korrelation von UAWs unter Psychopharmaka mit dem Alter der Patienten. Es zeigte sich, dass ältere Patienten (> 60 Jahre) seltener als jüngere Patienten unerwünschte Arzneimittelwirkungen unter Psychopharmaka entwickelten; dies zeigte sich auch im Bezug auf die Leberwerterhöhungen. Im speziellen bei Antipsychotikagabe lag die Häufigkeit von schweren UAWs bei etwa $1,78 \%$ bei jüngeren Patienten und bei $1,32 \%$ bei älteren Patienten (Greil et al. 2013).

Diese Publikationen zum Thema unerwünschter Arzneimittelwirkungen, insbesondere der Leberwerterhöhungen unter Psychopharmakotherapie verdeutlichen die Wichtigkeit von weiteren Untersuchung zu dieser Thematik.

\subsection{Zielsetzung der Untersuchung}

In dieser Arbeit sollen die Daten des AMSP hinsichtlich des Auftretens schwerer Leberwerterhöhungen (projekteigene Definition, genauere Definition siehe 2.1.6) untersucht werden. Das zu untersuchende Kollektiv besteht aus den Patienten mit schwerer Leberwerterhöhung von 1993 bis 2012. Hierbei sollen die Inzidenzen der Leberwerterhöhung unter den beteiligten Antipsychotika genauer bestimmt werden, um so Häufigkeits- 
unterschiede bezogen auf Alter, Geschlecht, Risikofaktoren, somatische Erkrankungen, Diagnosen, Komorbiditäten, Verlauf und Dauer der Therapie zwischen den Antipsychotika zu erkennen. Wie in der Methodik genauer beschrieben, wurden mittels eines Erfassungsbogens von AMSP Risikofaktoren erfasst und wichtige Patientendaten erhoben, anhand derer mögliche „Anschuldigungen“ der beteiligten Antipsychotika erfolgen können, unter Einbeziehung einer etwaigen Komedikation, der spezifischen Art der Leberwerterhöhung und des therapeutischen Vorgehens nach UAW, z.B. Absetzen des Medikamentes.

Eine Studie mit den Daten von AMSP von Bender et al. (2004) konnte zeigen, dass bei etwa 0,1\% der Patienten unter Antipsychotikatherapie eine schwere Leberwerterhöhung auftrat. Besonders traten diese UAWs bei Patienten auf, die mit den atypischen Antipsychotika Clozapin oder Olanzapin therapiert wurden (Bender et al. 2004). Detaillierter wurde das Auftreten von schweren UAWs in einer früheren Arbeit mit den Daten von AMSP für Antidepressiva analysiert und beschrieb das Auftreten schwerer Leberwerterhöhung am häufigsten unter trizyklischen Antidepressiva (Grohmann et al. 1999).

Weiterhin sollen die Häufigkeiten der Leberwerterhöhungen in unterschiedlichen Altersgruppen (0-30 Jahre, 31-60 Jahre, 61-90 Jahre, 91-120 Jahre) und geschlechtergetrennt (Männer und Frauen) genauer beschrieben werden. Im Geschlechtervergleich soll auch geschaut werden, wie häufig Leberwerterhöhungen bei den einzelnen Antipsychotika auftraten, ob es Unterschiede bei der Dosis gab und die Häufigkeiten der UAW über die verschiedenen Altersgruppen dargestellt werden.

Diese Analysen sollen insbesondere sehr seltene und möglicherweise bisher aus präklinischen Studien unbekannte Leberwerterhöhungen bei verschiedenen Antipsychotika hervorheben. 


\section{MATERIAL UND METHODEN}

\subsection{Arzneimittelsicherheit in der Psychiatrie}

\subsubsection{Projektbeschreibung}

Das Projekt „Arzneimittelsicherheit in der Psychiatrie“ (AMSP) erfasst seit Oktober 1993 alle als schwer definierten unerwünschten Arzneimittelwirkungen, Charakteristika der Medikamente und Patienten, Dosis und mögliche Einflussfaktoren, um so Risiken zu erkennen und die Therapie langfristig zu optimieren (Grohmann et al. 2004b). Bei AMSP handelt es sich um eine Post-Marketing-Beobachtungsstudie, die Medikamente langfristig nach ihrer Marktzulassung hinsichtlich ihrer Sicherheit überwacht, um schwere, aber auch seltene unerwünschte Arzneimittelwirkungen und mögliche Risikofaktoren zu erkennen. Phase I- bis III-Studien vor der Marktzulassung des Medikamentes können aufgrund strenger Auswahlkritierien der Probanden und zu geringer Fallzahlen die Situation im Klinikalltag nicht adäquat nachstellen, weshalb der Pharmakovigilanz als Phase IV-Studie große Bedeutung zukommt (Schäfer 1997; Amery 1999).

An AMSP sind 67 Kliniken aus Deutschland, Österreich und der Schweiz beteiligt (Stand: 2014, Siehe Anhang Anlage 1). Mittels eines standardisierten Erfassungsbogens werden alle als schwer definierten UAWs von einem Drug-Monitor einer Klinik erfasst und der Projektzentrale gemeldet. Speziell ausgebildete Ärzte in den jeweiligen psychiatrischen Kliniken arbeiten als sogenannte Drug-Monitore.

AMSP ist eine Fortführung der 1979 gegründeten Arbeitsgruppe "Arzneimittelüberwachung in der Psychiatrie“ (AMÜP), an der damals zwei Kliniken (München und Berlin) beteiligt waren. Ergebnisse dieser Arbeitsgruppe lassen sich in zahlreichen Publikationen nachlesen und lieferten den Grundstein für das heutige AMSP-Projekt (Grohmann et al. 2004b). 


\subsubsection{Erfassung der UAWs}

Im Rahmen eines standardisierten Erfassungsbogens werden alle als schwer definierten UAWs dokumentiert.

Zusätzlich zur Dokumentation der UAWs werden auch mögliche Einflussfaktoren erfasst. So können im Rahmen statistischer Ausarbeitungen mögliche Risikofaktoren erfasst werden, um langfristig das Aufreten von schweren UAWs zu vermeiden.

Pro Erfassungsbogen wird jedoch nur eine schwere UAW als Fall beschrieben. Sollte also ein Patient an mehr als einer schweren UAW im Rahmen seiner stationären Therapie leiden, so wird pro UAW separat ein Fall beschrieben. Fall und Patient können in der Beschreibung jedoch nicht synonym verwendet werden, da es möglich ist, dass ein Patient innerhalb der Zeit der Datenerfassung (1993 bis 2012) die selbe UAW erneut erleidet und als neuer Fall erfasst wird.

Erfasste UAWs werden im weiteren Verlauf auf regionalen und auch zentralen Fallkonferenzen diskutiert und hinsichtlich der Wahrscheinlichkeit der UAW und einer möglichen Kausalität bezüglich des Medikamentes oder der Medikamente genauer erörtert. Die Überlegungen in Bezug auf die Kausalität eines Psychopharmakons basieren auf Informationen der aktuell verfügbaren Literatur, den eigenen Erfahrungen der Drug-Monitore und bisherigen Erkenntnissen der AMSP-Datenbank.

\subsubsection{Drug-Monitore}

Unter Drug-Monitoren versteht man in der Regel zwei bis drei Ärzte eines am AMSP teilnehmenden Krankenhauses, die regelmäßig das Aufreten von schweren UAWs erfassen, dokumentieren und an die regionale Zentrale melden. Alle Ärzte eines psychiatrischen Krankenhauses sind jedoch auch in sofern an der Studie mitbeteiligt, dass sie verdächtige UAWs an die zuständigen Drug-Monitore melden und mit innen besprechen. Eine Information bezüglich der wichtigsten schweren UAWs liegt auf allen Stationen bereit.

Die zuständigen Drug-Monitore stellen ihre Fälle dann auf regionalen und zentralen Fallkonferenzen vor, woraufhin die UAWs in anonymisierter Form an nationale Behörden und Hersteller übermittelt werden. 


\subsubsection{Alleinanschuldigung vs. Kombinationsanschuldigung}

Hinsichtlich der UAWs wird nach vorher im Rahmen der AMSP beschriebenen Wahrscheinlichkeits-Graden eines oder mehrere der verabreichten Medikamenten für die UAW „angeschuldigt“ (Siehe hierzu Tabelle 4, S. 30).

Es wird dann von einer Alleinanschuldigung gesprochen, wenn nach den Kriterien der AMSP nur ein einziges Medikament im kausalen Zusammenhang (also mindestens wahrscheinlich (=W2)) zum Auftreten der UAWs steht; völlig unabhängig davon, ob nebenbei noch weitere Medikamente verabreicht werden. Wichtig für diese Klassifizierung ist jedoch, dass eine Alleinanschuldigung nicht automatisch eine Monotherapie bedeutet, bei der dem betroffenen Patienten nur ausschließlich ein einziges Medikament verabreicht wurde.

Basierend auf dem Wissen hinsichtlich pharmakodynamischer Eigenschaften verschiedener Medikamente, können im Rahmen der Fallkonferenzen Psychopharmaka, die eine UAW verursachten, alleine oder in Kombination mit einem anderen Medikament angeschuldigt werden.

Da Psychopharmaka besonders häufig in Kombinationen untereinander oder auch mit anderen Medikamenten, die beispielsweise in der Behandlung internistischer Erkrankungen („Internistika“) verabreicht werden, kann es sein, dass die Differenzierung zwischen den Medikamenten nicht ganz eindeutig ist. So ist es möglich, dass mehr als ein Medikament je nach Zusammenhang zur UAW mit einem Wahrscheinlichkeits-Grad eingestuft wird.

Bei einer Anschuldigung mehrerer Medikamente, so genannter „Kombinationsanschuldigungen", werden Medikamente nach AMSP dann in Kombination angeschuldigt, wenn mehr als ein Medikament für die entsprechende UAW verantwortlich gemacht oder ein additiver Effekt vermutet werden kann. Für diese Fälle gibt es wieder gesonderte Wahrscheinlichkeitsgrade. So erhält eine Kombinationsanschuldigung den W-Grad "möglich“ (W1) wenn mindestens zwei Medikamente mit W1 angeschuldigt wurden und kein weiteres mit W2, bzw. W3. Hierzu zählen auch Fälle, in denen weitere Medikamente eingenommen wurden, die aber in keinem kausalen Zusammenhang zum Auftreten der UAW stehen (W0). 
W-Grad „wahrscheinlich“ (W2) wird für eine Kombination mit mindestens zwei Medikamenten mit W2 (und keinem weiteren Medikament mit W3) vergeben. W-Grad „sicher“ (W3) erhält eine Kombinationsanschuldigung aus mindestens zwei Medikamenten mit W3. Zu letzteren beiden zählen auch jene Fälle, die weitere Medikamente eingenommen haben, die aber als eher unwahrscheinlich (W0 oder W1) für das Auftreten der UAW eingestuft wurden. Die Wahrscheinlichkeitsgrade werden in Anbetracht des Zeitverlaufes der UAW vergeben, wenn beispielweise ein Medikament $A$ zeitlich zum Auftreten der UAW passt als Medikament B, so ist dieses als wahrscheinlicher zu betrachten. Kann nicht über den Zeitverlauf differenziert werden, wird nach aktuellem Wissen aus der Fachliteratur zusätzlich betrachtet, bei welchem Medikament die UAW in der Vergangenheit häufiger aufgetreten ist und somit wahrscheinlicher für die aktuelle UAW ist. Darüber hinaus wird noch nach UAW-Verlauf klassifiziert. Klingt die UAW nach Absetzen des mit wahrscheinlich (=W2) angeschuldigten Medikamentes ab, wird jedoch ein weiteres noch parallel gegeben, welches ebenfalls im Zusammenhang mit der UAW stehen könnte, wird dieses mit mögich (=W1) angeschuldigt. Klingt die UAW allerdings nur sehr verzögert oder gar nicht $a b$, so ist das weitergegebene Medikament ebenfalls mit wahrscheinlich (=W2) anzuschuldigen.

Bei dem Auftreten von UAWs nach dem Absetzen eines Medikaments muss gesondert in Anbetracht der Dosis, der Halbwertszeit und Art der UAW dies abgewägt werden. 
Tabelle 4: Wahrscheinlichkeitsgrade

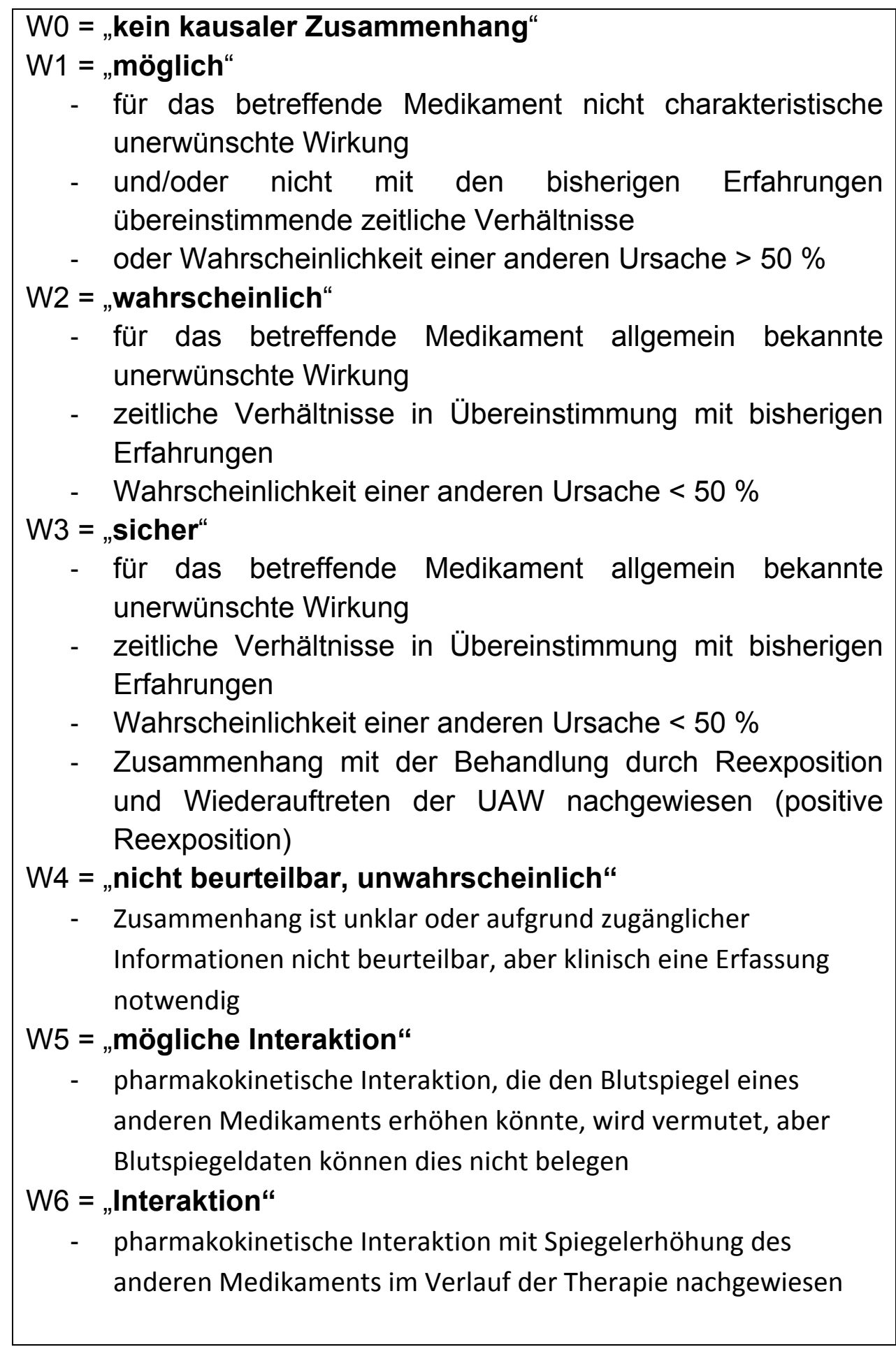

Erstellt auf Grundlage der Ausführungen von Rüther (1994, S 8 - 9) und Grohmann et al. (2004b, S 5 - 6) 


\subsubsection{Definition von UAWs nach AMSP}

Nach AMSP-Kriterien werden unerwünschte Arzneimittelwirkungen dann als schwer eingestuft, wenn sie das Leben oder schwerwiegend die Gesundheit des Patienten gefährden, die körperlichen Funktionen des Patienten stark einschränken oder die Verlegung in eine andere klinische Fachabteilung zur intensiveren Behandlung erfordern. Diese Anforderungen entsprechen den Kriterien der GCP (Good Clinical Practice) der WHO und werden mittels AMSP ebenfalls erfasst (Wroblewski und Schmickler 2005).

Darüber hinaus werden für die jeweiligen Organfunktionen, so auch für die Leberwerterhöhungen spezielle labormedizinsche Grenzwerte festgelegt (Grohmann et al. 2004b). Diese Grenzwerte wurden mit Experten des jeweiligen Fachbereiches anhand wissenschaftlicher Erkenntnis und klinischer Erfahrungen erwogen. Nach dem AMSP-Fragebogen werden Erhöhungen von AST, ALT, YGT und AP dokumentiert; zusätzlich können fakultativ auch weitere Parameter der Leberfunktion wie Bilirubin, GLDH oder Cholinesterase erfasst werden (abhängig von der jeweiligen Klinik).

\subsubsection{Kriterien für die Leberwerterhöhung als „schwere“ UAW}

Eine „schwere Leberwerterhöhung“ nach AMSP liegt dann vor, wenn AST, ALT, YGT oder AP mindestens um mehr als das Fünffache des oberen Referenzwertes angestiegen sind.

Bis 2002 galten allerdings noch andere Richtwerte. So war die Leberwerterhöhung dann schwer, wenn die Transaminasen ALT und/oder AST > $100 \mathrm{U} / \mathrm{L}$ und/oder $\mathrm{YGT}>200 \mathrm{U} / \mathrm{L}$ in den Laboruntersuchungen vorzufinden waren (Grohmann et al. 2004b).

\subsubsection{Erfassungsbogen für schwere UAWs nach AMSP}

Der Erfassungsbogen der AMSP dient der Dokumentation jeder einzelnen unerwünschten Arzneimittelwirkung. Auf einem Erfassungsbogen wird immer exakt ein Fall, das heißt eine UAW, dokumentiert, unabhängig davon, wieviele UAWs der betroffene Patient gleichzeitig aufweist.

Im Rahmen des Erfassungsbogens werden folgende Parameter berücksichtigt: 
- Patientenbezogene Daten: Alter, Geschlecht, Diagnosen, Aufnahmedatum

- Fallart: Handelt es sich um eine neue UAW? Ist die UAW "schwer" nach den Kriterien von AMSP?

- UAW-spezifische Daten: Symptomatik, Beginn, Ende, Dauer

- Mögliche Risikofaktoren wie eine UAW-Empfindlichkeit (der Patient wie in der Anamnese schon andere Medikamentenunverträglichkeiten auf) oder ein schädlicher Gebrauch, wie beispielsweise regelmäßiger Alkoholkonsum/-missbrauch

- Alternative Ursachen für die UAW

- Angaben zu den verabreichten Medikamenten: Einnahmedauer, Dosis, Wahrscheinlichkeitsgrad

- Labordaten

- Maßnahmen nach UAW (Absetzen, Reduktion, Fortführen der Therapie, Konsil, Verlegung des Patienten)

- Verlauf der UAW

- Weiterbehandlung

- Reexposition und frühere Exposition

(Der Erfassungsbogen ist im Anhang unter Anlage 2 beigefügt.)

\subsubsection{Erfassung der Gesamtpopulation anhand von Stichtagserhebungen}

In den teilnehmenden Kliniken werden nicht die kompletten Daten von allen Patienten ermittelt. Es gibt zweimal jährlich an bestimmten Stichtagen Erfassungen, die an diesen Tagen verabreichten Medikamente, sowie Geschlecht, Alter, psychiatrische Diagnose, Dosis etc. aller Patienten erfassen. So werden mit einer entsprechenden mathematischen Formel die Gesamtzahlen der Patienten mit einem bestimmten Medikament geschätzt (siehe unten).

Für die Gesamtzahlen gehen in dem jeweiligen Jahr nur die Kliniken ein, die eine UAW-Rate von mindestens $0,5 \%$ haben, da eine geringere Inzidenz als Möglichkeit einer unzureichenden Dokumentation der UAWs angesehen wird (Grohmann et al. 2004b). 
Anhand der Stichtagszählungen zweimal pro Jahr wird mittels einer von AMSP erhobenen Formel die Anzahl einer mit Medikament $X$ behandelten Patientengruppe in den teilnehmenden Kliniken berechnet. So können besonders für häufig genutzte Psychopharmaka statistisch repräsentative Referenzwerte bestimmt werden (Engel et al. 2004).

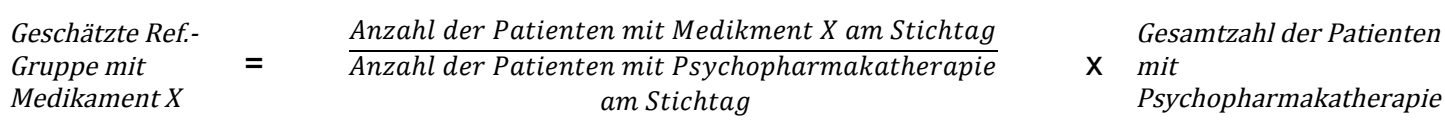

Aus der Datenbank von AMSP anhand der Stichtagszählungen bis Ende 2012 ergeben sich zur Berechnung der Referenzgruppe mit der Formel folgende Werte:

Anzahl der Patienten mit Psychopharmakotherapie am Stichtag $=48050$ Gesamtzahl der Patienten mit Psychopharmakotherapie = 386135

So kann beispielsweise für das Antipsychotikum Olanzapin anhand der oben aufgeführten mathematischen Formel folgende geschätzte Referenzgruppe für den Zeitraum von 1993 bis 2012 ermittelt werden. Diese Anzahl sagt somit aus, wieviele Patienten anhand der Stichtagszählungen schätzungsweise von 1993 bis 2012 in den teilnehmenden Kliniken überhaupt mit Olanzapin therapiert wurden.

$$
\begin{aligned}
\begin{array}{l}
\text { Geschätzte Ref.-Gruppe } \\
\text { mit Olanzapin }
\end{array} & =\frac{5614}{48050} \quad \text { x } 386135 \\
& =45115^{\star}
\end{aligned}
$$

*Das Ergebnis wurde bis auf die erste Stelle vor dem Komma gerundet

\subsubsection{Rechtliche Grundlagen}

Im Anhang unter Anlage 3 ist ein Ethikvotum der Ludwig-MaximiliansUniverstität München vom 19.02.2010 beigefügt. Da keinerlei Untersuchungen am Menschen zusätzlich durchgeführt werden, nicht in die 
Therapie eingegriffen wird und die Datenerhebung retrospektiv und nicht personenbezogen erfolgt, liegen keinerlei datenrechtliche und ethische Bedenken vor.

\subsection{Erfassung des Patientenkollektivs}

Für die folgende wissenschaftliche Arbeit wurden alle Patienten mit Leberwerterhöhungen nach der Definition von AMSP von 1993 bis 2012 erfasst und anonymisiert in einer speziellen Excel-Tabelle zusammengetragen. Zusätzlich zu den Leberwerterhöhungen nach den Definitionen von AMSP (AST, ALT, YGT und AP) wurden auch in wenigen Fällen das Bilirubin oder die Cholinesterase erfasst.

Die Patienten waren am Tag der Erfassung der unerwünschten Arzneimittelwirkung mindestens 18 Jahre alt.

\subsection{Berücksichtigte Medikamente}

Für die statistische Auswertung wurden in dieser Arbeit nur Antipsychotika bedacht, die anhand des Wahrscheinlichkeitsgrades mindestens mit wahrscheinlich (= W2) oder sicher (= W3) hinsichtlich ihrer Anschuldbarkeit für das Auftreten der Leberwerterhöhung eingestuft wurden.

Die Antipsychotika werden nach AMSP in drei Gruppen „typischantipsychotisch“, „typisch-hypnotisch-sedierend“ und „atypisch“ unterteilt.

Zu den typisch-antipsychotisch wirkenden Antipsychotika zählen Benperidol, Bromperidol, Flupentixol, Flupentixoldecanoat, Haloperidol, Perazin und Zuclopentixol. Den typisch-hypnotisch-sedierend wirkendenen Antipsychotika werden Chlorprothixen, Levomepromazin, Melperon, Pipamperon, Promethazin und Prothipendyl zugerechnet.

Atypische Antipsychotika sind Amisulprid, Aripiprazol, Clozapin, Olanzapin, Quetiapin, Risperidon. 


\subsection{Statistische Auswertung}

Die Auswertung erfolgte mittels Excel für Mac 2011 und IBM SPSS Statistics Version 22. Die Untersuchung hinsichtlich der Unterschiede zwischen zwei binären Variablen wurde mit dem Chi-Quadrat-Test durchgeführt. Analog mit stetigen Variablen wurde so mit dem Mann-Whitney-U-Test verfahren. Bei dem Vergleich der Mediane für stetige Variablen der Fälle mit Leberwerterhöhungen mit den Medianen der anhand der Stichtagszählungen geschätzten Referenzgruppe wurde der Wilcoxon-Vorzeichen-Rang-Test für abhängige Stichproben erhoben.

Zusätzlich zu den Medianen wurden auch immer Minimum und Maximum mit angegeben. Diese Messgrößen wurden auch für die Schätzzahlen der Stichtagszählungen von AMSP mit angebenen und fanden zur Vergleichbarkeit auch für das Kollektiv der Fälle mit Leberwerterhöhung Anwendung.

Zur Ermittlung der prozentualen Anteile der Fälle mit Leberwerterhöhungen an den entsprechenden Referenzgruppen wurde folgende Formel verwendet, wobei $\mathrm{x}$ als Platzhalter für ein beliebiges Kollektiv steht. So kann hier beispielsweise die prozentuale Häufigkeit der Leberwerterhöhung von Olanzapin gemessen an der Referenzgruppe (Gesamtzahl der über AMSP erfassten Patienten, die ebenfalls Olanzapin einnahm), bestimmt werden.

Häufigkeit $(\mathrm{x})=\frac{\text { Fälle }(x) \text { mit Leberwerterhöhung }}{\text { Referenzgruppe }(x) \text { anhand der Stichtagszählung }} * 100$

Zur Ermittlung der Inzidenzen der Leberwerterhöhungen anhand der verschiedenen Referenzgruppen wurde die BETA.INV-Funktion von Excel für Mac 2011 benutzt, um so das 95 \%-Konfidenzintervall für die Inzidenz der schweren Leberwerterhöhung anzugeben.

Unter der Annahme, das Signifikanzniveau der gesamten Studie dieser Arbeit liegt bei $p<0,05$, also $5 \%$ Wahrscheinlichkeit die Nullhypothese fälschlicherweise zu verwerfen (= Alpha-Fehler), muss folgendes beachtet werden: 
Bei der Durchführung mehrerer univariater Tests, bei denen jeweils das Signifikanzniveau bei $p<0,05$ liegt, kann es zur Kumulierung des Alphafehlers kommen.

Um diesem Umstand entgegen zu wirken, muss die Bewertung der einzelnen Tests unter Einhaltung des Alpha-Fehlers der Gesamtstudie von 5\%, strenger erfolgen.

Eine Möglichkeit ist die sogenannte Bonferroni-Korrektur, wonach die Anforderung an den $p$-Wert der einzelnen Tests statt $p<0,05$ nun $p<0,05$ geteilt durch die Anzahl der durchgeführten Tests (=k) ist (Kerr AW et al. 2002).

$\mathrm{p}<\frac{0,05}{k}$

$k=$ Anzahl durchgeführter Tests

In dieser Arbeit mit AMSP wurden 44 statistische Tests durchgeführt, wobei sich ein nach Bonferroni korrigierte Anforderung an der Alpha-Fehler jeden einzelnen Tests von $p<0,001$ ergibt. Der Wert wurde zur Vereinfachung auf die dritte Nachkommastelle gerundet.

\subsection{Grafiken}

Die Grafiken in dieser Arbeit wurden mit der Hilfe von Photoshop CS5 für Mac Version 2010 modifiziert oder erstellt und zu Teilen handgezeichnet. 


\section{ERGEBNISSE}

\subsection{Analyse}

\subsubsection{Beschreibung des Patientenkollektivs}

Im Zeitraum von 1993 bis 2012 wurden 213 Fälle mit schwerer Leberwerterhöhung von AMSP erfasst. Unter den 213 Fällen befanden sich 111 Männer (52,1\%) und 102 Frauen (47,9 \%). Von den 213 Fällen wurde bei 150 Fällen das Antipsychotikum alleine angeschuldigt (70,4\%), in 63 Fällen $(29,6 \%)$ wurden Kombinationen unterschiedlicher Pharmaka für die Leberwerterhöhung verantwortlich gemacht. Das mediane Alter des Kollektivs mit Leberwerterhöhung lag bei 36 Jahren, die mediane Aufenthaltsdauer betrug 71,5 Tage und die mediane Dauer der UAW umfasste 28 Tage. Bei 18 Fällen (8,5\%) kam es neben der Leberwerterhöhung noch $\mathrm{zu}$ einer weiteren unerwünschten Arzneimittelwirkung. 171 Fälle $(80,3 \%)$ erhielten neben den angeschuldigten Antipsychotika noch weitere Medikamente. Somatische Komorbiditäten gab es bei 58 der 213 Fälle $(27,2 \%)$.

Diese Daten sind in Tabelle 5 zusammengefasst.

Tabelle 5: Allgemeine Parameter des Patientenkollektivs

\begin{tabular}{|l|r|r|}
\hline Allgemeine Parameter & $\mathbf{n}$ & $\mathbf{\%}$ \\
\hline Männer & 111 & 52,1 \\
\hline Frauen & 102 & 47,9 \\
\hline Alleinanschuldigung & 150 & 70,4 \\
\hline Kombinationsanschuldigung & 63 & 29,6 \\
\hline Weitere UAW & 18 & 8,5 \\
\hline Komedikation & 171 & 80,3 \\
\hline Somatische Komorbiditäten & 58 & 27,2 \\
\hline & & Min;Max \\
\hline Alter (Jahre) & 36 & $18 ; 83$ \\
\hline Aufenthaltsdauer in Tagen $(\mathrm{n}=198)$ & 71,5 & $4 ; 617$ \\
\hline Dauer der UAW in Tagen $(\mathrm{n}=131)$ & 28 & $4 ; 197$ \\
\hline
\end{tabular}

$\mathrm{n}=$ Anzahl der Fälle mit Leberwerterhöhung, Min = Minimum, Max = Maximum

Der Anteil der Männer mit Leberwerterhöhung $(n=111)$ betrug 0,09 \% an der männlichen Referenzgruppe ( $n=125355)$, die von 1993 bis 2012 mit Antipsychotika therapiert wurden. Bei Frauen $(n=102)$ lag der Prozentsatz bei $0,07 \%$ gemessen an allen Frauen unter Antipsychotikatherapie ( $n=153506)$ von 1993 bis 2012. Bezüglich der Inzidenz der schweren 
Leberwerterhöhung konnte zwischen Männern und Frauen kein signifikanter unterschied festgestellt werden $(p=0,036)$.

\subsubsection{Psychiatrische Diagnosen}

Unter den 213 Fällen mit Leberwerterhöhung litt der größte Anteil mit 127 Patienten (59,6 \%) an einer Schizophrenie, gefolgt von einer Depression mit 47 Fällen $(22,1 \%)$. Weitere Zahlen zu den Diagnosen befinden sich in Tabelle 6.

Tabelle 6: Psychiatrische Diagnosen

\begin{tabular}{|l|r|r|}
\hline Psychiatrische Diagnosen & $\mathbf{n}$ & $\mathbf{\%}$ \\
\hline Schizophrenien & 127 & 59,6 \\
\hline Depressionen & 47 & 22,1 \\
\hline Organische Psychosen & 13 & 6,1 \\
\hline Manien & 11 & 5,2 \\
\hline Neurosen & 10 & 4,7 \\
\hline Sucht & 3 & 1,4 \\
\hline Sonstige psychiatrische Diagnosen & 2 & 0,9 \\
\hline Gesamt & 213 & 100 \\
\hline
\end{tabular}

$\mathrm{n}=$ Anzahl der Patienten mit der jeweiligen Diagnose und einer Leberwerterhöhung

Abbildung 4 stellt grafisch die prozentualen Häufigkeiten der psychiatrischen Diagnosen bei Männern und Frauen dar. Hier sind die Schizophrenien mit $72,1 \%$ die häufigste Diagnose, gefolgt von den depressiven Störungen mit 10,8 \% und den Manien und organischen Psychosen mit jeweils 6,3\%. Wie in Abbildung 4 dargestellt sind bei Frauen die Schizophrenien ebenfalls die häufigste Diagnose mit 46,1\%. Die Depressionen haben einen Anteil von 34,3 \%. An dritter Stelle sind die organischen Psychosen mit 5,9 \%. 


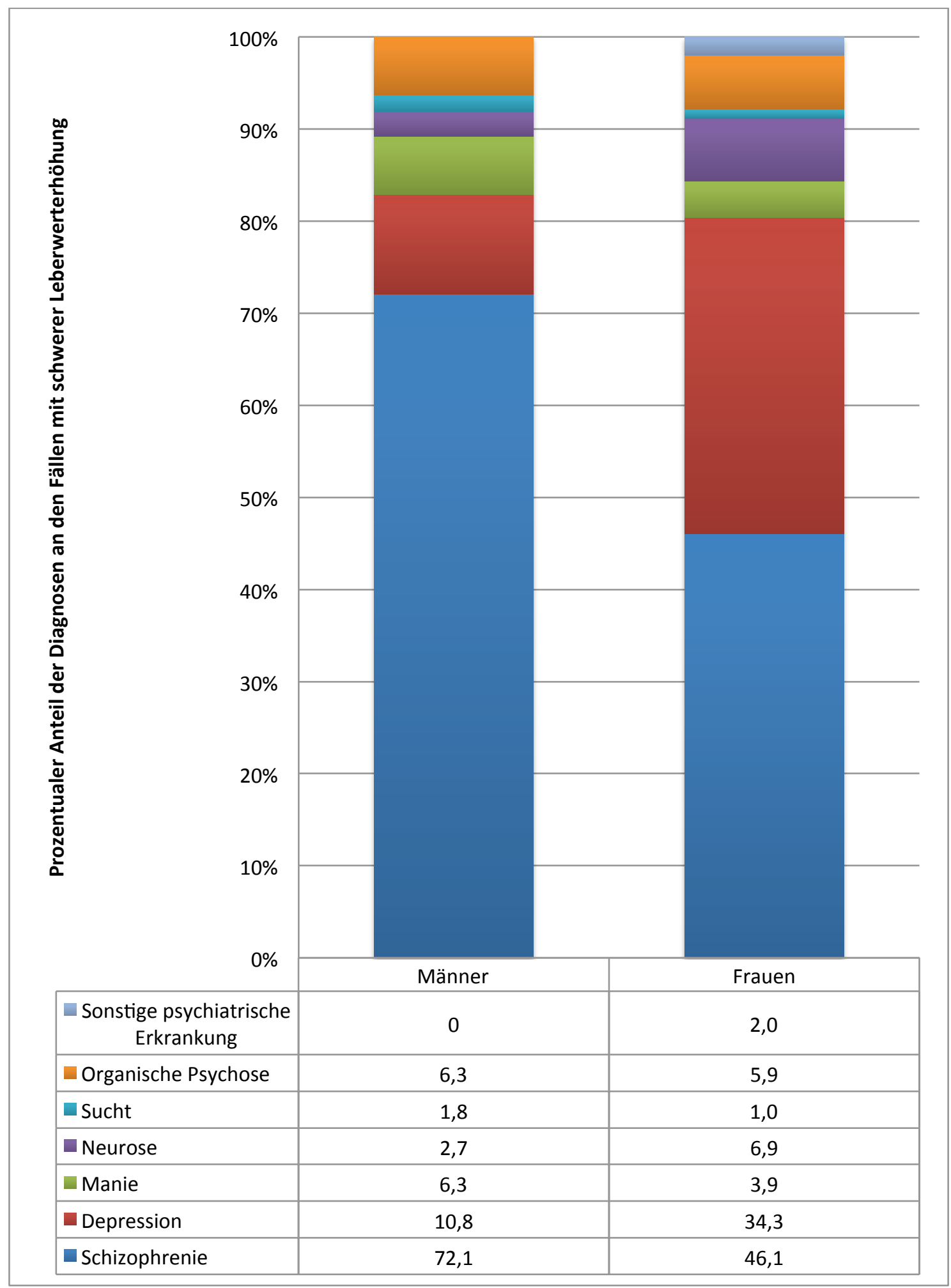

Abbildung 4: Häufigkeiten der Diagnosen bei Männern und Frauen unter den Fällen mit Leberwerterhöhungen 


\subsubsection{Somatische Diagnosen und Risikofaktoren bezüglich des Auftretens einer UAW}

Bei der Analyse der somatischen Diagnosen stellte sich heraus, dass acht der $213(3,8 \%)$ Fälle an Adipositas, vier an viraler Hepatitis (A, B, C, D oder E) $(1,9 \%)$ und fünf an anderen Lebererkrankungen (2,3\%) litten. Im Rahmen der Untersuchung der Risikofaktoren hatten 53 Patienten (24,9\%) eine Organvorschädigung der Leber und sieben (3,3\%) berichteten eine erhöhte Prädisposition für das Auftreten einer UAW (siehe Tabelle 7). Ergänzend ist zu sagen, dass bei allen Fällen mit Adipositas (BMI $\geq 30$ ) auch eine Organvorschädigung bestand.

Tabelle 7: Risikofaktoren bezüglich des Auftretens der UAW

\begin{tabular}{|l|r|r|}
\hline Somatische Diagnosen & $\mathbf{n}$ & \% \\
\hline Adipositas (BMI $\geq 30$ ) & 8 & 3,8 \\
\hline Hepatitis (A, B, C, D oder E) & 4 & 1,9 \\
\hline Andere Lebererkrankung & 5 & 2,3 \\
\hline Risikofaktoren & & \\
\hline Organvorschädigung & 53 & 24,9 \\
\hline Erhöhte Prädisposition für eine UAW & 7 & 3,3 \\
\hline Schädlicher Gebrauch (Alkohol, Drogen) & 9 & 4,2 \\
\hline
\end{tabular}

$\mathrm{n}=$ Anzahl der Fälle mit Leberwerterhöhungen für alle erwähnten Leberparameter

\subsubsection{Verlauf}

In Tabelle 8 sind die Maßnahmen und der Verlauf bei den Patienten mit Leberwerterhöhungen aufgeführt. Am häufigsten kam es zum Absetzen des Antipsychotikums aufgrund des Auftretens der UAW ( $n=170 ; 79,8 \%$ ), bei 33 Patienten (15,5 \%) wurde das Antipsychotikum reduziert. Bei 56 Patienten $(26,3 \%)$ erfolgte ein Konsil zur weiteren organischen Abklärung.

Aufgrund der Methodik von AMSP wurde bei 110 Fällen (51,6\%) das Abklingen der UAW am Beobachtungsende dokumentiert, bei 97 Fällen $(45,5 \%)$ war die UAW am Abklingen und in einem Fall $(0,5 \%)$ kam es zum bleibenden Schaden mit der Folge einer Lebertransplantation. Der Verlauf von vier Patienten (1,9\%) ist nicht bekannt, bzw. wurde nicht genauer dokumentiert. 
Tabelle 8: Gegenmaßnahmen und Verlauf der UAW

\begin{tabular}{|l|r|r|}
\hline Maßnahmen & $\mathbf{n}$ & $\mathbf{\%}$ \\
\hline Reduktion & 33 & 15,5 \\
\hline Absetzen & 170 & 79,8 \\
\hline Verlegung & 8 & 3,8 \\
\hline Konsil & 56 & 26,3 \\
\hline Verlauf & $\mathbf{n}$ & $\%$ \\
\hline UAW abgeklungen & 97 & 45,5 \\
\hline UAW am Abklingen & 110 & 51,6 \\
\hline bleibender Schaden & 1 & 0,5 \\
\hline unverändert bei Beobachtungsende & 1 & 0,5 \\
\hline unbekannt & 4 & 1,9 \\
\hline
\end{tabular}

$\mathrm{n}=$ Anzahl der Fälle mit Leberwerterhöhungen

\subsubsection{Antipsychotika}

Insgesamt wurden 242 antipsychotische Medikamentengaben bei 213 Fällen bezüglich einer schweren Leberwerterhöhung angeschuldigt. Dabei betrug der Anteil der atypischen Antipsychotika an den angeschuldigten Antipsychotikagaben 70,2 \%. Die Häufigkeiten der Leberwerterhöhungen unter den angeschuldigten typischen Antipsychotika wurde anhand ihrer einleitend beschriebenen Subgruppen (Butyrophenone, Phenothiazine, Thioxanthen) genauer beschrieben.

Bei den typischen Antipsychotika sind die Phenothiazine als Untergruppe am häufigsten vertreten (16,1\%). Perazin wurde als häufigstes Phenothiazin 19 Mal angeschuldigt. Chlorprothixen ist mit sieben Anschuldigungen das häufigste Thioxanthen. Haloperidol macht mit 13 Anschuldigungen den größten Anteil unter den Butyrophenonen aus.

Bei den atypischen Antipsychotika und auch generell das am häufigsten angeschuldigte Antipsychotikum ist Olanzapin mit 79 Anschuldigungen nach AMSP. Damit hat es einen Anteil von $32,6 \%$ an allen angeschuldigten Antipsychotika (siehe hierzu Tabelle 9). 
Tabelle 9: Antipsychotika (Allein- und Kombinationsanschuldigungen)

\begin{tabular}{|c|c|c|c|c|c|}
\hline AP-Typ & Med.Gruppe & Antipsychotikum & $\mathbf{n}$ & $\begin{array}{l}\text { \% Med. } \\
\text { Gruppe }\end{array}$ & $\%$ Alle \\
\hline \multirow{7}{*}{ Atypisch } & \multirow{7}{*}{$\begin{array}{l}\text { Atypische } \\
\text { Antipsychotika }\end{array}$} & Amisulprid & 4 & 2,4 & 1,7 \\
\hline & & Aripiprazol & 1 & 0,6 & 0,4 \\
\hline & & Clozapin & 41 & 24,1 & 16,9 \\
\hline & & Olanzapin & 79 & 46,5 & 32,6 \\
\hline & & Quetiapin & 26 & 15,3 & 10,7 \\
\hline & & Risperidon & 19 & 11,2 & 7,9 \\
\hline & & Summe & 170 & & 70,2 \\
\hline \multirow{16}{*}{ Typisch } & \multirow{6}{*}{ Butyrophenone } & Benperidol & 1 & 5,3 & 0,4 \\
\hline & & Bromperidol & 1 & 5,3 & 0,4 \\
\hline & & Haloperidol & 13 & 68,4 & 5,4 \\
\hline & & Melperon & 3 & 15,8 & 1,2 \\
\hline & & Pipamperon & 1 & 5,3 & 0,4 \\
\hline & & Summe & 19 & & 7,9 \\
\hline & \multirow{5}{*}{ Phenothiazine } & Levomepromazin & 8 & 20,5 & 3,3 \\
\hline & & Perazin & 19 & 48,7 & 7,9 \\
\hline & & Promethazin & 9 & 23,1 & 3,7 \\
\hline & & Prothipendyl & 3 & 7,7 & 1,2 \\
\hline & & Summe & 39 & & 16,1 \\
\hline & \multirow{5}{*}{ Thioxanthene } & Chlorprothixen & 7 & 50 & 2,9 \\
\hline & & Flupentixol & 3 & 21,4 & 1,2 \\
\hline & & Flupentixoldecanoat & 2 & 14,3 & 0,8 \\
\hline & & Zuclopentixol & 2 & 14,3 & 0,8 \\
\hline & & Summe & 14 & & 5,8 \\
\hline
\end{tabular}

AP-Typ = Antipsychotika-Typ, Med.Gruppe = Medikamenten-Gruppe, $\mathrm{n}=$ Anzahl der Fälle mit Leberwerterhöhungen, \% Med.Gruppe = Prozentualer Anteil der Fälle an der jeweiligen Antipsychotikagruppe (atypisch, Butyrophenone, Phenothiazine oder Thioxanthene), \% Alle = Prozentualer Anteil der Fälle an allen Antipsychotika

Tabelle 10 führt separat die Antipsychotika auf, die in Kombination bezüglich der Leberwerterhöhung angeschuldigt wurden. Insgesamt wurden 92 Antipsychotika in Kombination angeschuldigt, hierunter ist nicht genauer definiert, ob sie mit einem weiteren Antipsychotikum in Kombination angeschuldigt wurden oder mit einem Medikament einer anderen Substanzklasse. Diese 92 Antipsychotika sind aufgrund von Kombinationsanschuldigungen von mehr als einem Antipsychotikum unter den 63 Kombinationsanschuldigungen mit schwerer LWE zusammengefasst.

Es fällt auf, dass 10 von 13 Fällen mit Haloperidol in Kombination angeschuldigt wurden. Ebenso ist auch Melperon mit allen drei angeschuldigten Fällen in der Sparte der Kombinationsanschuldigungen vertreten. Auch Chlorprothixen wurde insgesamt sieben Mal (siehe Tabelle 10) angeschuldigt; sechs Mal davon in Kombination. Olanzapin macht in der Sparte der Kombinationsanschuldigungen mit 20 Fällen (21,7 \%) erneut den größten Anteil aus. 
Tabelle 10: Antipsychotika (Kombinationsanschuldigungen bezüglich des Auftretens der Leberwerterhöhung)

\begin{tabular}{|c|c|c|c|c|c|}
\hline AP-Typ & Med.Gruppe & Antipsychotikum & $n$ & $\begin{array}{l}\text { \% Med. } \\
\text { Gruppe }\end{array}$ & $\%$ Alle \\
\hline \multirow{7}{*}{ atypisch } & \multirow{7}{*}{$\begin{array}{l}\text { Atypische } \\
\text { Antipsychotika }\end{array}$} & Amisulprid & 1 & 2,3 & 1,1 \\
\hline & & Aripiprazol & 1 & 2,3 & 1,1 \\
\hline & & Clozapin & 10 & 22,7 & 10,9 \\
\hline & & Olanzapin & 20 & 45,5 & 21,7 \\
\hline & & Quetiapin & 5 & 11,4 & 5,4 \\
\hline & & Risperidon & 7 & 15,9 & 7,6 \\
\hline & & Summe & 44 & & 47,8 \\
\hline \multirow{16}{*}{ typisch } & \multirow{6}{*}{ Butyrophenone } & Benperidol & 0 & 0 & 0 \\
\hline & & Bromperidol & 1 & 6,7 & 1,1 \\
\hline & & Haloperidol & 10 & 66,7 & 10,9 \\
\hline & & Melperon & 3 & 20 & 3,3 \\
\hline & & Pipamperon & 1 & 6,7 & 1,1 \\
\hline & & Summe & 15 & & 16,3 \\
\hline & \multirow{5}{*}{ Phenothiazine } & Levomepromazin & 6 & 28,6 & 6,5 \\
\hline & & Perazin & 5 & 23,8 & 5,4 \\
\hline & & Promethazin & 7 & 33,3 & 7,6 \\
\hline & & Prothipendyl & 3 & 14,3 & 3,3 \\
\hline & & Summe & 21 & & 22,8 \\
\hline & \multirow{5}{*}{ Thioxanthene } & Chlorprothixen & 6 & 50 & 6,5 \\
\hline & & Flupentixol & 3 & 25 & 3,3 \\
\hline & & Flupentixoldecanoat & 2 & 16,7 & 2,2 \\
\hline & & Zuclopenthixol & 1 & 8,3 & 1,1 \\
\hline & & Summe & 12 & & 13,0 \\
\hline
\end{tabular}

AP-Typ = Antipsychotika-Typ, Med.Gruppe = Medikamenten-Gruppe, $\mathrm{n}=$ Anzahl der Fälle mit Leberwerterhöhungen (Kombinationsanschuldigungen), \% Med.Gruppe $=$ Prozentualer Anteil der Fälle an der jeweiligen Antipsychotikagruppe (atypisch, Butyrophenone, Phenothiazine oder Thioxanthene), \% Alle = Prozentualer Anteil der Fälle an allen Antipsychotika

Unter 213 Fällen mit Leberwerterhöhungen befanden sich 63 Fälle mit Kombinationsanschuldigungen. Dies bedeutet, dass mehr als eine Substanz für die UAW „Leberwerterhöhung“ beschuldigt wurde. In Tabelle 11 sind in absteigender Reihenfolge die häufigsten Kombinationsanschuldigungen dargestellt.

Sowohl die Anzahl (n) als auch die Prozente (\%) können zusammen die Anzahl der 63 Patienten und entsprechend 100 \% überschreiten, da bei einem Patienten mehr als zwei Medikamente in Kombination für das auftreten der Leberwerterhöhung beschuldigt worden sein können. Am häufigsten mit 49,2 \% der Fälle ist eine Kombinationsanschuldigung von einem Antipsychotikum mit einem Antidepressivum. 
Tabelle 11: Häufigkeiten der Kombinationsanschuldigungen bezüglich des Auftretens einer schweren Leberwerterhöhung

\begin{tabular}{|c|c|c|}
\hline Med.Gruppe & $\mathbf{n}$ & $\%$ \\
\hline Antidepressiva & 31 & 49,2 \\
\hline Antipsychotika & 25 & 39,7 \\
\hline Antiepileptika & 11 & 17,5 \\
\hline $\begin{array}{l}\text { Andere Nicht- } \\
\text { Psychopharmaka }\end{array}$ & 7 & 11,1 \\
\hline Tranquilizer & 1 & 1,6 \\
\hline
\end{tabular}

Med.Gruppe = Medikamenten-Gruppe, $\mathrm{n}=$ Anzahl der Fälle mit

Kombinationsanschuldigungen für eine schwere Leberwerterhöhungen

In Abbildung 5 sind die Anzahlen der häufigsten Kombinationsanschuldigungen von mindestens einem Antipsychotikum mit einem weiteren Antipsychotikum (blaue Säule), einem Antidepressivum (rote Säule) oder einem mood stabilizer (auch Antikonvulsivum) (grüne Säule) dargestellt. Mit eingeschlossen in die Auswertung sind nur jene Kombinationsanschuldigungen von denen es mindestens drei gab. Diese Voraussetzung traf auch nur auf diese drei Substanzklassen als Kombinationspräparate zu. Die häufigsten Kombinations-anschuldigungen sind Antipsychotika mit Olanzapin, beziehungsweise Mirtazapin und Venlafaxin mit jeweils 9 Kombinationen, was jeweils $14,3 \%$ der Kombinationsanschuldigungen $(n=63)$ entspricht. Clozapin hat als in Kombination angeschuldigtes Präparat einen Anteil von 11,1\% $(n=7)$, Haloperidol und Valproinsäure folgen danach mit jeweils $9,5 \%(n=6)$. Darüber hinaus gibt es noch zahlreiche weitere Antipsychotika, Antidepressiva und mood stabilizer, aber auch Präparate aus anderen Fachabteilungen, die mit einem Antipsychotikum in Kombination angeschuldigt wurden, aber aufgrund der geringen Fallzahlen hier nicht im Detail dargestellt werden. 


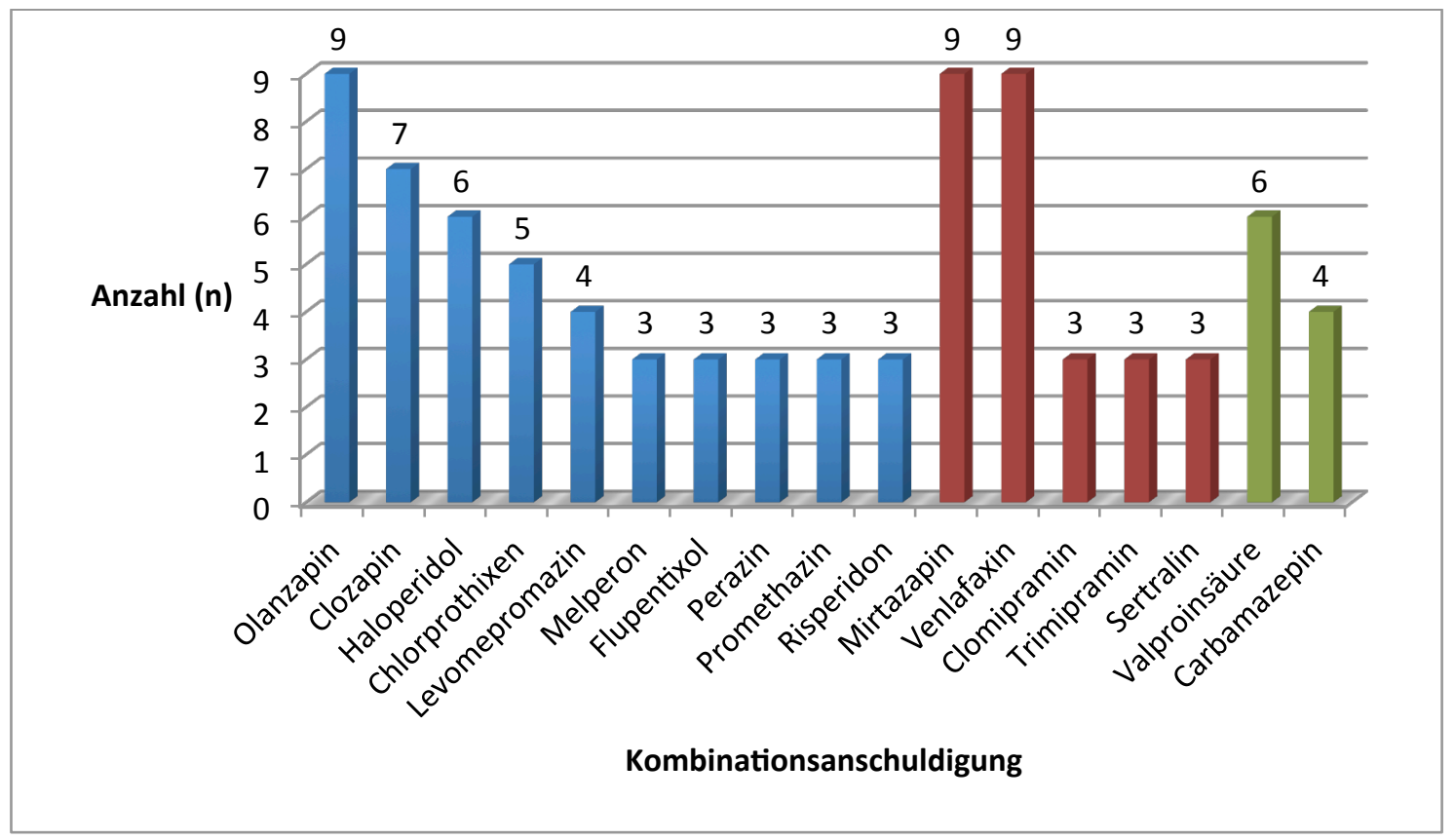

Abbildung 5: Anzahl der Kombinationsanschuldigungen: Antipsychotika, Antidepressiva, mood stabilizer unter den Fällen mit Leberwerterhöhungen

In Tabelle 12 sind die 240 Anschuldigungen und die jeweilige Dosis der Antipsychotikagaben (in $\mathrm{mg}$ ), die für die Leberwerterhöhungen verantwortlich gemacht wurden, aufgeführt. Die Anzahl der Anschuldigungen des jeweiligen Antipsychotikums, für das die Dosis ermittelt wurde, kann von der absoluten Anzahl der Anschuldigungen für das entsprechende Präparat variieren, da nicht bei allen Antipsychotika die tägliche Dosis dokumentiert wurde. So ist beispielsweise hier die Anzahl von Olanzapin nur bei 77 Fällen statt 79 dokumentiert. In der Summe wurden Median, Minimum und Maximum nicht aufgeführt, da die jeweiligen Antipsychotika sehr unterschiedliche Dosierungen haben, die miteinander nicht vergleichbar sind. 
Tabelle 12: Dosis der Antipsychotika bei den Fällen mit Leberwerterhöhungen

\begin{tabular}{|l|r|r|r|r|}
\hline Antipsychotikum & $\mathbf{n}$ & Median (mg) & Minimum (mg) & Maximum (mg) \\
\hline Amisulprid & 4 & 700 & 300 & 900 \\
\hline Aripiprazol & 1 & 15 & 15 & 15 \\
\hline Clozapin & 41 & 200 & 50 & 700 \\
\hline Olanzapin & 77 & 15 & 5 & 40 \\
\hline Quetiapin & 26 & 362,5 & 75 & 1500 \\
\hline Risperidon & 19 & 4 & 1 & 8 \\
\hline Benperidol & 1 & 12 & 12 & 12 \\
\hline Bromperidol & 1 & 2 & 2 & 2 \\
\hline Haloperidol & 13 & 5 & 1 & 24 \\
\hline Melperon & 3 & 75 & 25 & 200 \\
\hline Pipamperon & 1 & 60 & 60 & 60 \\
\hline Levomepromazin & 8 & 100 & 50 & 500 \\
\hline Perazin & 19 & 300 & 100 & 800 \\
\hline Promethazin & 9 & 150 & 75 & 250 \\
\hline Prothipendyl & 3 & 80 & 40 & 80 \\
\hline Chlorprothixen & 7 & 100 & 50 & 250 \\
\hline Flupentixol & 3 & 10 & 8 & 10 \\
\hline Flupentixoldecanoat & 2 & 2,143 & 1,429 & 2,857 \\
\hline Zuclopenthixol & 2 & 82,5 & 25 & 140 \\
\hline Summe & 240 & & & \\
\hline
\end{tabular}

$\mathrm{n}=$ Anzahl der Fälle mit Lebertwerterhöhung, $\mathrm{mg}=$ Milligramm, angegeben ist die Dosis pro Tag

Da bei einigen Medikamenten die Fallzahl sehr gering ist, werden im Folgenden nur die häufigeren Antipsychotika auf Unterschiede hinsichtlich der Dosis zwischen der Gruppe mit Leberwerterhöhung und der Referenzgruppe untersucht. Zur Ermittlung der Referenzgruppe siehe 2.1.8. Bei den untersuchten Antipsychotika konnte zwischen den Fällen mit schwerer Leberwerterhöhung und der Referenzgruppe kein statistischer Unterschied hinsichtlich der Dosis des Antipsychotikums festgestellt werden (Siehe Tabelle 13). 
Tabelle 13: Unterschiede in der Dosis der Antipsychotika zwischen den Fällen mit Leberwerterhöhung und der Referenzgruppe aus den Stichtagserhebungen

\begin{tabular}{|c|c|c|c|c|c|}
\hline \multirow[b]{2}{*}{ Antipsychotikum } & \multicolumn{2}{|c|}{ Referenzgruppe } & \multicolumn{2}{|l|}{ LWE } & \multirow[b]{2}{*}{ P-Wer } \\
\hline & $\mathbf{N}$ & $\begin{array}{l}\text { Dosis Median in } \\
\text { mg } \\
\text { (Min; Max) }\end{array}$ & $\mathbf{n}$ & $\begin{array}{l}\text { Dosis Median in } \\
\text { mg }\end{array}$ & \\
\hline Clozapin & 34129 & $300(2 ; 1500)$ & 41 & 200 & 0,008 \\
\hline Olanzapin & 45115 & $15(0,5 ; 70)$ & 77 & 15 & 0,947 \\
\hline Quetiapin & 48016 & $300(1 ; 2400)$ & 26 & 362,5 & 0,144 \\
\hline Risperidon & 40269 & $3(0,03 ; 17)$ & 19 & 4 & 0,075 \\
\hline Haloperidol & 34073 & $8(0,3 ; 130)$ & 13 & 5 & 0,783 \\
\hline Levomepromazin & 12183 & $100(1 ; 800)$ & 8 & 100 & 0,684 \\
\hline Perazin & 15236 & $200(5 ; 900)$ & 19 & 300 & 0,002 \\
\hline Promethazin & 14529 & $50(5 ; 900)$ & 9 & 150 & 0,007 \\
\hline Chlorprothixen & 12681 & $90(1,5 ; 1200)$ & 7 & 100 & 0,115 \\
\hline
\end{tabular}

$\mathrm{n}=$ Anzahl der Fälle mit Leberwerterhöhung, $\mathrm{N}=$ Anzahl der Fälle in der Referenzgruppe aus den Stichtagszählungen, LWE = Leberwerterhöhungen, $\mathrm{mg}=$ Milligramm, Min = Minimum, Max = Maximum, angegeben ist die Dosis pro Tag, nach Bonferroni korrigiert: $p<0,001$

In der Tabelle 14 sind die Anzahl an Patienten von 1993 bis 2012 (=N) und die Anzahl an Fällen mit Leberwerterhöhungen $(=n)$ aufgeführt. Hieraus wurde die geschätzte Inzidenz in Prozent ermittelt (siehe 2.1.8).

Am häufigsten tritt die Leberwerterhöhung mit 0,18 \% bei Olanzapin und mit $0,12 \%$ bei Clozapin und Perazin auf. Obwohl relativ viele Patienten in dem Kollektiv unter Quetiapin $(n=26)$, Risperidon $(n=19)$ oder Haloperidol $(n=13)$ eine Leberwerterhöhung entwickelten, ist die UAW Leberwerterhöhung gemessen an den geschätzten Absolutzahlen relativ selten $(0,05 \%$ bei Quetiapin und Risperidon, $0,04 \%$ bei Haloperidol). Am seltensten trat die UAW bei Pipamperon $(<0,01 \%)$ auf; es wurde ein einziger Fall mit einer Leberwerterhöhung unter diesem Medikament im Rahmen von AMSP registriert. 
Tabelle 14: Inzidenz der Leberwerterhöhung unter den Antipsychotika

\begin{tabular}{|c|r|r|r|}
\hline & $\mathbf{N}$ & $\mathbf{n}$ & \% \\
\hline Atypische AP & 181158 & 170 & 0,09 \\
\hline Amisulprid & 11524 & 4 & 0,03 \\
\hline Aripirazol & 9957 & 1 & 0,01 \\
\hline Clozapin & 34129 & 41 & 0,12 \\
\hline Olanzapin & 45115 & 79 & 0,18 \\
\hline Quetiapin & 48016 & 26 & 0,05 \\
\hline Risperidon & 40269 & 19 & 0,05 \\
\hline Butyrophenone & 75427 & 19 & 0,03 \\
\hline Benperidol & 2419 & 1 & 0,04 \\
\hline Bromperidol & 900 & 1 & 0,11 \\
\hline Haloperidol & 34073 & 13 & 0,04 \\
\hline Melperon & 17181 & 3 & 0,02 \\
\hline Pipamperon & 19343 & 1 & 0,01 \\
\hline Phenothiazine & 61854 & 39 & 0,06 \\
\hline Levomepromazin & 12183 & 8 & 0,07 \\
\hline Perazin & 15236 & 19 & 0,12 \\
\hline Promethazin & 14529 & 9 & 0,06 \\
\hline Prothipendyl & 11660 & 3 & 0,03 \\
\hline Thioxanthene & 35745 & 14 & 0,04 \\
\hline Chlorprothixen & 12681 & 7 & 0,06 \\
\hline Flupentixol & 9659 & 3 & 0,03 \\
\hline Flupentixoldecanoat & 5585 & 2 & 0,04 \\
\hline Zuclopentixol & 6485 & 2 & 0,03 \\
\hline
\end{tabular}

$\mathrm{AP}=$ Antipsychotika, $\mathrm{N}=$ Anzahl der Fälle in der Referenzgruppe, $\mathrm{n}=$ Anzahl der Fälle mit Leberwerterhöhung

In Abbildung 6 sind die ermittelten Inzidenzen der Leberwerterhöhung (siehe 2.1.8) für das jeweilige Antipsychotikum grafisch dargestellt. Zusätzlich wurden die $95 \%$-Konfidenzintervalle mit angegeben. Für die Antipsychotikatherapie insgesamt ergibt sich eine Inzidenz von 0,08 \% für das Auftreten einer schweren Leberwerterhöhung. Von 1993 bis 2012 wurden ingesamt 278861 Patienten mit Antipsychotika in den teilnehmenden Kliniken des AMSP behandelt. 


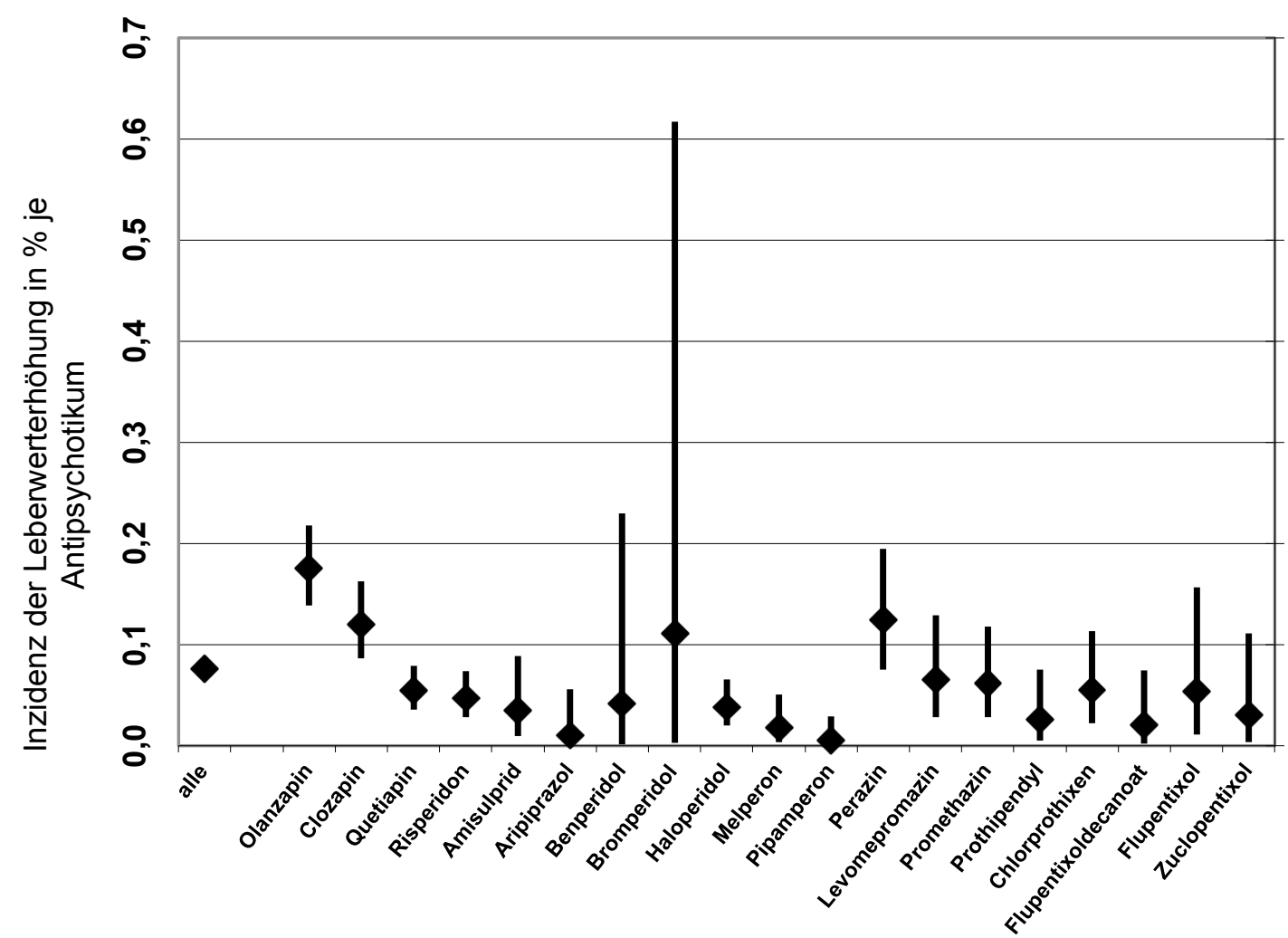

Abbildung 6: Leberwerterhöhungen in \% der überwachten Patienten des jeweiligen Antipsychotikums

Angegeben ist die ermittelte Inzidenz der schweren Leberwerterhöhung über die verschiedenen Antipsychotika und das $95 \%$-Konfidenzintervall für die ermittelte Inzidenz.

Auffällig ist, wie in Abbildung 7 dargestelt, dass bei fast allen Antipsychotika die ALT am häufigsten oberhalb des fünffachen Referenzwertes angestiegen ist. Bei Levomepromazin und Perazin sogar in $100 \%$ der Fälle. Bei Quetiapin ist die YGT mit 54,2\% der Fälle mit Leberwerterhöhung relativ hoch bei einer entsprechend hohen Fallzahl $(n=24)$, bei Risperidon $(n=12)$ mit $16,7 \%$ sehr gering. Auffällig ist auch, dass bei Olanzapin mit der höchsten Fallzahl die YGT etwas häufiger oberhalb des fünffachen Referenzwertes angestiegen ist als die AST. 


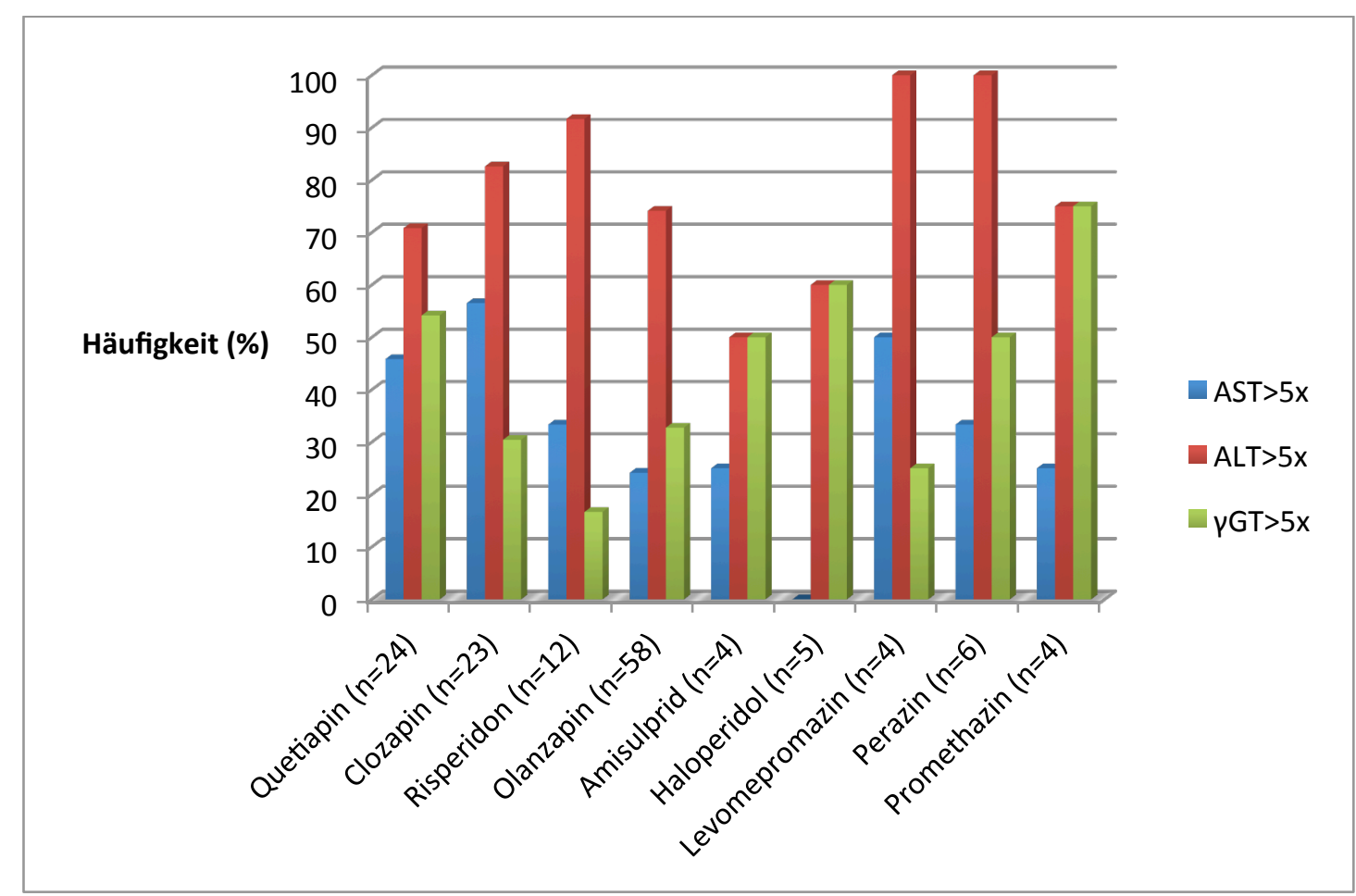

Abbildung 7: Prozentualer Anteil der verschiedenen Leberwerterhöhungen (AST, ALT, YGT) an den Fällen mit Leberwerterhöhungen bei den jeweiligen Antipsychotika

\subsubsection{Präexposition und Reexposition}

Für die Fälle mit Leberwerterhöhungen $(n=213)$ wurde eine Präexpositionen mit dem angeschuldigten Antipsychotikum in allen Fällen außer einem dokumentiert. Vier der 213 Fälle (1,9\%) hatten früher schon einmal die gleiche UAW unter dem nun angeschuldigten Antipsychotikum. 14 Fälle $(6,6 \%)$ haben das angeschuldigte Antipsychotikum früher schon einmal eingenommen, jedoch ohne eine schwere Leberwerterhöhung zu entwickeln. In zwei Fällen war der Verlauf unter der vorherigen Therapie nicht bekannt und in 90,1\% der Fälle $(n=192)$ wurde das Antipsychotikum vor der aktuellen Therapie, unter der die Leberwerterhöhung auftrat, noch nicht verabreicht.

Darüber hinaus wurde auch die anschließende Reexposition mit den angeschuldigten Antipsychotika für die Fälle mit Leberwerterhöhung $(n=213)$ beschrieben. Dabei entwickelten drei Fälle $(1,4 \%)$ die gleiche UAW, in weiteren drei Fällen (1,4 \%) trat die UAW nicht erneut auf und bei 184 Fällen $(86,4 \%)$ wurde das Antipsychotikum nicht noch einmal verabreicht. In 10,3\% der Fälle ( $n=22)$ konnte das Antipsychotikum jedoch auch ohne Absetzen weitergegeben werden (siehe Tabelle 15). 
Tabelle 15: Präexposition und Reexposition mit dem jeweiligen Antipsychotikum

\begin{tabular}{|l|r|r|}
\hline Präexposition & \multicolumn{1}{|l|}{$\mathbf{n}$} \\
\hline Ja, gleiche UAW & 4 & 1,9 \\
\hline Ja, negativ & 14 & 6,6 \\
\hline Ja, Verlauf unbekannt & 2 & 0,9 \\
\hline Nein & 192 & 90,1 \\
\hline Nicht bekannt & 1 & 0,5 \\
\hline Reexposition & $\mathbf{n}$ & $\%$ \\
\hline Ja, gleiche UAW & 3 & 1,4 \\
\hline Ja, negativ & 3 & 1,4 \\
\hline Ja, Verlauf unbekannt & 1 & 0,5 \\
\hline Nein & 184 & 86,4 \\
\hline Weitergabe ohne Absetzen & 22 & 10,3 \\
\hline
\end{tabular}

$\mathrm{n}=$ Anzahl der Fälle mit Leberwerterhöhungen

\subsubsection{Laborparameter}

Ab 2003 wurden die Laborparameter in allen Kliniken standardisiert erfasst. Von 2003 bis 2012 wurden bei 134 Fällen mit Leberwerterhöhungen nach den Kriterien von AMSP (siehe 2.1.6) die Laborparameter bestimmt. Dabei wurde in 131 Fällen die ALT, in 126 Fällen die AST und in 114 Fällen die YGT dokumentiert. Voraussetzung für eine schwere Leberwerterhöhung nach AMSP ist mindestens ein Leberwert (AST, ALT, YGT oder AP), der das Fünffache des oberen Referenzwertes überschreitet.

Weitere Parameter wurden sehr selten bestimmt. Bilirubin direkt und Bilirubin gesamt wurden in insgesamt sechs Fällen, die Cholinesterase in zwei Fällen erfasst. Eine Verringerung des Quicks wurde nicht dokumentiert.

Unter den 134 Fällen mit Leberwerterhöhung ab 2003 war die AST in 46 Fällen (34,3\%) um mehr als das Fünffache des oberen Referenzwertes erhöht, die ALT in 103 Fällen (76,9 \%). Die yGT war in 49 Fällen um mehr als das Fünffache des oberen Referenzwertes erhöht, die AP wurde kein einziges Mal als um mehr als das Fünffache des obereren Referenzwertes erhöht, dokumentiert.

In Tabelle 16 ist zusätzlich die Anzahl der jeweils dokumentierten Laborwerte ab 2003 (N) aufgeführt, unabhängig davon, ob der Laborwert um mehr als das Fünffache des obereren Referenzwertes erhöht war. 
Tabelle 16: Häufigkeiten der Laborwerte oberhalb des fünffachen Referenzwertes unter den Fällen mit Leberwerterhöhungen

\begin{tabular}{|l|r|r|r|r|}
\hline Laborparameter & $\mathbf{n}$ & $\mathbf{\%}$ & $\mathbf{N}$ & $\mathbf{\% N}$ \\
\hline AST über Fünffach & 46 & 34,3 & 126 & 36,5 \\
\hline ALT über Fünffach & 103 & 76,9 & 131 & 78,6 \\
\hline YGT über Fünffach & 49 & 36,6 & 103 & 47,6 \\
\hline AP über Fünffach & 0 & 0 & 45 & 0 \\
\hline
\end{tabular}

$\mathrm{n}=$ Anzahl der Fälle mit Leberwerterhöhungen, $\% \mathrm{n}=$ Prozentualer Anteil an allen Fällen ( $n=134)$ mit Leberwerterhöhung ab 2003, $N=$ Anzahl der Fälle bei denen der jeweilige Laborwert ab 2003 dokumentiert wurde, \%N = Prozentualer Anteil der jeweils um mehr als das fünffache erhöhten Laborwerte an den jeweiligen ab 2003 dokumentierten Laborwerten $(=\mathrm{N})$.

\subsubsection{Geschätzte Inzidenzen der Leberwerterhöhung in drei Altersgruppen}

Anhand der Anzahl der Fälle mit Leberwerterhöhung konnte der prozentuale Anteil an allen stationär erfassten Patienten von 1993 bis 2012 in der jeweiligen Altersgruppe bestimmt werden (Methodik siehe 2.1.8). Wie in Abbildung 8 dargestellt, beträgt die geschätzte Inzidenz der Fälle mit Leberwerterhöhung in der Altersgruppe von 0 bis 30 Jahren 0,15\% $(n=77$; $\mathrm{N}=52050)$, in der mittleren Altersgruppe (31-60 Jahre) 0,07\% $(n=109$, $N=153224)$ und in der Altersgruppe der 60 bis 90-Jährigen 0,04\% $(n=27$; $\mathrm{N}=71722$ ). Da in der Kohorte der Fälle mit Leberwerterhöhung kein Patient im Altersbereich von 90 bis 120 Jahre lag, liegt hier die geschätzte Inzidenz bei $0 \%(n=0 ; N=1864)$. Damit ist die Inzidenz über die Altersgruppen fallend $(p<0,001)$. 


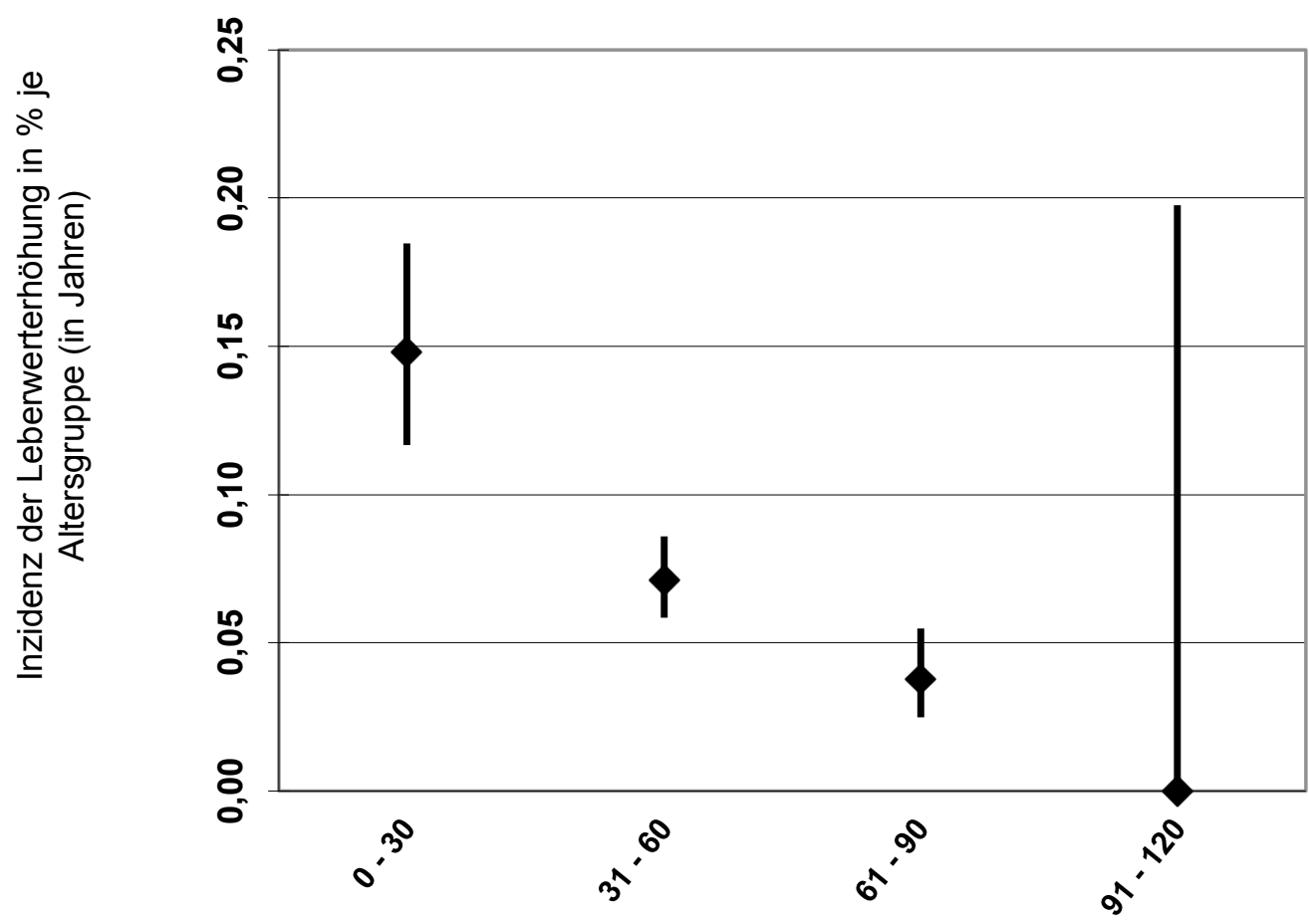

Abbildung 8: Ermittelte Inzidenz der Leberwerterhöhung unter den Altersgruppen (in Jahren)

Angeben ist die geschätzte Inzidenz der schweren Leberwerterhöhung über die verschiedenen Altersgruppe ( 0 bis 30 Jahre, 31 bis 60 Jahre, 61 bis 90 Jahre und 91 bis 120 Jahre) und das 95 \%-Konfidenzintervall für die geschätzte Inzidenz.

\subsubsection{Entwicklung in der Antipsychotikatherapie von 1994 bis 2012}

Abbildung 9 zeigt den Verlauf der Antipsychotikatherapie über die Jahre von 1994 bis 2012. 1994 umfassten die typischen Antipsychotika mit antipsychotischer Wirkung noch etwa $70 \%$ aller Antipsychotikatherapien. 2012 kommen sie nur noch bei etwa $18 \%$ der Fälle zum Einsatz. Die typischen Antipsychotika mit sedativer Wirkung bleiben seit 1994 bis 2012 konstant bei etwa $20 \%$ aller Antipsychotikatherapien. Stark angestiegen ist der Einsatz der atypischen Antipsychotika. Wo sie 1994 nur etwa bei $20 \%$ der Fälle mit Antipsychotikatherapie zum Einsatz kamen, wurden sie 2012 bei etwa $80 \%$ eingesetzt. 


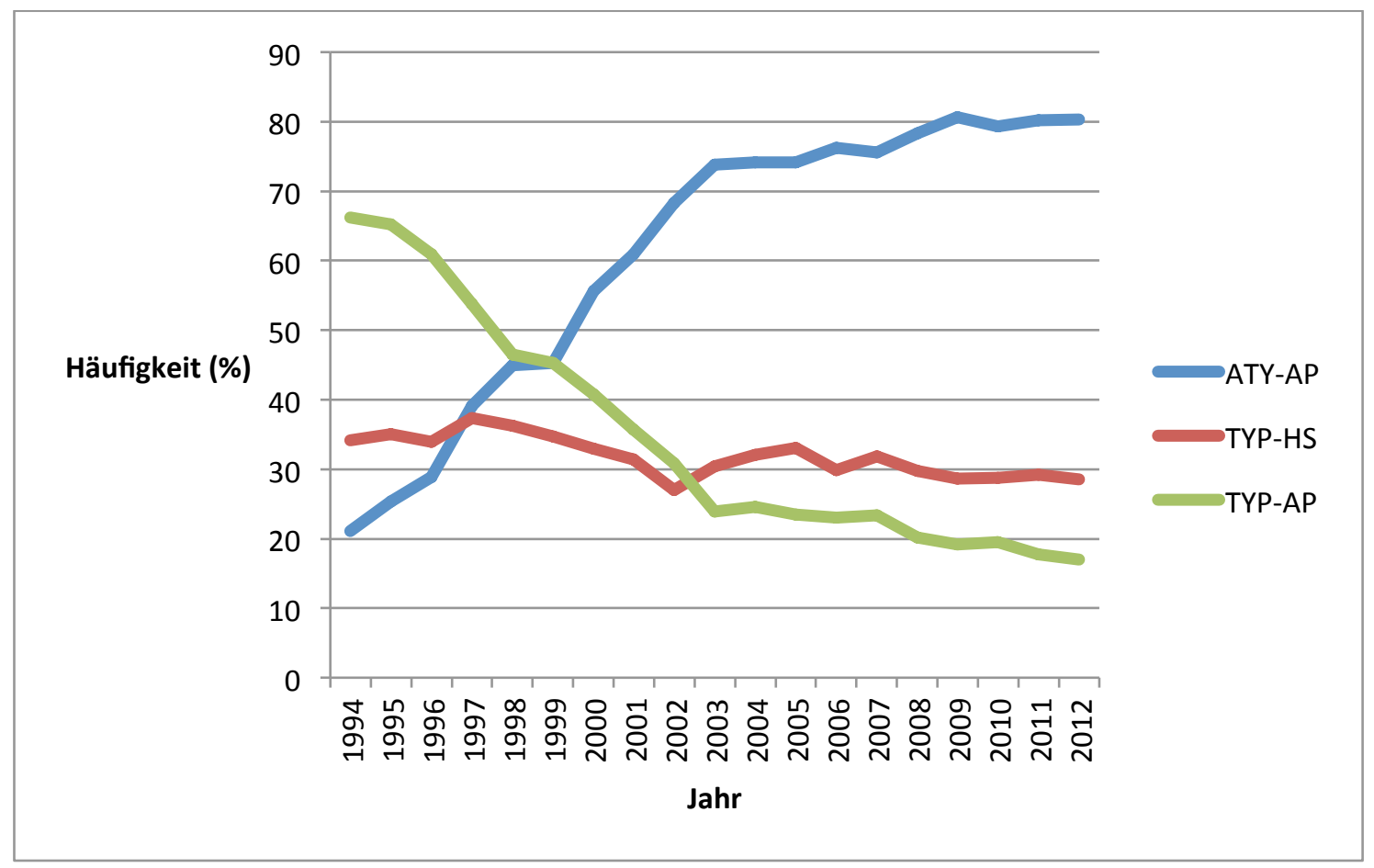

Abbildung 9: Entwicklungen in der Antipsychotikatherapie von 1994 bis 2012 ATY-AP = Atypische Antipsychotika, TYP-AP = typische Antipsychotika mit antipsychotischer Wirkungen, TYP-HS = typische Antipsychotika mit hypnotisch sedierender Wirkung.

1994 war Haloperidol mit $22 \%$ das noch am häufigsten verabreichte Antipsychotikum und Clozapin war das einzige atypische Antipsychotikum unter den fünf am häufigsten verabreichten Antipsychotika. Von 1999 bis 2006 war Olanzapin das häufigste verabreichte Antipsychotikum, seit 2007 ist Quetiapin führend und macht 2012 mit $30 \%$ fast ein Drittel der Antipsychotikatherapien aus. 2011 war kein einziges typisches Antipsychotikum unter den fünf Häufigsten (Siehe Tabelle 17). 
Tabelle 17: Die häufigsten verschriebenen Antipsychotika von 1994 bis 2012

\begin{tabular}{|c|c|c|c|c|c|c|c|c|c|c|}
\hline Jahr & 1. & $\%$ & 2. & $\%$ & 3. & $\%$ & 4. & $\%$ & 5. & $\%$ \\
\hline 1994 & Haloperidol & 22 & Clozapin & 17 & Perazin & 12 & Levomepr. & 12 & Pipamperon & 9 \\
\hline 1995 & Haloperidol & 27 & Clozapin & 16 & Perazin & 15 & Levomepr. & 10 & Chlorprothixen & 8 \\
\hline 1996 & Haloperidol & 26 & Clozapin & 20 & Perazin & 12 & Levomepr. & 8 & Melperon & 7 \\
\hline 1997 & Haloperidol & 22 & Clozapin & 18 & Perazin & 11 & Chlorproth. & 9 & Olanzapin & 9 \\
\hline 1998 & Haloperidol & 18 & Clozapin & 18 & Olanzapin & 15 & Risperidon & 10 & Chlorpr+Promet & 8 \\
\hline 1999 & Olanzapin & 18 & Clozapin & 17 & Haloperidol & 15 & Risperidon & 11 & Chlorpr+Promet & 9 \\
\hline 2000 & Olanzapin & 19 & Risperidon & 15 & Clozapin & 14 & Haloperidol & 13 & Perazin & 8 \\
\hline 2001 & Olanzapin & 21 & Risperidon & 14 & Haloperidol & 11 & Clozapin & 12 & Quetiapin & 10 \\
\hline 2002 & Olanzapin & 23 & Risperidon & 17 & Clozapin & 12 & Haloperidol & 10 & Quetiapin & 9 \\
\hline 2003 & Olanzapin & 24 & Risperidon & 19 & Clozapin & 12 & Quetiapin & 11 & Haloperidol & 9 \\
\hline 2004 & Olanzapin & 21 & Risperidon & 17 & Quetiapin & 15 & Clozapin & 12 & Haloperidol & 10 \\
\hline 2005 & Olanzapin & 20 & Quetiapin & 20 & Risperidon & 16 & Haloperidol & 10 & Clozapin & 10 \\
\hline 2006 & Olanzapin & 22 & Quetiapin & 20 & Risperidon & 17 & Clozapin & 11 & Haloperidol & 10 \\
\hline 2007 & Quetiapin & 22 & Olanzapin & 19 & Risperidon & 17 & Clozapin & 10 & Haloperidol & 10 \\
\hline 2008 & Quetiapin & 27 & Olanzapin & 19 & Risperidon & 17 & Haloperidol & 10 & Clozapin & 9 \\
\hline 2009 & Quetiapin & 32 & Risperidon & 17 & Olanzapin & 16 & Clozapin & 11 & Haloperidol & 9 \\
\hline 2010 & Quetiapin & 31 & Risperidon & 18 & Olanzapin & 17 & Clozapin & 9 & Haloperidol & 9 \\
\hline 2011 & Quetiapin & 31 & Olanzapin & 18 & Risperidon & 17 & Clozapin & 8 & Aripiprazol & 8 \\
\hline 2012 & Quetiapin & 30 & Olanzapin & 19 & Risperidon & 18 & Aripiprazol & 9 & $\begin{array}{l}\text { Pipamperon, } \\
\text { Clozapin }\end{array}$ & 9 \\
\hline
\end{tabular}

\subsubsection{Dauer der Therapie bis zum Auftreten der UAW}

Im Rahmen von AMSP wurde bei den meisten Patienten die Dauer der Gabe bis zum Auftreten der Leberwerterhöhung genau dokumentiert.

Bei dieser Analyse ausgeschlossen wurden die Fälle, bei denen die UAW möglicherweise unter einem anderen Medikament begann oder die Messung der Leberwerte zu selten erfolgte.

Es wurde die mediane, maximale und minimale Dauer der Therapie (gemessen in Tagen) bis UAW-Beginn ermittelt (Siehe Tabelle 18).

Bei Chlorprothixen mit einer medianen Therapiedauer von 41 Tagen dauerte es relativ lange bis die UAW auftrat. Bei Olanzapin mit median 18 Tagen ging es da etwas schneller. Die UAW trat bei Prothipendyl mit median acht Tagen sehr schnell auf. Hier wurden allerdings nur drei Fälle registriert. 
Aussagekräftiger ist jedoch die Betrachtung des minimalen und maximalen Wertes der jeweiligen Zeitspanne, bis die jeweilige UAW aufgetreten ist. Bei Olanzapin, Quetiapin, Clozapin und Perazin war die Zeitspanne bis zum Auftreten der UAW von wenigen Tagen bis hin zu über 1,5 Jahre sehr variabel. Bei Amisulprid wurde nur in drei Fällen die Therapiedauer bis zum Auftreten der UAW bestimmt. Jedoch ist auch hier zu erkennen, dass die Spanne von minimal 10 Tagen bis hin zu 344 Tagen der Therapiedauer, bis die UAW erstmals auftrat, sehr breit ist. Bei Chlorprothixen, Haloperidol, Levomepromazin, Promethazin und Risperidon war die maximale Therapiedauer bis zum Auftreten einer UAW kürzer. Eine Normalverteilung zeigte sich bei keiner der Zeitspannen der verschiedenen Antipsychotika.

Tabelle 18: Dauer der Therapie bis zum Auftreten der UAW

\begin{tabular}{|c|c|c|c|c|}
\hline Antipsychotikum & $\mathbf{n}$ & Median (d) & Minimum (d) & Maximum (d) \\
\hline Amisulprid & 3 & 55 & 10 & 344 \\
\hline Aripiprazol & 0 & I & I & 1 \\
\hline Clozapin & 34 & 20,5 & 1 & 286 \\
\hline Olanzapin & 54 & 18 & 1 & 112 \\
\hline Quetiapin & 16 & 18,5 & 6 & 462 \\
\hline Risperidon & 16 & 12,5 & 4 & 62 \\
\hline Benperidol & 1 & 30 & 30 & 30 \\
\hline Bromperidol & 1 & 16 & 16 & 16 \\
\hline Haloperidol & 7 & 15 & 13 & 25 \\
\hline Melperon & 3 & 30 & 8 & 78 \\
\hline Pipamperon & 1 & 2 & 2 & 2 \\
\hline Levomepromazin & 6 & 14 & 3 & 35 \\
\hline Perazin & 18 & 21,5 & 2 & 147 \\
\hline Promethazin & 7 & 25 & 7 & 34 \\
\hline Prothipendyl & 3 & 8 & 6 & 26 \\
\hline Chlorprothixen & 6 & 41 & 6 & 49 \\
\hline Flupentixol & 2 & 15,5 & 1 & 30 \\
\hline Flupentixoldecanoat & 1 & 29 & 29 & 29 \\
\hline Zuclopenthixol & 2 & 28 & 11 & 45 \\
\hline
\end{tabular}

$\mathrm{n}=$ Anzahl der Fälle mit Leberwerterhöhungen, Angaben in (d) = Tagen. 


\subsection{Signifikanztests / Unterschiede}

\subsubsection{Geschlechtsunterschiede}

In Abbildung 10 sind die geschätzten Inzidenzen der schweren Leberwerterhöhung des jeweiligen Geschlechts in Prozent dargestellt. Bei Frauen befindet sich der überwiegende Anteil in der Altersgruppe von 31 bis 60 Jahren, die höchste geschätze Inzidenz liegt aber in der jüngsten Altersgruppe von 0 bis 30 Jahren. Männer hingegen sind überwiegend zwischen 0 und 30 Jahren alt.

Das mediane Alter bei Männern $(n=111)$ lag bei 30 Jahren bei den Fällen mit Leberwerterhöhung, das mediane Alter der Frauen $(n=102)$ bei 48 Jahren. Es konnte gezeigt werden, dass es einen signifikanten Altersunterschied zwischen Männern und Frauen bei Leberwerterhöhung gibt $(p<0,001)$. In der mittleren Altersgruppe von 31 bis 60 Jahren gibt es keinen Unterschied zwischen den Geschlechtern. In der Altersgruppe von 0 bis 30 Jahren konnte zwischen der geschätzten Inzdenz der schweren Leberwerterhöhung zwischen Männern (0,19 \%) und Frauen (0,09 \%) ebenso kein signifikanter Unterschied festgestellt werden $(p=0,003)$ werden. Die ermittelte Inzidenz in der Altersgruppe von 61 bis 90 Jahren ist zwischen Frauen $(0,05 \%)$ und Männern $(0,02 \%)$ nicht signifikant unterschiedlich $(p=0,04)$. In Abbildung 10 ist erkennbar, dass bei Männern die Inzidenz über die Altersgruppen abnimmt $(p<0,001)$, wohingegen die Inzidenz bei Frauen relativ konstant bleibt $(p=0,114)$. Im Altersbereich über 90 Jahre gab es keinen einzigen Fall, weder bei Männern noch Frauen, von schwerer Leberwerterhöhung unter Antipsychotikatherapie. In der Referenzgruppe von 1993 bis 2012 befanden sich in der Altersgruppe der über 90 jährigen Patienten 530 Männer und 1334 Frauen, welche mit Antipsychotika therapiert wurden. 


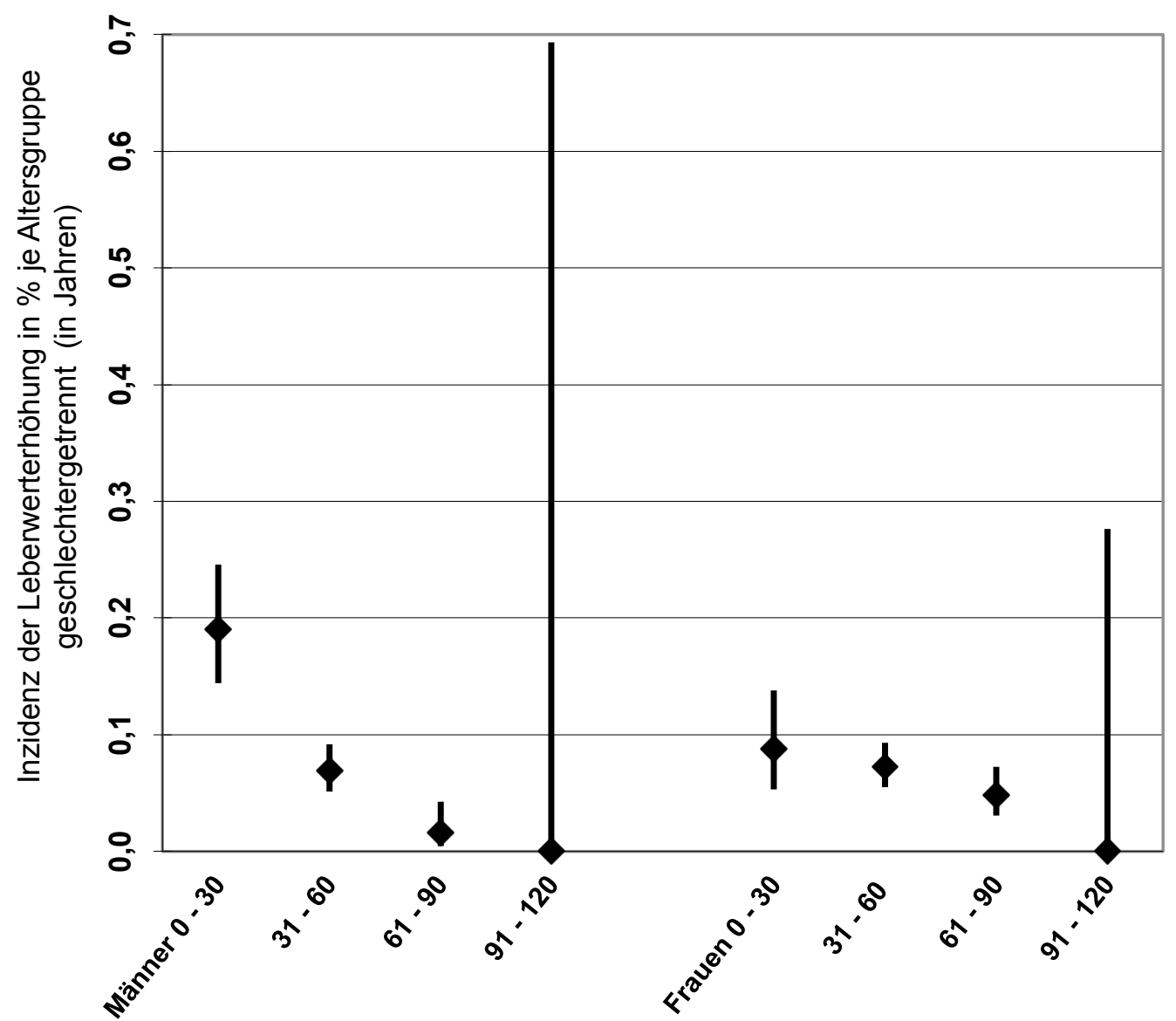

Abbildung 10: Ermittelte Inzidenz der schweren Leberwerterhöhung über die Geschlechter und Altersgruppen (in Jahren) verteilt

Angegeben ist die geschätzte Inzidenz der schweren Leberwerterhöhungen über die geschlechtergetrennten Altersgruppen ( 0 bis 30 Jahre, 31 bis 60 Jahre, 61 bis 90 Jahre und 91 bis 120 Jahre) und das $95 \%$-Konfidenzintervall für die geschätze Inzidenz.

Bei Männern wurden Antipsychotika 82 Mal allein angeschuldigt und 29 Mal in einer pharmakologischen Kombination. Bei Frauen wurden in 68 Fällen Antipsychotika alleine angeschuldigt und in 34 Fällen in Kombination. Es zeigte sich kein signifikanter Unterschied $(p=0,25)$ zwischen dem Anschuldigungsprofil der beiden Geschlechter (siehe Tabelle 19).

Bei Männern war in 20 Fällen (37,7\%) die Leber vorgeschädigt, bei Frauen bei 33 Fällen (62,3\%). Es konnte jedoch kein signifikanter Unterschied zwischen den Geschlechtern festgestellt werden $(p=0,014)$. Auch bezüglich der übrigen unter Tabelle 19 aufgeführten Risikofaktoren konnte kein signifkanter Geschlechtsunterschied festgestellt werden. 
Tabelle 19: Geschlechtsunterschiede: Risikofaktoren und somatische Diagnosen

\begin{tabular}{|c|c|c|c|c|c|}
\hline & \multicolumn{2}{|l|}{ Männer } & \multicolumn{2}{|l|}{ Frauen } & \multirow[b]{2}{*}{ P-Wert } \\
\hline & $\mathbf{n}$ & $\%$ & $\mathbf{n}$ & $\%$ & \\
\hline Organvorschädigung & 20 & 37,7 & 33 & 62,3 & 0,014 \\
\hline $\begin{array}{l}\text { schädlicher Gebrauch } \\
\text { von Alkohol }\end{array}$ & 8 & 88,9 & 1 & 11,1 & 0,037 \\
\hline Adipositas & 1 & 12,5 & 7 & 87,5 & 0,029 \\
\hline Hepatitis & 3 & 75,0 & 1 & 25,0 & 0,623 \\
\hline $\begin{array}{l}\text { Andere } \\
\text { Lebererkrankungen }\end{array}$ & 3 & 60,0 & 2 & 40,0 & 1,000 \\
\hline
\end{tabular}

$n=$ Anzahl der Fälle mit Leberwerterhöhungen, nach Bonferroni korrigiert: $p<0,001$

In Tabelle 20 wurden die Häufigkeiten der Antipsychotika über die Geschlechter verteilt analysiert. Quetiapin wurde 20 Mal bei Frauen angeschuldigt und nur 6 Mal bei Männern. Olanzapin hingegen wurde $51 \mathrm{Mal}$ bei Männern angeschuldigt und 28 Mal bei Frauen. Es konnten keine signifikanten Geschlechtsunterschiede zwischen den unter Tabelle 20 aufgeführten Antipsychotika bezüglich der Häufigkeit der Anschludigung zwischen den Geschlechtern festgestellt werden. Zur Vereinfachung wurden in Tabelle 20 nur die am häufigsten angeschuldigten Antipsychotika aufgeführt.

Tabelle 20: Geschlechtsunterschiede: Antipsychotika

\begin{tabular}{|l|r|r|r|r|r|r|r|}
\hline & \multicolumn{3}{l}{ Männer } & \multicolumn{2}{l|}{ Frauen } & \\
\hline Antipsychotikum & $\mathbf{n}$ & $\mathbf{N}$ & \% & $\mathbf{n}$ & $\mathbf{N}$ & \% & p-Wert \\
\hline Clozapin & 22 & 18475 & 0,12 & 19 & 15654 & 0,12 & 0,951 \\
\hline Olanzapin & 51 & 22107 & 0,23 & 28 & 23007 & 0,12 & 0,006 \\
\hline Quetiapin & 6 & 19070 & 0,03 & 20 & 28946 & 0,07 & 0,083 \\
\hline Risperidon & 11 & 18218 & 0,06 & 8 & 22051 & 0,04 & 0,267 \\
\hline Haloperidol & 7 & 16378 & 0,04 & 6 & 17696 & 0,03 & 0,677 \\
\hline Levomepromazin & 5 & 6305 & 0,08 & 3 & 5926 & 0,05 & 0,534 \\
\hline Perazin & 11 & 6718 & 0,16 & 8 & 8518 & 0,09 & 0,225 \\
\hline Promethazin & 2 & 5440 & 0,04 & 7 & 9089 & 0,08 & 0,345 \\
\hline Chlorprothixen & 4 & 5939 & 0,07 & 3 & 6742 & 0,04 & 0,585 \\
\hline
\end{tabular}

$\mathrm{n}=$ Anzahl der Fälle mit Leberwerterhöhungen, $\mathrm{N}=$ Anzahl der Fälle in der Referenzgruppe, nach Bonferroni korrigiert: $p<0,001$ 
Um mögliche Zusammenhänge zwischen der Häufigkeit der Anschuldigung und den Dosierungen festzustellen, wurden die Geschlechtsunterschiede bezogen auf die Dosis der einzelnen Antipsychotika untersucht, wobei sich kein signifikanter Unterschied zeigte (siehe Tabelle 21). In dieser Testung wurden nur die Antipsychotika untersucht, die häufiger als vier Mal angeschuldigt waren, da für zu geringe Fallzahlen keine statistische Berechnung möglich gewesen wäre.

Tabelle 21: Geschlechtsunterschiede: Dosierung

\begin{tabular}{|c|c|c|c|}
\hline & Männer & Frauen & \\
\hline Antipsychotikum & $\begin{array}{l}\text { Dosis (mg) } \\
\text { (Median (Min;Max)) }\end{array}$ & $\begin{array}{l}\text { Dosis (mg) } \\
\text { (Median (Min;Max)) }\end{array}$ & P-Wert \\
\hline Clozapin & $187,5(75 ; 700)$ & $200(50 ; 600)$ & 0,743 \\
\hline Olanzapin & $17,5(5 ; 30)$ & $10(5 ; 40)$ & 0,045 \\
\hline Quetiapin & $300(100 ; 1200)$ & $400(75 ; 1500)$ & 0,882 \\
\hline Risperidon & $4(2 ; 6)$ & $4(1 ; 8)$ & 0,657 \\
\hline Haloperidol & $5(1 ; 24)$ & $6,5(4 ; 15)$ & 0,836 \\
\hline Levomepromazin & $100(50 ; 500)$ & $100(50 ; 160)$ & 1,000 \\
\hline Perazin & $400(100 ; 600)$ & $275(100 ; 800)$ & 0,091 \\
\hline Promethazin & $130(100 ; 160)$ & $150(75 ; 250)$ & 1,000 \\
\hline Chlorprothixen & $120(90 ; 150)$ & $100(50 ; 250)$ & 0,857 \\
\hline
\end{tabular}

Min $=$ Minimum, Max $=$ Maximum, nach Bonferroni korrigiert: $p<0,001$

Die AP wurde von 2003 bis 201224 Mal bestimmt. Verglichen dazu wurden VGT mit 114, ALT mit 131 und AST mit 126 Messungen häufiger bestimmt. In Tabelle 22 wurden die Anzahl der Laborwerte, die das Fünffache des oberen Referenzwertes überschritten haben, im Geschlechtervergleich analysiert. Die AP konnte nicht analysiert werden, da hier bei keinem der 134 Fälle eine AP das Fünffache des oberen Referenzwertes überschritten hat. Bei Vergleich der Anzahl derer, die mindestens das Fünffache des oberen Referenzwertes überschritten haben, lässt sich zwischen Männern und Frauen hinsichtlich der drei Laborparameter AST, ALT und YGT kein signfikanter Unterschied feststellen. 
Tabelle 22: Geschlechtsunterschiede hinsichtlich der Laborwerte oberhalb des fünffachen Referenzwertes

\begin{tabular}{|l|r|r|c|}
\hline Laborparameter & Männer (n) (\%) & Frauen (n) (\%) & P-Wert \\
\hline AST $>5 x$ & $18(16,2)$ & $28(27,4)$ & 0,064 \\
\hline ALT $>5 x$ & $52(46,8)$ & $51(50,0)$ & 0,703 \\
\hline YGT $>5 x$ & $17(15,3)$ & $32(31,4)$ & 0,028 \\
\hline
\end{tabular}

$n=$ Anzahl der Fälle mit Leberwerterhöhung, nach Bonferroni korrigiert: $p<0,001$

In Abbildung 11 ist zur Veranschaulichung der prozentuale Anteil der Laborwerte oberhalb des fünffachen Referenzwertes über die Geschlechter verteilt dargestellt. Während die ALT etwa bei beiden Geschlechtern gleich häufig oberhalb des fünffachen Referenzwertes lag, scheinen AST und YGT häufiger bei Frauen oberhalb des fünffachen Referenzwertes gelegen zu haben. Ein signifikanter Unterschied konnte jedoch nicht festgestellt werden.

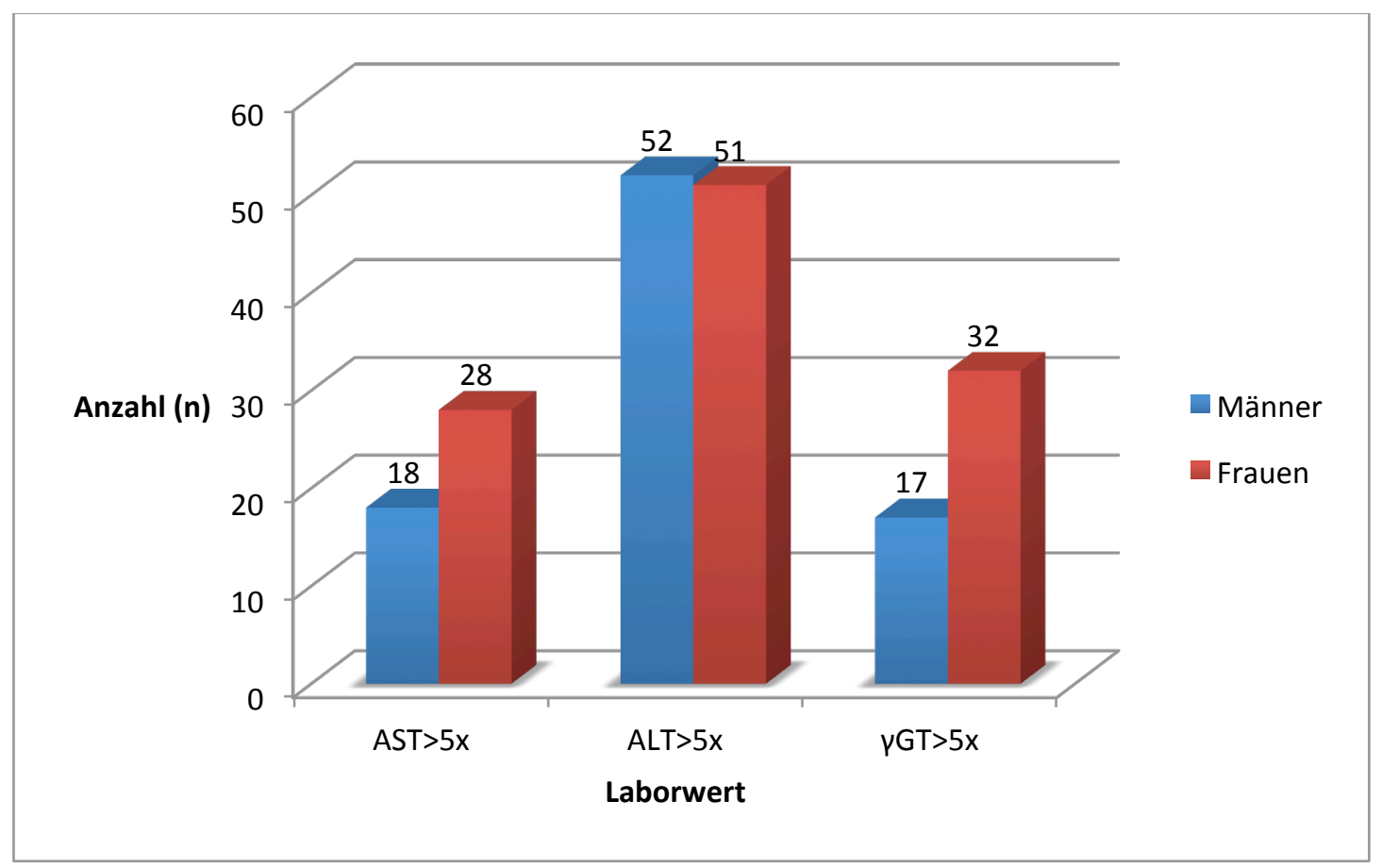

Abbildung 11: Anteil der Leberwerterhöhungen oberhalb des fünffachen Referenzwertes an allen gemessenen Werten

$>5 x=$ um mehr als das Fünffache des oberen Referenzwertes erhöhter Wert 


\subsubsection{Dosis im Zusammenhang mit weiterer UAW}

Um den Zusammenhang zwischen Dosis und dem Auftreten einer weiteren UAW festzustellen, wurden die Dosis der einzelnen Antipsychotika zwischen denen mit weiterer UAW und den Fällen ohne weiterer UAW miteinander verglichen. Es fanden sich bei 18 von 213 Patienten mit Leberwerterhöhung weitere unerwünschte Arzneimittelwirkungen. Am häufigsten trat eine weitere UAW bei Olanzapin in elf Fällen auf.

Unter den 18 Fällen mit weiterer UAW befanden sich drei Fälle, bei denen es sich um eine Kombinationsanschuldigung handelte. Darunter befand sich ein Patient mit einer Dreifachanschuldigung für Risperidon, Clozapin und Melperon. Weiterhin wurden einmal Clozapin und einmal Levomepromazin separat mit mindestens einem weiteren Medikament in Kombination angeschuldigt.

\subsection{Kasuistik: Leberversagen}

Unter den 213 Fällen mit Leberwerterhöhung befanden sich zwei Fälle mit Leberversagen, die aufgrund des sehr schweren Verlaufs einer Leberwerterhöhung im Folgenden exemplarisch genauer dargestellt werden.

\subsubsection{Fall 1: Leberversagen mit anschließender Lebertransplantation}

Tabelle 23: Kasuistik 1: Leberversagen

\begin{tabular}{|c|c|}
\hline \\
\hline & $\begin{array}{ll}\text { Geschlecht: } & \text { Männlich } \\
\text { Alter: } & 38 \text { Jahre } \\
\text { Psychiatrische Grunderkrankung: } & \text { F31.2 (Bipolar affektive Störung, } \\
& \text { gegenwärtig manische Episode mit } \\
& \text { psychotischen Symptomen) }\end{array}$ \\
\hline \multicolumn{2}{|c|}{$\begin{array}{ll}\text { allart: } & \text { schwer nach AMSP, stationär } \\
\text { Veitere UAW zeitgleich: } & \text { nein } \\
\text { nschuldigung } & \text { Kombinationsanschuldigung }\end{array}$} \\
\hline \multicolumn{2}{|c|}{$\begin{array}{l}\text { Genaue Beschreibung der UAW-Symptomatik: } \\
\text { Der Patient gibt Unwohlsein an und klagt über einen empfindlichen Magen, } \\
\text { im weiteren Verlauf beklagt er Brechreiz und Druckschmerz im linken } \\
\text { Oberbauch. Es folgen Abgeschlagenheit, Magenschmerzen, Appetitlosigkeit } \\
\text { und Müdigkeit. Im Labor zeichnet sich eine Leberwerterhöhung und eine } \\
\text { Gerinnungsstörung ab, woraufhin eine Vitamin K-Gabe erfolgte. Im weiteren } \\
\text { Verlauf wurde das Abdomen sonografisch untersucht und eine } \\
\text { Hepatomegalie diagnostiziert. Bei weiterem Anstieg der Leberwerte erfolgte }\end{array}$} \\
\hline
\end{tabular}


eine Verlegung auf eine internistische Intensivstation. Nach anfänglicher Stabilisierung erfolgte dann letztlich die Lebertransplantation zwei Wochen später.

Lebensbedrohlich: ja

UAW-Dauer: Ende nicht bekannt

Eingenommene Medikamente zur Zeit des Auftretens der UAW (Angabe der maximalen täglichen Dosis):

Olanzapin

Valproat

tgl. $20 \mathrm{mg}$ p.o.

Flupentixoldecanoat

tgl. $1600 \mathrm{mg}$ p.o.

Flupentixol

30 mg i.m.

L-Thyroxin

tgl. 8 mg p.o.

Betoptima Augentropfen

tgl. 50myg p.o.

Artelac

tgl. 2 Augentropfen

tgl. 3 Augentropfen

Anschuldigungen:

Olanzapin

W-Grad 2: wahrscheinlich

Valproat

W-Grad 2: wahrscheinlich

Flupentixoldecanoat

W-Grad 2: wahrscheinlich

Flupentixol

W-Grad 2: wahrscheinlich

Begründung des Wahrscheinlichkeitsgrads:

Die schwere Leberschädigung ist bei Valproat bekannt, aber da der Patient dieses Medikament drei Jahre zuvor bereits in dreimal so hoher Dosis erhielt und ohne Leberschaden vertragen hat, ist eine alleinige Verursachung durch Valproat eher unwahrscheinlich. Damals erhielt der Patient dieses Medikament ebenfalls in Kombination mit Olanzapin, weshalb auch diese Kombination alleine eher unwahrscheinlich ist, sodass ein additiver Effekt der vier Medikamente Olanzapin, Valproat, Flupentixol und Flupentixoldecanoat am Wahrscheinlichsten erscheint.

Mögliche Risikofaktoren:

Rauchen: >10 Zigaretten/Tag

Fettleber diagnostiziert (Unklar, ob schon vorher oder als Zeichen der UAW) Laut Angehörigem des Patienten "gelegentlich zu viel Alkohol“

Laborwerte:

$\begin{array}{ll}\text { AST } & 407,92 \mathrm{U} / \mathrm{l} \\ \text { ALT } & 503,9 \mathrm{U} / \mathrm{l} \\ \text { YGT } & 46,79 \mathrm{U} / \mathrm{l} \\ \text { Valp } & 87 \mathrm{mg} / \mathrm{l}\end{array}$

\subsubsection{Fall 2: Leberversagen mit Spontanremission}

In der folgenden Tabelle 26 ist ein Fall in Form einer detaillierten Kasuistik dargestellt, bei dem nach nachgewiesenem Leberschaden sich die Laborwerte und die Leberfunktion im weiteren Verlauf wieder normalisierten. 
Tabelle 24: Kasuistik 2: Leberversagen

\begin{tabular}{|c|c|}
\hline \\
\hline $\begin{array}{l}\text { Fallart: } \\
\text { Weitere UAW zeitgleich: } \\
\text { Anschuldigung: }\end{array}$ & $\begin{array}{l}\text { schwer nach } \mathrm{AMSP} \text {, stationä } \\
\text { nein } \\
\text { Kombinationsanschuldigung }\end{array}$ \\
\hline \multicolumn{2}{|c|}{$\begin{array}{l}\text { Genaue Beschreibung der UAW-Symptomatik und des Verlaufs: } \\
\text { Fünf Tage zuvor wurde erstmals ein leichter Transaminasenanstieg } \\
\text { laborchemisch festgestellt (AST } 41 \mathrm{U} / \mathrm{l}) \text {. Kurz darauf traten Erbrechen, } \\
\text { Übelkeit und epigastrische Schmerzen auf. Hier wurde mit Pantozol } 40 \mathrm{mg} \\
\text { und MCP symptomatisch behandelt. Wieder einige Tage später waren } \\
\text { erhöhte Werte in der Laborkontrolle nachweisbar: LDH } 4321 \mathrm{U} / \mathrm{l} \text {, Bilirubin } \\
3,8 \mathrm{mg} / \mathrm{dl} \text {, AST } 5668 \mathrm{U} / \mathrm{I} \text {. Es erfolgte eine Verlegung in die Innere Medizin. } \\
\text { Histologisch wurde eine medikamentös-toxische Leberschädigung nach- } \\
\text { gewiesen. Zwei Tage später wurden bei Verlegung auf der Intensivstation } \\
\text { alle Medikamente abgesetzt und Tutofusin } 1 \mathrm{l} \text { i.v. und NaCl } 0,9 \% 1 \mathrm{I} \text { i.v. } \\
\text { verabreicht. Dort stiegen die Leberwerte zunächst weiter an und die Patientin } \\
\text { wurde einem Transplantationsteam vorgestellt. Da die Laborwerte sich aber } \\
\text { spontan normalisierten, war eine Transplantation letztlich nicht mehr nötig } \\
\text { und die UAW war wieder im Abklingen. }\end{array}$} \\
\hline \multicolumn{2}{|l|}{ Lebensbedrohlich: ja } \\
\hline $\begin{array}{l}\text { Eingenommene Medikam } \\
\text { maximalen täglichen Dos } \\
\text { Olanzapin } \\
\text { Doxepin } \\
\text { Zopiclon } \\
\text { Mirtazapin } \\
\text { L-Thyroxin } \\
\text { Lorazepam } \\
\text { Kalinor }\end{array}$ & $\begin{array}{l}\text { iente zur Zeit des Auftretens der UAW (Angabe der } \\
\text { is): } \\
\text { tgl. } 10 \mathrm{mg} \text { p.o. } \\
\text { tgl. } 150 \mathrm{mg} \text { p.o. } \\
\text { tgl. } 3,75 \mathrm{mg} \text { p.o. } \\
\text { tgl. } 30 \mathrm{mg} \text { p.o. } \\
\text { tgl. } 50 \mathrm{myg} \text { p.o. } \\
\text { tgl. } 1,5 \mathrm{mg} \text { p.o. } \\
\text { tgl. } 1 \text { Brausetablette }\end{array}$ \\
\hline $\begin{array}{l}\text { Anschuldigungen: } \\
\text { Olanzapin } \\
\text { Doxepin } \\
\text { Lorazepam }\end{array}$ & $\begin{array}{l}\text { W-Grad 2: wahrscheinlich } \\
\text { W-Grad 2: wahrscheinlich } \\
\text { W-Grad 1: möglich }\end{array}$ \\
\hline \multicolumn{2}{|c|}{$\begin{array}{l}\text { Begründung des Wahrscheinlichkeitsgrads: } \\
\text { Es sind hepatotoxische Effekte bei Olanzapin, Doxepin und Mirtazapin } \\
\text { bekannt. Sehr selten ist diese Nebenwirkung auch bei Lorazepam bekannt, } \\
\text { daher mit W1 angeschuldigt. Die Exposition von Mirtazapin war nur sehr kurz } \\
\text { und die Gabe erfolgte erst kurz nach dem Anstieg der Laborwerte und dem } \\
\text { Beginn der Symptomatik und wurde deshalb nicht mit angeschuldigt. }\end{array}$} \\
\hline
\end{tabular}


Die Patientin nahm zuletzt acht Tage vor Leberwertanstieg Paracetamol ein, deshalb ist ein Zusammenhang eher unwahrscheinlich.

Mögliche Risikofaktoren:

Vorschädigung des betroffenen Organs bei Suizidversuch mit 25 Tabletten Paracetamol. Bei Aufnahme waren Zeichen der leichten Leberschädigung (AST $61 \mathrm{U} / \mathrm{l}$ ) und verminderten Syntheseleistung (CHE $3370 \mathrm{U} / \mathrm{l}$, Albumin 2,9 $\mathrm{g} / \mathrm{l}$, Thromboplastinzeit $59 \%$ ) vorzufinden. Diese normalisierten sich im Verlauf.

Alternativerklärungen:

Möglicherweise weiterer Suizidversuch mit Paracetamol, welcher von der Patientin aber klar verneint wird.

Laborwerte:

AST $\quad 7363 \mathrm{U} / \mathrm{l}$

ALT $8827 \mathrm{U} / \mathrm{I}$

GLDH $\quad 1130 \mathrm{U} / \mathrm{l}$

Bilirubin ges. 3,8 mg/dl

CHE $\quad 3370 \mathrm{U} / \mathrm{I}$

$\mathrm{LDH} \quad 4321 \mathrm{U} / \mathrm{I}$ 


\section{DISKUSSION}

\subsection{Allgemeine Ergebnisse}

Insgesamt wurden von 1993 bis 2012213 Fälle mit schweren Leberwerterhöhungen im Rahmen des AMSP-Projektes ermittelt. Es lässt sich vor allem festhalten, dass die Leberwerterhöhung über das Fünffache des oberen Referenzwertes hinaus als schwere UAW sehr selten ist und in ihrer Inzidenz zwischen < 0,01 und 0,18 \% bei den jeweiligen Antipsychotika variiert. Jedoch zeigt genau dieses Ergebnis die Wichtigkeit eines Pharmakovigilanzprogrammes wie AMSP, welches mittels Langzeitbeobachtung seltene und schwere UAWs nach ihrer Marktzulassung erfasst, die in klinischen Phase I- bis Phase III- Studien nicht erfasst werden (Engel et al. 2004). In der Literatur waren transiente Leberwerterhöhungen über dem Referenzberereich vor allem bei atypischen Antipsychotika mit bis zu einem Viertel der behandelten Patienten relativ häufig (Pae et al. 2005; Atasoy et al. 2007). In der vorliegenden Studie dieser Arbeit wurden jedoch nur die schweren Fälle von Leberwerterhöhung nach oben genannter Definition (siehe 2.1.6) mit einbezogen (Grohmann et al. 2004b).

Es zeigte sich, dass bei einem Anstieg von mehr als dem Fünffachen des oberen Referenzwertes von ALT, AST und YGT, beziehungsweise dem Überschreiten der Grenzen, die bis zum Jahr 2003 galten, sich die Leber in über $95 \%$ der Fälle erholte, was vor allem auch daran lag, dass in den allermeisten Fällen die Antipsychotika abgesetzt ( $n=170 ; 79,8 \%$ ) oder reduziert ( $n=33 ; 15,5 \%$ ) wurden und vermutlich an der Fähigkeit der Leber, sich sehr gut bei großem Schaden zu regenerieren (Fausto 2000). In drei der vorliegenden Fälle konnte die Therapie sogar ohne Absetzen fortgeführt werden. Diese Möglichkeit zeigten auch weitere Fallberichte von Therapien mit Clozapin (Eggert et al. 1994; Erdogan et al. 2004). Eine Fortführung der Gabe des Medikamentes ist vermutlich vor allem dann sinnvoll, wenn Patienten besonders gut darauf ansprechen und im weiteren Verlauf die Leberwerterhöhungen wieder abklingen. Dass eine Leberwerterhöhung jedoch auch sehr schwerwiegende Folgen haben kann, zeigten zwei Fälle von Leberversagen im Zeitraum von 1993 bis 2012. Einer dieser Patienten 
regenerierte, wobei bei dem anderen eine Transplantation nötig war. Solch schwerwiegende UAWs mit teilweise tödlichen Verläufen wurden in der Literatur in einigen Fallberichten bereits bei Quetiapin beschrieben (El Hajj et al. 2004; Shpaner et al. 2008; Reuben et al. 2010; Al Mutairi et al. 2012). Eine weitere Studie zeigte, dass selbst leichte Leberwerterhöhung noch in der Norm mit einem erhöhten Risiko, an einer leberassoziierten Erkrankung zu versterben, verbunden ist (Hyeon et al. 2004), was eine Beobachtung erhöhter Werte sehr sinnvoll erscheinen lässt, selbst wenn, wie in dieser Arbeit, schwere Leberwerterhöhungen fast ausschließlich folgenlos abheilten.

Es ist zu vermuten, dass bei einer asymptomatischen Leberwerterhöhung diese bei einer Wiedereinnahme des Medikamentes erneut auftreten kann, denn in den beschriebenen Fällen, die das Psychopharmakon zuvor schon einmal eingenommen haben und die UAW entwickelt haben, trat diese in vier von 18 Fällen erneut auf. Sicherlich führte diese Befürchtung auch dazu, dass in den meisten Fällen (86,4 \%) eine Reexposition gemieden wurde. Darüber hinaus waren auch 90,1 \% der Fälle mit Leberwerterhöhung zuvor nicht dem angeschuldigten Medikament exponiert, was für eine sehr spezifische Reaktion des Medikamentes bei dem jeweiligen Patienten spricht.

Bei den 134 Fällen von 2003 bis 2012, deren Leberwerterhöhungen besser vergleichbar waren, war die ALT insgesamt am häufigsten ( $n=103 ; 76,9 \%$ ) um mehr als das Fünffache des oberen Referenzwertes erhöht. Da die ALT vor allem im Zytoplasma vorzufinden ist (Toerring-Jettenbach und Issels 2007), steigt diese bei einem Leberschaden sehr schnell an. Neben dem Anstieg von Markern für hepatozellulären Untergang wurden die Indikatoren der Leberfunktion wie Bilirubin, Prothrombinzeit und Albumin (Navarro und Senior 2006) in nur sehr wenigen Fällen angegeben, weshalb zur Einschränkung der Leberfunktion hier keine Aussage getroffen werden kann. Es ist jedoch zu vermuten, dass von den Drug-Monitoren sehr häufig nur die pathologisch erhöhten Parameter notiert und in der Datenbank erfasst wurden. 


\subsection{Der Einfluss von Risikofaktoren auf die Leberwerterhöhung}

Bei etwa einem Viertel der Fälle mit Leberwerterhöhung wurden Organvorschädigungen beschrieben. Lediglich acht der Fälle mit schwerer Leberwerterhöhung waren adipös, was keinen Rückschluss von der Adipositas auf die Leberwerterhöhung zulässt. Bei allen Fällen mit Adipositas wurde auch gleichzeitig ein Organvorschaden beobachtet. Ein Zusammenhang zwischen Adipositas und erhöhter Leberenzymaktivität ist in der Literatur bekannt (Salvaggio et al. 1991), sodass ein toxischer Effekt von erhöhten Blutfettwerten auf die Leber anzunehmen ist und so trotz geringer Fallzahlen der Zusammenhang von Organvorschädigung und Adipositas vermutet werden kann. Sicherlich sollte hier auch bedacht werden, dass der Lebensstil von Patienten mit Schizophrenie schlechter als in der Allgemeinbevölkerung zu sein scheint und dadurch die erhöhte Mortalität der Schizophrenie bedingt. Unter einem schlechten Lebensstil ist ein erhöhtes Rauchverhalten, ein erhöhter Alkoholkonsum, schlechte Ernährung, mangelnde Bewegung und Übergewicht zu verstehen (Brown et al. 1999). Der überwiegende Anteil der in der dieser Arbeit analysierten Patienten litt an einer Schizophrenie, möglicherweise war in dieser Kohorte auch der Lebensstil entsprechend schlecht, was zu einer Lebervorschädigung geführt haben könnte.

Obwohl das Rauchverhalten der Patienten mit Leberwerterhöhung nicht erfasst wurde, ist zu vermuten, dass ein Großteil der Patienten mit Schizophrenie raucht (De Leon und Diaz 2005), was eine Cytochrominduktion, zum Beispiel bei CYP1A2, bewirken kann und so höherere Dosen von Medikamenten bedarf (Kroon 2007). Es könnte aber ebenfalls sein, dass es aufgrund des Nikotinkonsums zu einer schnelleren Metabolisierung des Medikamentes in einen möglicherweise toxischen Metaboliten durch CYP1A2 kommt und die Toxizität zunimmt. 


\subsection{Antipsychotika}

\subsubsection{Häufigkeit der Leberwerterhöhung}

Olanzapin $(0,18 \%)$, Clozapin $(0,12 \%)$ und Perazin $(0,12 \%)$ hatten bezüglich des Auftretens der Leberwerterhöhung die höchsten Inzidenzen. Eine Studie von AMSP beschrieb ähnliche Inzidenzen der Leberwerterhöhungen für Olanzapin und Clozapin für die Zeit von 2001 bis 2009 für AMSP (Grohmann et al. 2014). Doch wie lässt sich diese, im Vergleich zu den anderen Antipsychotika, relativ hohe Inzidenz erklären? In der Literatur ist eine starke Gewichtszunahme bei Clozapin und Olanzapin beschrieben (Allison et al. 1999; Kraus et al. 1999; Wirshing et al. 1999), die möglicherweise im Zusammenhang mit der Leberwerterhöhung stehen könnte. Erhöhungen der Leberwerte konnten in Beziehung zur Gewichtszunahme bereits beschrieben werden (Lee et al. 2001; Himmerich et al. 2005; Rettenbacher et al. 2006). Es konnte auch bereits gezeigt werden, dass das metabolische Syndrom mit einer Erhöhung der yGT vergesellschaftet ist, was möglicherweise die hohen Werte erklärt (Rantala et al. 2000).

Insgesamt sind die atypischen Antipsychotika mit etwa $70 \%$ der Fälle mit Leberwerterhöhung am häufigsten angeschuldigt, was im Zusammenhang mit der Entstehung von metabolischen UAWs stehen könnte, die vor allem bei den atypischen Antipsychotika auftreten (Tschoner et al. 2007). Dafür sind vor allem die Bindungen an D2-, 5-HT2C- und H1-Rezeptoren verantwortlich, besonders an die letzten beiden binden hochaffin Olanzapin und Clozapin. Über die D2-Rezeptor vermittelt gesteigerte Prolaktinsekretion wird der Glucose- und Lipidstoffwechsel beeinflusst und über die beiden anderen Rezeptoren die Gewichtszunahme und die vermehrte Nahrungsaufnahme getriggert (Reynolds und Kirk 2010). Über die Gewichtszunahme und den erhöhten Blutfettspiegel kann die Leber konsekutiv geschädigt werden und die Leberenzyme könnten ansteigen.

Dass die Inzidenz bei Perazin relativ hoch ist, könnte unter dem Aspekt der Lysosomotropie (Macintyre und Cutler 1988; Fayek et al. 2001) diskutiert werden. Für Perazin konnte die Akkumulation in sauren Lysosomen beschrieben werden, was eine Konzentrationserhöhung von Komedikationen 
in Organen mit weniger Lysosomen zur Folge hatte (Daniel und Wójcikowski 1999). Unter anderem konnten so unerwünschte Arzneimittelwirkungen am Herzen erklärt werden (Mackin 2008). Da dieser Mechanismus für Perazin bekannt ist, könnte es sein, dass die Akkumulation von Perazin in Lysosomen mit Anstieg der Konzentration des Medikamentes in Membranen diese daraufhin zerstören und so einen Leberschaden anrichten könnte. Diese Hypothese bedarf allerdings weiterer experimenteller Untersuchungen, um diesen Zusammenhang zu verifizieren.

\subsubsection{Zusammenhang von Dosis und Leberwerterhöhung}

Hinsichtlich der Dosis konnte zwischen dem untersuchten Patientenkollektiv mit Leberwerterhöhung und der Referenzgruppe bei keinem der angeschuldigten Antipsychotika ein signifikanter Unterschied gezeigt werden. In einer Studie mit den Daten von AMSP von 2004 konnte eine signifikant höhere Dosis bei Perazin und signifikant niedrigere Dosis für Clozapin für alle bis dahin erkannten schweren UAWs allgemein beschrieben werden (Bender et al. 2004). Die signifikant höhere Dosis für Perazin sollte in jedem Fall unter dem unter 1.5.3 und 4.3.1 aufgeführten Aspekt der Lysosomotropie betrachtet werden und könnte somit in hohen Dosen eher lebertoxisch wirken.

Greil et al. (2013) zeigten, dass die Dosis der Psychopharmaka mit dem Alter abnimmt, womöglich aus Vorsicht und vor dem Hintergrund von Komorbiditäten, die weitere Medikationen im höheren Alter erfordern. Ergebnis dieser Studie war auch, dass Patienten im höheren Alter seltener unerwünschte Arzneimittelwirkungen entwickelten als im jüngeren Alter (Greil et al. 2013). In Übereinstimmung hiermit nimmt auch in dem Kollektiv der Fälle mit Leberwerterhöhung die Inzidenz der schweren UAW ab. Da es sich bei Greil et al. (2013) ebenfalls um eine Studie von AMSP handelt, jedoch ausschließlich mit schweizer Daten, ist zu vermuten, dass auch im gesamten AMSP-Kollektiv die Dosis über das Alter abnimmt. 


\subsubsection{Dauer der Therapie bis zum Auftreten der UAW}

Bei der Dauer der Therapie bis zum Auftreten der UAW fiel auf, dass Olanzapin, Clozapin und Quetiapin als Vertreter der atypischen Antipsychotika und Perazin als typisches Antipsychotikum eine sehr variable Latenz bis zum UAW-Beginn aufwiesen. Bei dem atypischen Antipsychotikum Risperidon war die Latenz mit maximal 62 Tagen relativ kurz. Promethazin, Chlorprothixen, Haloperdol und Levomepromazin zeigten ebenfalls eher kurze Latenzen bis zum Auftreten der UAW.

Die kürzeren Latenzen könnten darauf hinweisen, dass es sich um eine TypA-Reaktion handeln könnte, die aufgrund des zeitlichen Zusammenhangs zur Gabe des Medikamentes nachvollziehbarer ist. Hierzu passend ist auch das Ergebnis, dass in 10 von 13 Fällen Haloperidol in Kombination angeschuldigt wurde, was die Möglichkeit der Toxizitätsverstärkung mehrerer potentiell hepatotoxischer Substanzen im Sinne einer Typ-A-Reaktion nahelegt. Die besonders variablen Latenzen von Olanzapin, Clozapin, Quetiapin und Perazin sprechen eher für idiosynkratische Leberwerterhöhungen, Typ-BReaktionen (Park et al. 1992).

\subsection{Polypharmazie}

Ein weiterer zentraler Aspekt, der vor dem Hintergrund des Auftretens schwerer UAWs zu diskutieren ist, ist die häufige Komedikation in der psychopharmakologischen Therapie. Mehr als $80 \%$ der Fälle mit Leberwerterhöhung nahmen neben dem angeschuldigten Antipsychotikum noch weitere Medikamente ein. Aufgrund der speziellen Methodik von AMSP wurde auch bei Kombinationsbehandlung in $70,4 \%$ der Fälle das Antipsychotikum alleine angeschuldigt (mit den Wahrscheinlichkeitsgraden wahrscheinlich (=W2) und sicher (=W3)).

Eine Studie zeigte, dass die Gabe mehrere Psychopharmaka in höheren Dosen zu einer höheren Rate an unerwünschten Arzneimittelwirkungen führte und gleichzeitig keinen klinischen Vorteil in der Therapie bot (Centorrino et al. 2004). Die in dieser Arbeit beobachteten Patienten sind alle stationär, was für ein psychiatrisch schwerwiegenderes Patientenklientel als im ambulanten Bereich spricht und möglicherweise höhere Dosen und 
Kombinationsverschreibungen zur optimalen Therapie verlangt. Bei der Referenzgruppe aus den Stichtagszählungen von AMSP handelt es sich ebenfalls um stationäre Patienten.

Antipsychotika wurden zunehmend auch bei Patienten mit Depressionen und bipolaren Störungen verabreicht, was sich auch in dem relativ hohen Anteil von Patienten mit Depression, die eine schwere Leberwerterhöhung erlitten haben, widerspiegelt.

In einer Studie von 2007 konnte im Rahmen des AMSP-Projektes eine weitaus höhere prozentuale Gabe von Antipsychotika (45,8\%) bei Depression im Vergleich zum Jahr 2000 (37,9\%) beschrieben werden (Konstantinidis et al. 2012). In einer weiteren Studie konnte gezeigt werden, dass der überwiegende Anteil (85\%) von Patienten mit einer bipolar affektiven Störung mehr als nur eine Stoffgruppe von Psychopharmaka erhielt (Haeberle et al. 2012). Anhand dieser Erkenntnisse stellt sich die Frage, ob off-Label-Use potentiell toxischer ist als eine konventionelle Therapie. Dieser Frage sollte zukünftig mit weiteren Studien nachgegangen werden, um so einen gezielten Vergleich zwischen formell zugelassenen Indikationen und off-Label-Behandlungen hinsichtlich ihres Auftretens schwerer UAWs zu stellen.

In einer Studie von 2007 konnte ein Zusammenhang des metabolischen Syndroms mit der Gabe von mehr als einem Antipsychotikum nachgewiesen werden. Weiterhin konnte in dieser Studie gezeigt werden, dass Schizophrenien, bipolar affektive Störungen, ein höherer BMI, ein höheres Lebensalter und die Kombination mit einem typischen Antipsychotikum das Risiko für das Auftreten eines metabolisches Syndroms erhöhen (Correll et al. 2007). Bei den Fällen mit Leberwerterhöhung wurden von jenen mit Kombinationsanschuldigung 39,7\% mit einem weiteren Antipsychotikum in Kombination für die Leberwerterhöhung angeschuldigt, häufiger waren Kombinationsanschuldigungen mit Antidepressiva (49,2\%). Bei den Kombinationsanschuldigungen lässt sich vermuten, da bei der Gabe von mehr als einem Psychopharmakon die Blutfette erhöht sein können und das metabolische Syndrom einen Zusammenhang darstellt, dass das Risiko für eine dadurch induzierte Leberschädigung steigen könnte. 
Darüber hinaus sollte auch beachtet werden, dass eine Studie in vitro die inhibitorische Wirkung von Olanzapin an CYP3A4, CYP2C9, CYP2C19 und CYP2D6 beschrieb (Ring et al. 1996), was die häufigen Kombinationsanschuldigungen von Olanzapin miterklären könnte. So könnte durch die Kombination von Olanzapin mit einem zweiten Medikament über die Blutspiegelsteigerung eben jenes Stoffes eine Schädigung eintreten.

\subsection{Geschlechtsunterschiede}

Zwischen Männern und Frauen konnte hinsichtlich der Inzidenz der schweren Leberwerterhöhung unter Antipsychotikatherapie kein signifikanter unterschied beschrieben werden. Die bisherige Literatur zeigte diesbezüglich, dass Frauen im Schnitt niedrigere Dosen in der Antipsychotikatherapie als Männer erhielten, trotzdem entwickelten Frauen deutlich häufiger unerwünschte Arzneimittelwirkungen als Männer (Seeman 2004; Smith 2010). Zwischen der Häufigkeit der Anschuldigungen der einzelnen Antipsychotika und deren Dosierungen konnte zwischen Männern und Frauen statistisch kein Unterschied fegstellt werden.

Bezogen auf die erhöhten Leberwerte konnte jedoch, wie einleitend berichtet, bei Clozapin das männliche Geschlecht als ein Risikofaktor in der Literatur beschrieben werden (Hummer et al. 1997). In der Studie mit den Daten von AMSP konnte jedoch kein Unterschied in der Inzidenz der Leberwerterhöhungen unter der Therapie mit Clozapin zwischen Männern und Frauen festgestellt werden. Bei Männern lag die Inzidenz der schweren Leberwerterhöhung bei Olanzapin bei $0,23 \%$, was im Vergleich relativ hoch ist.

Bezogen auf der Alter zeigte sich, dass Männer mit schwerer Leberwerterhöhung signifikant jünger waren als Frauen $(p<0,001)$. Über die verschiedenen Altersgruppen 0-30, 31-60 und 61-90 konnte festgestellt werden, dass die Inzidenz bei Männern abnimmt $(p<0,001)$. 


\subsection{Kasuistiken}

Beide Fälle von akutem Leberversagen wiesen um mehr als das Fünffach erhöhte Werte für die Transaminasen ALT und AST auf. Im zweiten Fall lagen die Werte sogar um weit mehr als das 50-fache erhöht vor. Dennoch war das Outcome bei diesem Fall besser, denn die Leber regenerierte sich und heilte folgenlos ab, sodass keine weitere medizinische Intervention nötig war und die Leberwerte laborchemisch rückläufig waren.

In dem ersten Fall musste der Patient trotzt deutlich niedrigerer Transaminasen als im zweiten vorgestellten Fall Lebertransplantiert werden. Leider fehlt bei diesem Patienten die Bestimmung des Bilirubins, sodass der „Hy's law“ als Risikostratifizierung nicht zur Anwendung kommen kann. Im zweiten Fall der jungen Patientin war die ALT um mehr als das Dreifache erhöht und Bilirubin um mehr als das Zweifache, was nach dem „Hy's law“ einem erhöhten Risiko für die Entwicklung eines Leberversagens entspricht (Temple 2006). Dieser Schaden ist nun bei dieser Patientin auch eingetreten. Dennoch, trotz extrem hoher Transaminasen, was für einen hohen hepatozellulären Schaden spricht, scheint sich die Leber auch dann noch gut regenerieren zu können. Dies entspricht den Beschreibungen in der Literatur (Navarro und Senior 2006). Dennoch scheint es individuell verschieden zu sein, wenn es, wie man sieht, auch bei sehr viel niedrigeren Plasmawerten der Transaminasen zu einem völligen Leberversagen kommen kann. Zu bedenken ist allerdings auch, dass die Patientin mit ihrem Alter von 20 Jahren jünger war als der Patient (38 Jahre), bei dem eine Lebertransplantation nötig wurde.

In beiden Fällen wurde Olanzapin angeschuldigt, was auch in dieser Arbeit ingesamt von der Inzidenz her als häufigstes Antipsychotikum für die Leberwerterhöhung verantwortlich gemacht wurde. In der Literatur wurden bisher keine Fälle von Leberversagen, so weit bekannt, bei Olanzapin beschrieben. Es wurden allerdings in Kasuistiken Fälle von Leberversagen bei Quetiapin beschrieben (El Hajj et al. 2004; Shpaner et al. 2008; Al Mutairi et al. 2012).

In dem ersten dargestellten Fall wurden ingesamt vier Psychopharmaka in Kombination (alle mit wahrscheinlich (=W2)) angeschuldigt. Bei Olanzapin und Valproat sind Leberwerterhöhungen bekannt, wobei der Schaden bei 
Valproat sogar im Tiermodell als mikrovesikuläre Steatose nachgewiesen werden konnte (Kesterson et al. 1984; Ozcanli et al. 2006). Demnach handelt es sich bei dem Leberschaden unter Valproat um einen vorhersehbaren Schaden im Sinne einer Typ-A-Reaktion (Edwards und Aronson 2000). Da der Patient diese beiden Medikamente in Kombination drei Jahre zuvor bei dreimal so hoher Dosis ohne Einschränkungen vertragen hatte, ging man von einem additiven Effekt durch Flupentixol und Flupentixoldecanoat aus, da Flupentixol ebenfalls über die Leber mittels CYP2D6 abgebaut wird (Benkert et al. 2010). In der Anamnese nahm der Patient "gelegentlich zu viel Alkohol“ (Wortlaut der Mutter) zu sich, was als Risikofaktor zu werten ist. Im zweiten Fall wurden bei der jungen Patientin Doxepin und Olanzapin angeschuldigt (beide W2) und zusätzlich Lorazepam (mit W1). Doxepin wird über CYP2C19 zum aktiven Metaboliten umgewandelt und über CYP2D6 hydroxiliert (Benkert et al. 2010). In einer Studie konnte nachgewiesen werden, dass Olanzapin inhibitorisch auf unter anderem CYP2C19 und CYP2D6 wirken kann (Ring et al. 1996). Besonders in Anbetracht des reaktiven Metaboliten von Doxepin, der dann möglicherweise durch die Inhibition von Cytochromen durch Olanzapin nicht mehr abgebaut werden kann, ist diese Kombination potentiell nicht ungefährlich. Da dies jedoch der einzige Fall ist, bei dem diese Kombination zu einem Leberversagen führte, spricht dies für ein sehr seltenes Ereignis.

Was den zweiten Fall jedoch auch schwieriger in der Beurteilung werden lässt, ist die Lebervorschädigung bei der Patientin durch Paracetamol und es ist auch nicht absolut sicher geklärt, ob nicht ein weiterer Suizidversuch erfolgte, der die hohen Leberwerte erklären könnte. Paracetamol ist nachgewiesen hepatotoxisch und verursacht dosisabhängig Leberzellnekrosen (James et al. 2003). Wenn Paracetamol bei dem Auftreten der UAW tatsächlich von der Patientin nicht eingenommen wurde, ist der vorherige Suizidversuch mit konsekutiver Leberschädigung dennoch nach AMSP als Organvorschädigung zu werten. 


\subsection{Limitierungen der Studie}

Aufgrund dessen, dass es sich bei den Referenzwerten für die Antipsychotikagaben von 1993 bis 2012 um mathematisch erhobene Schätzwerte nach Stichtagserhebungen handelt, können nicht alle detaillierten Eigenschaften der Patienten vollständig erfasst werden. So lässt sich zwischen dem Kollektiv mit UAW - wie in dieser Arbeit mit Leberwerterhöhung - und dem geschätzten Patientenkollektiv aller Kliniken kein Vergleich hinsichtlich Therapiedauer, Risikoprofilen, Komedikationen und vielem mehr stellen.

Da bereits Studien den Zusammenhang von Leberwerterhöhung und Gewichtszunahme unter Therapie mit atypischen Antipsychotika beschrieben (Himmerich et al. 2005; Rettenbacher et al. 2006), wäre es interessant gewesen, diesen Zusammenhang in dieser Arbeit zu verifizieren. Leider wurde über die Zeit von 1993 bis 2012 die Gewichtszunahme nicht zusätzlich zu den Leberwerten dokumentiert. Schwerwiegende Gewichtszunahmen sind über AMSP als weitere eigene UAW und somit als separater Fall klassifiziert. Dieser Zusammenhang konnte im Rahmen der vorliegenden Arbeit nicht überprüft werden.

Darüber hinaus wurde in nur einem Fall die Cholinesterase dokumentiert, die im Falle einer Erhöhung ein guter Parameter zum Nachweis einer Fettleber wäre (Nomura et al. 1986). Die Gerinnungsparameter und Albumin wurden in keinem der Fälle dokumentiert, wären als Marker der Leberfunktionseinschränkung (Navarro und Senior 2006) jedoch wichtige Parameter für weitere Analysen gewesen. Cholinesterase, Albumin, Bilirubin und die Gerinnungsparameter werden nicht standardisiert im AMSP-Bogen erfasst und stellen kein Kriterium für eine schwere Leberwerterhöhung nach AMSP dar. Es ist aber auch möglich, dass die Parameter nicht von der Norm abwichen und deshalb nicht von den Drug-Monitoren mit angegeben wurden. Als weiteres Problem der Analysen ist die Tatsache zu betrachten, dass von 1993 bis 2002 Leberwerterhöhungen als schwer bei Erhöhungen der Transaminasen ALT und/oder AST > $100 \mathrm{U} / \mathrm{L}$ und/oder yGT > $200 \mathrm{U} / \mathrm{L}$ galten, ab 2003 jedoch ein Transaminasenanstieg um mehr als das Fünffache des oberen Referenzwertes als schwerwiegend galt. Ebenso kritisch zu bewerten ist, dass die Labore der verschiedenen Kliniken von 
1993 bis 2002 nicht einheitlich bei $37^{\circ} \mathrm{C}$ die Laborparamter bestimmten. Aus diesem Grund wurden in dieser Arbeit zur Analyse die um mehr als das Fünffach erhöhten Werte nach den Kriterien des jeweiligen Labors ab 2003 verwendet, die standardisiert bei $37^{\circ} \mathrm{C}$ erhoben wurden. So konnte eine bessere Vergleichbarkeit der Laborwerte untereinander gewährleistet werden.

\subsection{Ausblick}

Die dargestellten Leberwerterhöhungen unter Antipsychotikatherapie vor dem Hintergrund der Erkenntnisse bisheriger Literatur zeigen, dass die engmaschige Kontrolle der Leberwerte bei Antipsychotikagabe sehr sinnvoll ist. Insbesondere die Erkenntnisse bezüglich des relativ häufigen Auftretens von schweren Leberwerterhöhungen bei Männern unter der Therapie mit Olanzapin $(0,23 \%)$ zeigen, dass die Gabe dieses Antipsychotikums laborchemisch sorgsam überwacht werden sollte. Das Auftreten schwerer UAWs ist wie die Zeitspannen der Therapien bis zum Auftreten der UAW nicht kalkulierbar und individuell sehr verschieden. Die Kasuistiken zeigten, dass ein Leberversagen insgesamt selten ist, jedoch auftreten kann und schnellstmöglich erkannt werden sollte, um optimal therapiert zu werden.

Bezüglich der Erfassung der Leberwerte wäre es zukünfig jedoch wichtig, die Cholinesterase zur Erkennung einer Fettleber (Nomura et al. 1986) und Bilirubin, Prothrombinzeit und Albumin zum Nachweis der Leberfunktionseinschränkung (Navarro und Senior 2006) zu bestimmen und, sofern sie bestimmt wurden, sie auch im Rahmen von AMSP zu dokumentieren und im Fragebogen routinemäßig mit zu erfassen. So könnten Funktionseinschränkungen der Leber noch frühzeitiger erkannt und auch langfristig für statistische Analysen herangezogen werden. Weiterhin wäre es interessant zu schauen, ob off-Label-Behandlungen und die Polypharmazie in der Psychiatrie einen höheren toxischen Effekt aufweisen als nach den Leitlinien empfohlene Behandlungen. 


\section{ZUSAMMENFASSUNG}

Die Detektion von UAWs gewinnt zunehmend an klinischer, ökonomischer und damit auch politischer Relevanz. „Arzneimittelsicherheit in der Psychiatrie“ ist ein langjährig etabliertes Pharmakovigilanzprogramm, welches Medikamente nach deren Marktzulassung in der Psychiatrie überwacht. Von 1993 bis 2012 wurden bei 213 Fällen Leberwerterhöhungen unter Antipsychotikatherapie als schwere UAW nach den Definitionen von AMSP erfasst. Von 1993 bis 2002 galten jene Fälle als schwer, wenn laborchemisch ALT, AST > $100 \mathrm{U} / \mathrm{L}$ und/oder yGT > $200 \mathrm{U} / \mathrm{L}$ nachzuweisen war. Ab 2003 werden jene Fälle als schwer definiert, bei denen ALT, AST, yGT oder AP um mehr als das Fünffache des oberen Referenzwertes erhöht sind. Für die Analysen der Laborwerte wurden die Fälle aufgrund der Vergleichbarkeit erst ab 2003 herangezogen $(n=134)$.

Am häufigsten war die ALT ( $n=103 ; 76,9 \%$ ) um mehr als das Fünffache der oberen Norm erhöht. Insgesamt fanden sich unter den 213 Fällen mit Leberwerterhöhung 150 Patienten (70,4 \%), bei denen das Antipsychotikum alleine für das Auftreten der UAW angeschuldigt wurde. Unter den Kombinationsanschuldigungen waren die Kombinationen mit Antidepressiva am häufigsten ( $n=31 ; 49,2 \%$ ), gefolgt von den Antipsychotika ( $n=25$; $39,7 \%$ ), wobei im Speziellen am häufigsten Olanzapin und die Antidepressiva Mirtazapin und Venlafaxin mit jeweils 9 Fällen in Kombination angeschuldigt wurden. Unter den Antipsychotika wurden die atypischen Antipsychotika am häufigsten angeschuldigt ( $n=170 ; 70,2 \%)$. Trotz der zahlreichen Alleinanschuldigungen wurden in $80,3 \%$ der Fälle mit Leberwerterhöhung die Antipsychotika in Komedikation verabreicht, was unter dem Aspekt der Polypharmazie als Toxizitätsverstärkung vermutet werden könnte.

Schwere Leberwerterhöhungen nach den Kriterien von AMSP sind insgesamt eher seltene UAWs. Olanzapin (0,18\%), Clozapin $(0,12 \%)$ und Perazin $(0,12 \%)$ wiesen dabei die höchste ermittelte Inzidenz der Leberwerterhöhung auf. Aus Studien ist ersichtlich, dass Olanzapin und Clozapin zu einer starken Gewichtszunahme führen und so das 
metabolische Syndrom mit konsekutiver Leberschädigung verursachen können, was die hohe Inzidenz erklären könnte.

$95 \%$ der Fälle erholten sich von der Leberwerterhöhung, was im Zusammenhang mit dem Absetzen ( $n=170 ; 79,8 \%$ ) oder der Reduktion ( $n=33 ; 15,5 \%$ ) des Antipsychotikums gesehen werden kann.

Bei der Betrachtung der Altersgruppen (0-30; 31-60; 61-90; 91-120 Jahre) konnte gezeigt werden, dass die Inzidenz bei der jüngsten Altersgruppe am höchsten war $(0,15 \%)$ und mit dem Alter stetig abnahm. Diese Beobachtung war vorwiegend beim männlichen Geschlecht vorzufinden, wohingegen bei Frauen die Häufigkeit über das Alter relativ konstant blieb. Männer waren auch signifikant jünger als Frauen.

Die gewonnenen Ergebnisse schaffen ein adäquates Bild über die Häufigkeiten und die schwierige Vorhersehbarkeit und Klassifzierung von schweren Leberwerterhöhungen, zeigen jedoch gerade anhand der schwerwiegenden Verläufe, dass es wichtig ist, die Möglichkeit des Auftretens dieser UAW zu kennen, um so früh wie möglich therapeutisch eingreifen zu können; auch nach schon jahrelanger Therapie. 


\section{ANHANG}

\section{Anlage 1: Tabellarische Auflistung der teilnehmenden Kliniken (Stand 2014)}

\begin{tabular}{|c|c|}
\hline Stadt & Name \\
\hline Aachen & Alexianer Krankenhaus \\
\hline Alzey & Rheinhessen-Fachklinik Alzey \\
\hline Augsburg & Bezirkskrankenhaus Augsburg \\
\hline Bad Emstal & Vitos Klinikum Kurhessen \\
\hline \multirow[t]{6}{*}{ Berlin } & Klinik für Psychiatrie und Psychotherapie, Campus Charité-Mitte \\
\hline & Evangelisches Krankenhaus Königin Elisabeth Herzberge \\
\hline & Schlosspark-Klinik GmbH \\
\hline & Krankenhaus Hedwigshöhe \\
\hline & Vivantes Klinikum Neukölln \\
\hline & Vivantes Klinikum Wenckebach \\
\hline Bernburg & Fachklinikum Bernburg SALUS gGmbH \\
\hline Bochum & LWL-Universitätsklinik Bochum \\
\hline Brandenburg & Asklepios Fachklinikum Brandenburg \\
\hline Bremen & $\begin{array}{l}\text { Behandlungszentrum für Psychiatrie und Psychotherapie Mitte und } \\
\text { West im Klinikum Bremen-Ost }\end{array}$ \\
\hline Darmstadt & Evangelisches Krankenhaus Elisabethenstift GmbH \\
\hline Dresden & Krankenhaus Dresden-Friedrichstadt \\
\hline \multirow[t]{3}{*}{ Düsseldorf } & Psychiatrische Klinik der Universität \\
\hline & $\begin{array}{l}\text { Gerontopsychiatrisches Zentrum in der Psychiatrischen Klinik der } \\
\text { Universtät }\end{array}$ \\
\hline & Kaiserwerther Diakonie, Florence-Nightingale Krankenhaus \\
\hline Eisenhüttenstadt & Städtisches Krankenhaus Eisenhüttenstadt $\mathrm{GmbH}$ \\
\hline Eltville & Klinik für Psychiatrie und Psychotherapie VITOS Eichberg \\
\hline Essen & LVR-Klinikum Essen \\
\hline Gera & SRH Wald-Klinikum Gera gGmbH \\
\hline Göttingen & $\begin{array}{l}\text { Klinik für Psychiatrie und Psychotherapie der Georg-August- } \\
\text { Universität }\end{array}$ \\
\hline Groß-Umstadt & Kreisklinik Groß-Umstadt \\
\hline Haina & Vitos Klinik für forensische Psychiatrie Haina \\
\hline Halle (Saale) & Universitätsklinikum Halle (Saale) \\
\hline Henningsdorf & Klinik Henningsdorf \\
\hline Hannover & Medizinische Hochschule Hannover \\
\hline Herford & Klinikum Herford \\
\hline Jena & Klinikum der Friedrich-Schiller-Universität Jena \\
\hline Kaiserslautern & $\begin{array}{l}\text { Klinik Psychiatrie, Psychosomatik und Psychotherapie } \\
\text { Kaiserslautern }\end{array}$ \\
\hline Katzenelnbogen & Fachklinik für Psychiatrie und Psychotherapie \\
\hline Kiel & Klinik für Psychiatrie und Psychotherapie der Universität Kiel \\
\hline Klingenmünster & Pfalzklinikum Landbeck \\
\hline Lübben & Asklepios Fachklinikum Lübben \\
\hline Magdeburg & Klinikum Magdeburg \\
\hline Mainz & Psychiatrische Klinik der Universtität Mainz \\
\hline Marburg & Universitätsklinikum Marburg \\
\hline Marsberg & Westfälische Kliniken für Psychiatrie und Psychotherapie Marsberg \\
\hline München & Psychiatrische Klinik der Universtät München \\
\hline Neubrandenburg & Diakonie Klinikum Dietrich Bonhoeffer \\
\hline Nütlingen & $\begin{array}{l}\text { Klinik für Psychiatrie und Psychotherapie Klinikum Kirchheim- } \\
\text { Nütlingen }\end{array}$ \\
\hline Potsdam & $\begin{array}{l}\text { Zentrum für Psychiatrie und Psychotherapie im Klinikum Ernst von } \\
\text { Bergmann } \mathrm{GmbH}\end{array}$ \\
\hline Riedstadt & Vitos Philippshospital Riedstadt \\
\hline
\end{tabular}




\begin{tabular}{|c|c|}
\hline Rockenhausen & Pfalzklinikum Rockenhausen \\
\hline Rüdersdorf & Immanuel Klinik Rüdersdorf \\
\hline Saalfeld/Saale & Thüringen-Klinik gGmbH, Saalfeld-Rudolstadt \\
\hline Stadtroda & Asklepios Klinikum Stadtroda, Klinik für Gerontopsychiatrie \\
\hline Teupnitz & Askleipios Fachklinikum Teupnitz \\
\hline Wiesbaden & HSK Dr. Horst Schmidt Klinik \\
\hline Wiesloch & Psychiatrische Zentrum Nordbaden \\
\hline Wilhelmshaven & Rheinhardt-Nieter-Krankenhaus (Stadtische Kliniken) \\
\hline Zülpich & $\begin{array}{l}\text { Fachklinik für Psychiatrie und Psychotherapie der Marienborn } \\
\text { gGmbH }\end{array}$ \\
\hline Braunau am Inn (Ö) & A.ö. Krankenhaus St. Josef Braunau GmbH \\
\hline \multirow[t]{2}{*}{ Graz (Ö) } & Landesnervenklinik Sigmund Freud \\
\hline & Universitätsklinik für Psychiatrie \\
\hline Linz (Ö) & OÖ Gesundheits- und Spitals-AG (gespag), LNK Wagner Jauregg \\
\hline Salzburg (Ö) & Landeskrankenhaus für Psychiatrie, Christianz Doppler Klinik \\
\hline Schwarzach (Ö) & Kardinal-Schwarzenberg'sches Krankenhaus \\
\hline Tulln (Ö) & Landesklinikum Tulln, Erwachsenenpsychiatrie \\
\hline Wels (Ö) & Klinikum Wels-Grieskirchen \\
\hline \multirow[t]{2}{*}{ Wien (Ö) } & Psychiatrisches Zentrum Baumgartner Höhe \\
\hline & AKH Universitätsklinik für Psychiatrie \\
\hline Basel $(\mathrm{CH})$ & Psychiatrische Klinik der Universtät Basel \\
\hline Brugg $(\mathrm{CH})$ & Psychiatrische Klinik Königsfelden \\
\hline Kilchberg $(\mathrm{CH})$ & $\begin{array}{lllll}\begin{array}{l}\text { Sanatorium Kilchberg } \\
\text { Psychotherapie }\end{array} & \text { Privatklinik für } & \text { Psychiatrie } & \text { und } \\
\end{array}$ \\
\hline Liestal $(\mathrm{CH})$ & Klinik für Psychiatrie und Psychotherapie Liestal \\
\hline Luzern $(\mathrm{CH})$ & Luzerner Psychiatrie \\
\hline Oberwil bei Zug $(\mathrm{CH})$ & Psychiatrische Klinik Zugersee \\
\hline Oetwil am See $(\mathrm{CH})$ & Clienia Schlössli AG Privatklinik für Psychiatrie und Psychotherapie \\
\hline St. Urban $(\mathrm{CH})$ & Luzerner Psychiatrie, Klinik St. Urban \\
\hline Wil $(\mathrm{CH})$ & Psychiatrische Klinik Wil \\
\hline Winterthur $(\mathrm{CH})$ & Integrierte Psychiatrie Winterthur - Züricher Umland \\
\hline Zug $(\mathrm{CH})$ & $\begin{array}{lccc}\begin{array}{l}\text { Psychiatrische Klinik Meissenberg, psychiatrische } \\
\text { psychotherapeutische Spezialklinik für Frauen }\end{array} & \text { und } \\
\end{array}$ \\
\hline Zürich $(\mathrm{CH})$ & Psychiatrische Universitätsklinik Zürich Sektor West \\
\hline
\end{tabular}




\section{Anlage 2: UAW-Erfassungsbögen von AMSP}

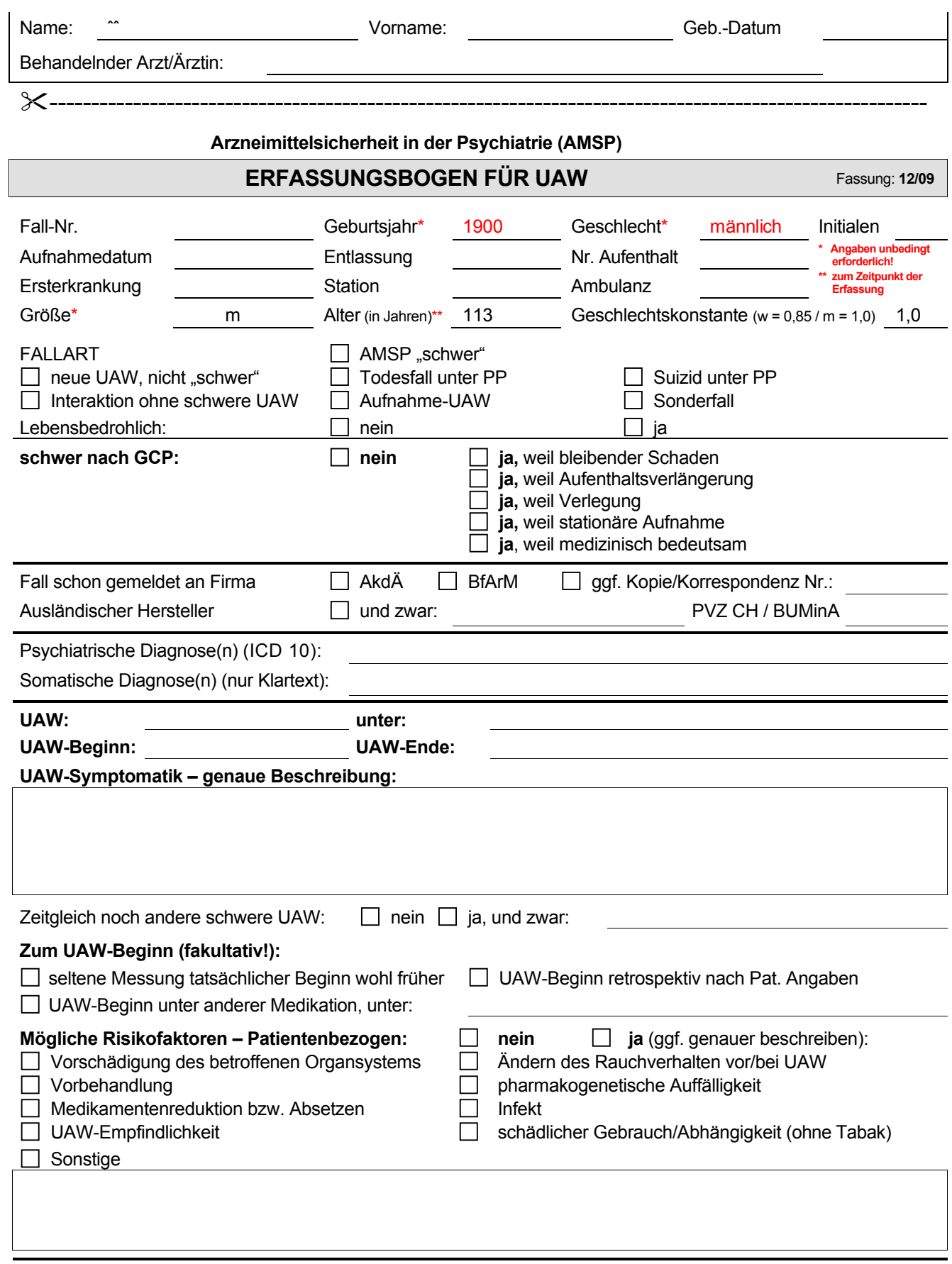

Alternative Ursache für unerwünschte Ereignisse - Patientenbezogen: (wenn ja, bitte angeben, ebenso auch, was ausgeschlossen wurde):

\begin{tabular}{|lll|}
$\square$ nein & $\square$ ja & \\
& & \\
& & \\
& & \\
AMSP & Seher wahrscheinlich \\
\hline
\end{tabular}


Maßnahmen nach UAW $\square$ Keine

$\square$ Reduktion von

$\square$ Absetzen von

$\square$ medikamentöse Gegenmaßnahmen (auch Dosis und Dauer)

\begin{tabular}{|l|l|}
\hline \\
\hline
\end{tabular}

$\square$ Nicht-medikamentöse Gegenmaßnahme

$\square$ Verlegung

$\square$ Konsil

$\square$ Diagnostik

Zutreffendes ankreuzen und beschreiben:

\begin{tabular}{lll}
\hline \\
\hline
\end{tabular}

Verlauf der UAW:
$\square$ UAW abgeklungen
$\square$ UAW im Abklingen
$\square$ unverändert bei Beobachtungsende
$\square$ Bleibender Schaden
$\square$ Exitus
$\square$ Verlauf unbekannt

\begin{tabular}{|l|l|}
\hline \\
\hline
\end{tabular}

Weiterbehandlung (Klartext)

\begin{tabular}{|l|}
\hline Weiterbehandlung (Klartext) \\
\hline
\end{tabular}

Rexposition: (nur ,ja“, wenn gleiche/höhere Dosis bzw. gleiche Kombination)

$\square$ ja, positiv (gleiche UAW) $\square$ ja, negativ (keine solche UAW) $\square$ ja, Verlauf unbekannt

$\square$ nein $\square$ Weitergabe

Art der Weiterbehandlung im Klartext: (bitte auch Angabe von Dosis, Datum, Verlauf)

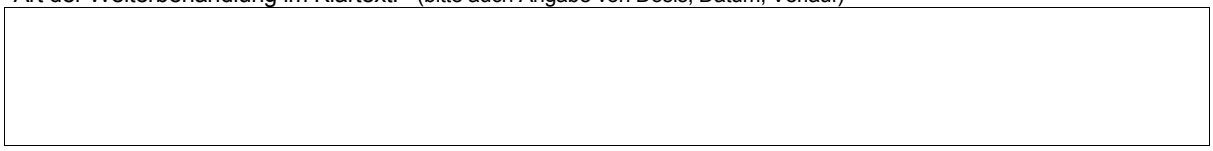

Frühere Exposition:

$\square$ Ja, positiv (gleiche UAW) $\square$ ja, negativ (keine solche UAW) $\square$ ja, Ausgang unbekannt $\square$ nein

(bitte auch Angabe von Dosis, Datum, Verlauf - bitte auch für ähnliche Med. angeben)

(1)




\section{Medikation vor UAW}

Bitte genauen Dosisverlauf; bei längerer Gabe jedenfalls letzte Dosisschritte vor UAW-Beginn mit genauem Datum, aber unbedingt auch den tatsächlichen Beginn der Behandlung, auch Nicht-Psychopharmaka, zumindest nach Größenordnung (seit Jahren, seit Monaten....) angeben. Datum bitte auch mit Jahreszahl!

UAW-Beginn:

Risikofaktoren - Medikationsbezogen:

$\square$ hohe Einstiegsdosis

schnelle Dosissteigerung

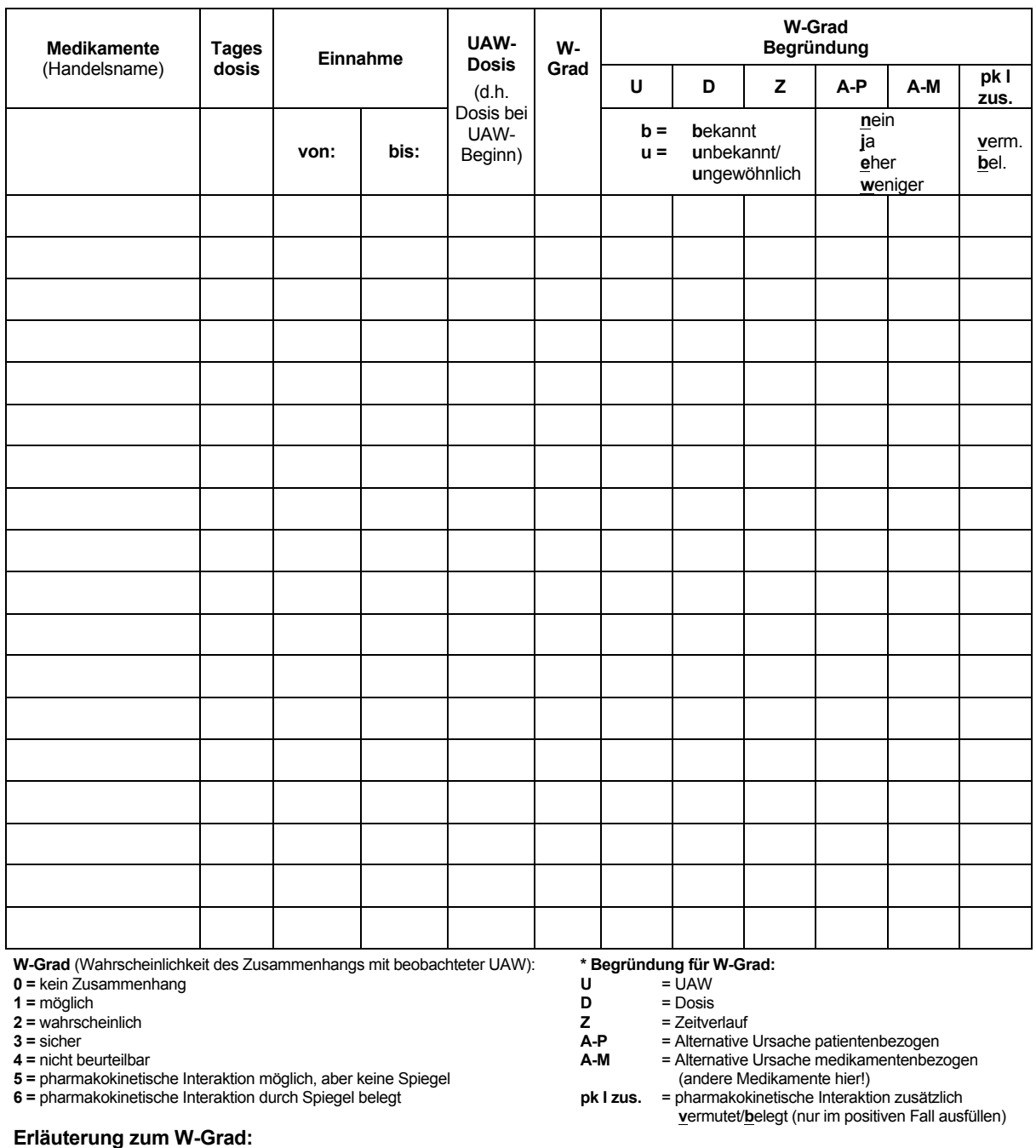

Erläuterung zum W-Grad: 
Befunde/Labordaten:

Jahr:

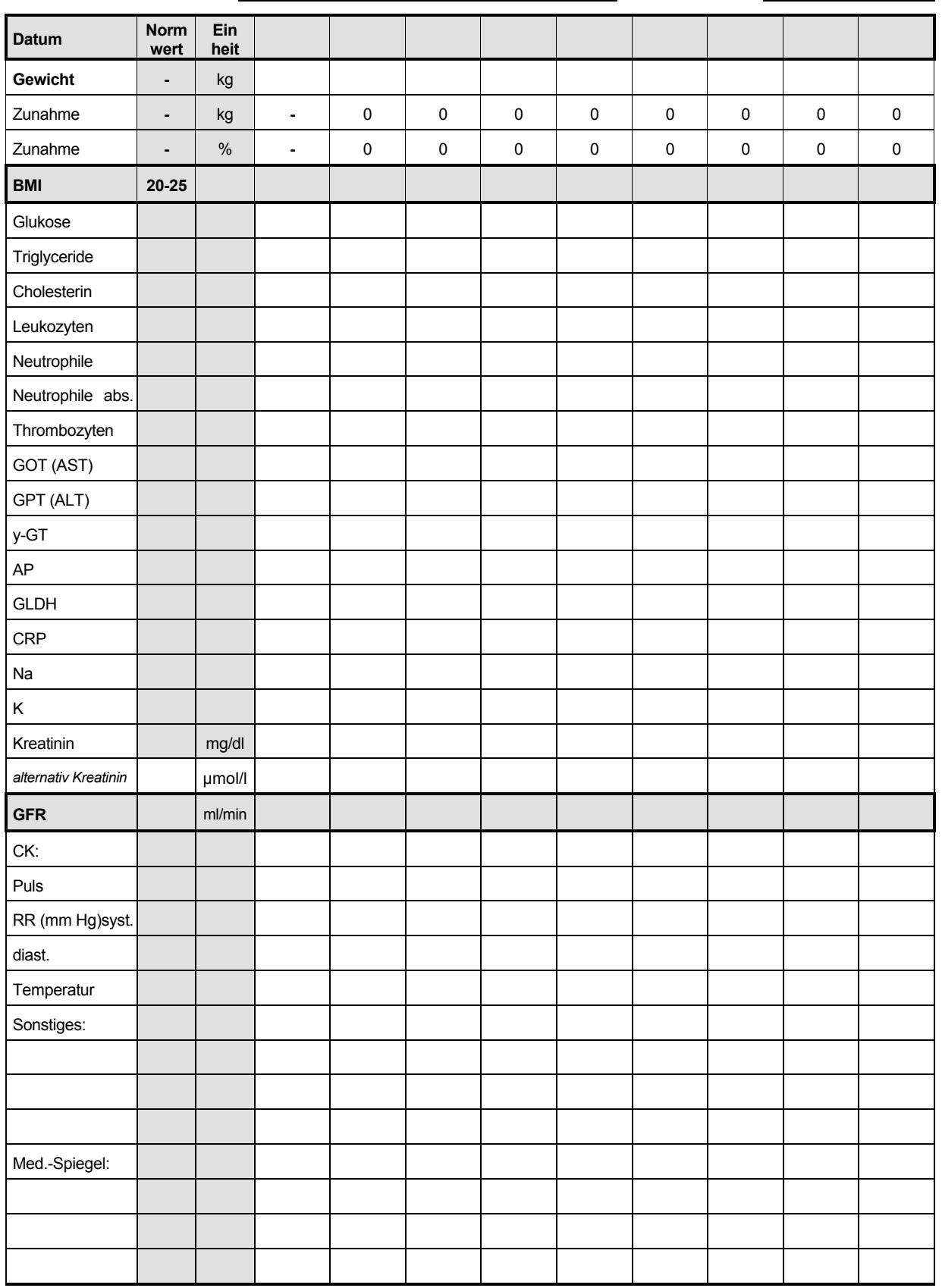




\section{Anlage 3: Ethikvotum}

T0 1911351 1 6539
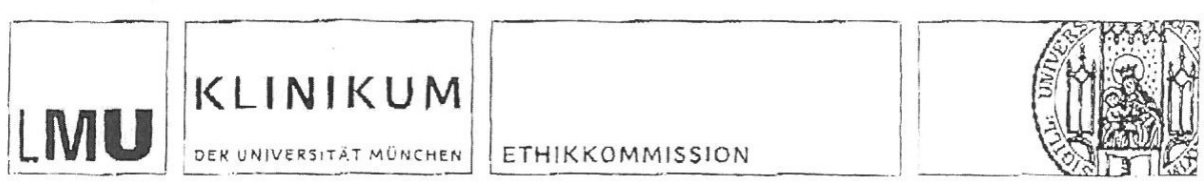

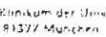

Vorsitemair

Prot Do W Eisemenerey.

Peleter $440101897095 \cdot 460 \%$

eléiax ras $101897045 \cdot 7610$

Herrn

thitkommissionges

Prof. Dr. G. Kullak- Ublick

Klinik f. Pharmakologie u. Toxikologie

(5) anitrugetithen nite

Universitatsspital Zürich

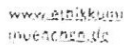

Rämistr. 100

CH-8091 Zürich

\section{Pusitisetritit}

Marefisgmintser is

0.8137m Muichon

Munctew. 19022010 Hind

\section{An frage Retrospekfive Datenbankstudie}

Sehr geehrter Herr Kollege Kullak- Ublick.

besten Dank für Ihre Anfrage vom 16.02.2010, die ich wie folgt beantworte

Sofern Sie Ihre Untersuchungen nur an Hand von Daten durchführen, die Ihnen vom AMSP in München zur Verfügung gestelit werden, bestehen keine ethisch-rechtlichen Bedenken gegen dieses Projekt. Die von thnen verwendeten Daten sind nicht personenbezogen. Es sind keine Untersuchungen am Menschen vorgesehen

Vorsorglich möchte ich darauf hinweisen, dass auch bei einer positiven Beurteilung Ihres vorhabens die arztliche und juristische Verantwortung für die Verantwortung des Projektes uneingeschränkt bei Ihnen und Ihren Mitarbeitern verbleibt.

Für Thre Untersuchungen wünsche ich Ihnen viel Erfolg.

Mit freundlichen Grüßen

$$
\text { Qive }
$$

Prof Dr. W. Eisenmenger

Vorsitzender der Ethikkqmmission

P.S. Für zukunftige Anträge an die EK siehe: Rlchtlinien fúr den Antrag an die Ethikkommission www ethikkommission med uni-muenchen de

Milgueder der xommission

W

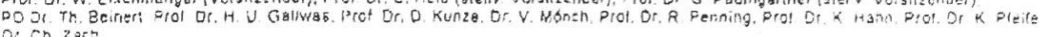

10.

NOISSIWWOXYY H1

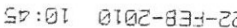




\section{LITERATURVERZEICHNIS}

Abernathy CO, Zimmerman HJ (1975): The Toxicity of Thioxanthene Neuroleptics to Isolated Rat Liver Cells. Exp Biol Med (Maywood) 150, 385-389

Adityanjee, Aderibigbe YA, Theodoridis D, Vieweg WVR (1999): Dementia praecox to schizophrenia: The first 100 years. Psychiatry Clinical Neurosc 53, 437-448

Akerboom T, Schneider I, Vom Dahl S, Sies H (1991): Cholestasis and changes of portal pressure caused by chlorpromazine in the perfused rat liver. Hepatology 13, 216-221

Al Mutairi F, Dwivedi G, Al Ameel T (2012): Fulminant hepatic failure in association with quetiapine: a case report. J Med Case Reports $\underline{6}, 418$

Alexander GC, Gallagher SA, Mascola A, Moloney RM, Stafford RS (2011): Increasing Off-Label use of antipsychotic medications in the United States, 1995-2008. Pharmacoepidemiol Drug Saf 20, 177-184

Allison DB, Mentore JL, Heo M, Chandler LP, Cappelleri JC, Infante MC, Weiden PJ (1999): Antipsychotic-induced weight gain: a comprehensive research synthesis. Am J Psychiatry 156, 1686-1696

Amery WK (1999): Why there is a need for pharmacovigilance. Pharmacoepidem Drug Safe $\underline{8}$, 61-64

Andrade RJ, Lucena MI, Fernández MC, Pelaez G, Pachkoria K, García-Ruiz E, García-Muñoz B, González-Grande R, Pizarro A, Durán JA, et al. (2005): Drug-Induced Liver Injury: An Analysis of 461 Incidences Submitted to the Spanish Registry Over a 10-Year Period. Gastroenterology 129, 512-521

Andreasen NC, Olsen S (1982): Negative v positive schizophrenia. Definition and validation. Arch Gen Psychiatry 39, 789-794

Atasoy N, Erdogan A, Yalug I, Ozturk U, Konuk N, Atik L, Ustundag Y (2007): A review of liver function tests during treatment with atypical antipsychotic drugs: A chart review study. Prog Neuropsychopharmacology Biol Psychiatry 31, 1255-1260

Balant-Gorgia DEA, Balant LP (1995): Therapeutic Drug Monitoring. CNS Drugs $\underline{4}, 432-453$

Bandelow B, Bleich S, Kropp S: Handbuch Psychopharmaka. Hogrefe, Göttingen 2011 
Beckh K: Gastroenterologie compact: alles für Klinik und Praxis; 27 Tabellen. Georg Thieme, Stuttgart 2010

Bender S, Grohmann R, Engel RR, Degner D, Dittmann-Balcar A, Rüther E (2004): Severe adverse drug reactions in psychiatric inpatients treated with neuroleptics. Pharmacopsychiatry 37 Suppl 1, S46-53

Benkert O, Hippius H, Fehr C, Gründer G, Heiser P, Hiemke C, Himmerich $\mathrm{H}$, Lange-Asschenfeldt $\mathrm{C}$, Müller $\mathrm{MJ}$, Paulzen $\mathrm{M}$, et al.: Kompendium der Psychiatrischen Pharmakotherapie. 8. Auflage; Springer, Berlin 2010

Benkert O, Hautzinger M, Graf-Morgenstern M, Heiser P, Schulz E, Hiemke C: Psychopharmakologischer Leitfaden für Psychologen und Psychotherapeuten. 2. Auflage; Springer, Berlin 2012

Bilzer M, Roggel F, Gerbes AL (2006): Role of Kupffer cells in host defense and liver disease. Liver Int 26, 1175-1186

Brisch R, Saniotis A, Wolf R, Bielau H, Bernstein H-G, Steiner J, Bogerts B, Braun K, Braun AK, Jankowski Z, et al. (2014): The role of dopamine in schizophrenia from a neurobiological and evolutionary perspective: old fashioned, but still in vogue. Front Psychiatry $\underline{5}, 47$

Brown S, Birtwistle J, Roe L, Thompson C (1999): The unhealthy lifestyle of people with schizophrenia. Psychological Medicine 29, 697-701

Bruhn HD, Fölscher UR, Schäfer H (Hrsg.): LaborMedizin: Indikationen, Methodik und Laborwerte; Pathophysiologie und Klinik; Mit 71 Tabellen. 2. Auflage; Schattauer, Stuttgart 2008

Burris KD, Molski TF, Xu C, Ryan E, Tottori K, Kikuchi T, Yocca FD, Molinoff PB (2002): Aripiprazole, a Novel Antipsychotic, Is a High-Affinity Partial Agonist at Human Dopamine D2 Receptors. J Pharmacol Exp Ther 302, 381-389

Centorrino F, Goren JL, Hennen J, Salvatore P, Kelleher JP, Baldessarini RJ (2004): Multiple Versus Single Antipsychotic Agents for Hospitalized Psychiatric Patients: Case-Control Study of Risks Versus Benefits. Am J Psychiatry 161, 700-706

Correll CU, Frederickson AM, Kane JM, Manu P (2007): Does antipsychotic polypharmacy increase the risk for metabolic syndrome? Schizophrenia Research 89, 91-100

Crow TJ, Johnstone EC, Longden A, Owen F, Riley G (1977): The Role of Dopamine in the Antipsychotic Effect and the Pathogenesis of Schizophrenia. Proc R Soc Med 70, 15-19 
Daniel WA (2003): Mechanisms of cellular distribution of psychotropic drugs. Significance for drug action and interactions. Progr Neuropsychopharmacol Biol Psychiatry 27, 65-73

De Kanter R, De Jager MH, Draaisma AL, Jurva JU, Olinga P, Meijer DKF, Groothuis GMM (2002): Drug-metabolizing activity of human and rat liver, lung, kidney and intestine slices. Xenobiotica 32, 349-362

Daniel WA, Wójcikowski J (1999): Lysosomal trapping as an important mechanism involved in the cellular distribution of perazine and in pharmacokinetic interaction with antidepressants. Eur Neuropsychopharmacol $\underline{9}, 483-491$

De Leon J, Diaz FJ (2005): A meta-analysis of worldwide studies demonstrates an association between schizophrenia and tobacco smoking behaviors. Schizophr Res 76, 135-157

De Ritis F, Coltorti M, Giusti G (1957): An enzymic test for the diagnosis of viral hepatitis: The transaminase serum activities. Clinica Chimica Acta 2, $70-74$

De Ritis F, Giusti G, Piccinino F, Cacciatore L (1965): Biochemical laboratory tests in viral hepatitis and other hepatic diseases. Bull World Health Organ 32, 59-72

Dost FH (1949): Die Clearance. Klin Wochenschr 27, 257-264

Dujovne CA, Zimmerman HJ (1969): Cytotoxicity of Phenothiazines on Chang Liver Cells as Measured by Enzyme Leakage. Exp Biol Med (Maywood) 131, 583-587

Edwards IR, Aronson JK (2000): Adverse drug reactions: definitions, diagnosis, and management. Lancet 356, 1255-1259

Eggert AE, Lynn M, Dorson PG, Taylor RL (1994): Clozapine rechallenge after marked liver enzyme elevation. J Clin Psychopharmacol 14, 425426

Eilers DR (1995): Therapeutic Drug Monitoring for the Treatment of Psychiatric Disorders. Clin Pharmacokinet 29, 442-450

El Hajj I, Sharara Al, Rockey DC (2004): Subfulminant liver failure associated with quetiapine. Eur J Gastroenterol Hepatol 16, 1415-1418

Engel RR, Grohmann R, Rüther E, Hippius H (2004): Research methods in drug surveillance. Pharmacopsychiatry 37 Suppl 1, S12-15

Erdogan A, Kocabasoglu N, Yalug I, Ozbay G, Senturk H (2004): Management of marked liver enzyme increase during clozapine treatment: a case report and review of the literature. Int J Psychiatry Med 34, 83-89 
Fausto N (2000): Liver regeneration. J Hepatol 32, 19-31

Fayek M, Kingsbury SJ, Zada J, Simpson GM (2001): Psychopharmacology: Cardiac Effects of Antipsychotic Medications. Psychiatr Serv 52, 607609

Greil W, Häberle A, Schuhmann T, Grohmann R, Baumann P (2013): Age and adverse drug reactions from psychopharmacological treatment: data from the AMSP drug surveillance programme in Switzerland. Swiss Med Wkly 143, w13772

Gressner AM, Arndt T: Lexikon der Medizinischen Laboratoriumsdiagnostik. Springer, Berlin Heidelberg 2013

Grohmann R, Rüther E, Engel RR, Hippius H (1999): Assessment of adverse drug reactions in psychiatric inpatients with the AMSP drug safety program: methods and first results for tricyclic antidepressants and SSRI. Pharmacopsychiatry $\underline{32,21-28}$

Grohmann R, Engel RR, Geissler KH, Rüther E (2004a): Psychotropic drug use in psychiatric inpatients: recent trends and changes over time-data from the AMSP study. Pharmacopsychiatry 37 Suppl 1, S27-38

Grohmann R, Engel RR, Rüther E, Hippius H (2004b): The AMSP drug safety program: methods and global results. Pharmacopsychiatry $\underline{37}$ Suppl 1, S4-11

Grohmann R, Engel RR, Möller H-J, Rüther E, Van der Velden JW, Stübner $S$ (2014): Flupentixol use and adverse reactions in comparison with other common first- and second-generation antipsychotics: data from the AMSP study. Eur Arch Psychiatry Clin Neurosci 264, 131-141

Gründer G: Handbuch der Psychopharmakotherapie. Auflage: 2. Aufl. 2012; Springer, Heidelberg 2011

Gu X, Manautou JE (2012): Molecular mechanisms underlying chemical liver injury. Expert Rev Mol Med 14, e4

Guengerich FP (2013): New Trends in Cytochrome P450 Research at the Half-Century Mark. J Biol Chem 288, 17063-17064

Haeberle A, Greil W, Russmann S, Grohmann R (2012): Mono- and combination drug therapies in hospitalized patients with bipolar depression. Data from the European drug surveillance program AMSP. BMC Psychiatry 12, 153

Han YD, Song SY, Lee JH, Lee DS, Yoon HC (2011): Multienzyme-modified biosensing surface for the electrochemical analysis of aspartate transaminase and alanine transaminase in human plasma. Anal Bioanal Chem 400, 797-805 
Hasler JA, Estabrook R, Murray M, Pikuleva I, Waterman M, Capdevila J, Holla V, Helvig C, Falck JR, Farrell G, et al. (1999): Human cytochromes P450. Mol Aspects Med 20, 1-137

Hautekeete ML, Geerts A (1997): The hepatic stellate (Ito) cell: its role in human liver disease. Virchows Archiv 430, 195-207

Heinrich PC, Müller M, Löffler G, Graeve L: Biochemie Des Menschen: Mit Molekularbiologie und Pathobiochemie. Springer, Berlin Heidelberg 2012

Heinz A (2000): Dopaminhypothese der Schizophrenien Neue Befunde für eine alte Theorie. Nervenarzt 71, 54-57

Hiemke C (2016): Consensus Guideline Based Therapeutic Drug Monitoring (TDM) in Psychiatry and Neurology. Curr Drug Deliv 13, 353-361

Himmerich H, Kaufmann C, Schuld A, Pollmächer T (2005): Elevation of liver enzyme levels during psychopharmacological treatment is associated with weight gain. J Psychiatr Res 39, 35-42

Hollister LE (1957): Allergy to chlorpromazine manifested by jaundice. Am J Med 23, 870-879

Hollister LE (1968): Human Pharmacology of Antipsychotic and Antidepressant Drugs. Annu Rev Pharmacol 8, 491-516

Horacek DJ, Bubenikova-Valesova V, Kopecek M, Palenicek T, Dockery C, Mohr P, Höschl C (2006): Mechanism of Action of Atypical Antipsychotic Drugs and the Neurobiology of Schizophrenia. CNS Drugs 20, 389-409

Hummer M, Kurz M, Kurzthaler I, Oberbauer H, Miller C, Fleischhacker WW (1997): Hepatotoxicity of clozapine. J Clin Psychopharmacol 17, 314317

Hyeon CK, Chung MN, Sun HJ, Kwang HH, Kyu Oh D, Suh I (2004): Normal serum aminotransferase concentration and risk of mortality from liver diseases: prospective cohort study. BMJ 328, 983

Idänpään-Heikkilä J, Alhava E, Olkinuora M, Palva IP (1977): Agranulocytosis during treatment with clozapine. Eur J Clin Pharmacol 11, 193-198

lyanagi T (2007): Molecular Mechanism of Phase I and Phase II DrugMetabolizing Enzymes: Implications for Detoxification. Int Rev Cytol 260, 35-112 
James LP, Mayeux PR, Hinson JA (2003): Acetaminophen-Induced Hepatotoxicity. Drug Metab Dispos 31, 1499-1506

Janković SM, Milovanović D, Mitrović M, Dukić-Dejanović S (1996): [Dopamine receptor subtypes]. Med Pregl 49, 281-285

Jüngst C, Gräber S, Klahn D, Wedemeyer H, Lammert F (2016): Häufigkeit und Risikofaktoren medikamentös-toxischer Leberschäden: eine umfragebasierte Studie in Apotheken. Gastroenterol 54, 131-138

Kagimoto M, Heim M, Kagimoto K, Zeugin T, Meyer UA (1990): Multiple mutations of the human cytochrome P450lID6 gene (CYP2D6) in poor metabolizers of debrisoquine. Study of the functional significance of individual mutations by expression of chimeric genes. J Biol Chem 265, 17209-17214

Kaplan MM, Righetti A (1970): Induction of rat liver alkaline phosphatase: the mechanism of the serum elevation in bile duct obstruction. Journal of Clinical Investigation $\underline{49}, 508$

Kaplowitz N (2004): Drug-Induced Liver Injury. Clin Infect Dis 38, S44-S48

Kapur S, Seeman P (2001): Does Fast Dissociation From the Dopamine D2 Receptor Explain the Action of Atypical Antipsychotics?: A New Hypothesis. Am J Psychiatry 158, 360-369

Kerr AW, Hall HK, Kozub SA: Doing Statistics with SPSS, Sage Publications, London, Thousand Oaks, New Delhi 2002

Kesterson JW, Granneman GR, Machinist JM (1984): The Hepatotoxicity of Valproic Acid and Its Metabolites in Rats. I. Toxicologic, Biochemical and Histopathologic Studies. Hepatology 4, 1143-1152

Klingenberg M (1958): Pigments of rat liver microsomes. Arch Biochem and Biophys $75,376-386$

Knable MB, Heinz A, Raedler T, Weinberger DR (1997): Extrapyramidal side effects with risperidone and haloperidol at comparable D2 receptor occupancy levels. Psychiatry Research: Neuroimaging 75, 91-101

Konstantinidis A, Papageorgiou K, Grohmann R, Horvath A, Engel R, Kasper $S$ (2012): Increase of antipsychotic medication in depressive inpatients from 2000 to 2007: results from the AMSP International Pharmacovigilance Program. Int J Neuropsychopharmacol 15, 449-457

Kraus T, Haack M, Schuld A, Hinze-Selch D, Kühn M, Uhr M, Pollmächer T (1999): Body weight and leptin plasma levels during treatment with antipsychotic drugs. Am J Psychiatry 156, 312-314 
Kroeze WK, Hufeisen SJ, Popadak BA, Renock SM, Steinberg S, Ernsberger P, Jayathilake K, Meltzer HY, Roth BL (2003): H1-histamine receptor affinity predicts short-term weight gain for typical and atypical antipsychotic drugs. Neuropsychopharmacology 28, 519-526

Kroon LA (2007): Drug interactions with smoking. Am J Health Syst Pharm 64, 1917-1921

Kuntz E, Kuntz H-D: Hepatology: Textbook and Atlas; 3. Auflage. Springer, Heidelberg 2009

Lauer UM: Leber und Gastrointestinaltrakt: Fallorientierte Einführung in die klinische Medizin. Georg Thieme, Stuttgart New York 2009

Lee D-H, Ha M-H, Christiani DC (2001): Body weight, alcohol consumption and liver enzyme activity—a 4-year follow-up study. Int J Epidemiol 30, 766-770

Lee WM (2003): Drug-Induced Hepatotoxicity. N Engl J Med 349, 474-485

Li AP (2002): A review of the common properties of drugs with idiosyncratic hepatotoxicity and the "multiple determinant hypothesis" for the manifestation of idiosyncratic drug toxicity. Chem Biol Interact 142, 723

Lidow MS, Goldman-Rakic PS, Gallager DW, Rakic P (1991): Distribution of dopaminergic receptors in the primate cerebral cortex: Quantitative autoradiographic analysis using $[3 \mathrm{H}]$ raclopride, $[3 \mathrm{H}]$ spiperone and $[3 \mathrm{H}] \mathrm{SCH} 23390$. Neuroscience 40 , 657-671

Lieberman JA (2004): Managing Anticholinergic Side Effects. Prim Care Companion J Clin Psychiatry 6, 20-23

Llinares Tello F, Hernández Prats C, Bosacoma Ros N, Pérez Martínez E, Climent Grana E, Navarro Polo JN, Ordovás Baines JP (2005): Acute cholestatic hepatitis probably associated with risperidone. Int $\mathrm{J}$ Psychiatry Med 35, 199-205

Lum G, Gambino SR (1972): Serum Gamma-Glutamyl Transpeptidase Activity as an Indicator of Disease of Liver, Pancreas, or Bone. Clin Chem 18, 358-362

Lynch MR (1992): Schizophrenia and the D1 receptor: Focus on negative symptoms. Prog Neuropsychopharmacol Biol Psychiatry 16, 797-832

Macintyre AC, Cutler DJ (1988): The potential role of lysosomes in tissue distribution of weak bases. Biopharm Drug Dispos $\underline{9}, 513-526$

Mackin P (2008): Cardiac side effects of psychiatric drugs. Hum Psychopharmacol Clin Exp 23, S3-S14 
Matsui-Sakata A, Ohtani H, Sawada Y (2005): Receptor Occupancy-based Analysis of the Contributions of Various Receptors to Antipsychoticsinduced Weight Gain and Diabetes Mellitus. Drug Metabolism and Pharmacokinetics 20, 368-378

McQuade RD, Stock E, Marcus R, Jody D, Gharbia NA, Vanveggel S, Archibald D, Carson WH (2004): A comparison of weight change during treatment with olanzapine or aripiprazole: results from a randomized, double-blind study. J Clin Psychiatry 65 Suppl 18, 47-56

Meier J, Nüesch E, Schmidt R (1974): Pharmacokinetic criteria for the evaluation of retard formulations. Eur J Clin Pharmacol 7, 429-432

Melkersson DK, Dahl M-L (2012): Adverse Metabolic Effects Associated with Atypical Antipsychotics. Drugs 64, 701-723

Meltzer HY, Alphs L, Green Al, Et al (2003): Clozapine treatment for suicidality in schizophrenia: International suicide prevention trial (intersept). Arch Gen Psychiatry 60, 82-91

Michalets EL (1998): Update: Clinically Significant Cytochrome P-450 Drug Interactions. Pharmacotherapy $\underline{18}, 84-112$

Miller DD, Caroff SN, Davis SM, Rosenheck RA, McEvoy JP, Saltz BL, Riggio S, Chakos MH, Swartz MS, Keefe RSE, et al. (2008): Extrapyramidal side-effects of antipsychotics in a randomised trial. BJP 193, 279-288

Minchin SA, Csernansky JG: Classification Schemes for Antipsychotic Drugs; in: Antipsychotics; hrsg. v. Csernansky PJG; Springer Berlin Heidelberg 1996, 1-27

Mörike K, Eichelbaum M (2000): Grundlagen der Arzneimitteltherapie und pharmakokinetische Grundbegriffe. Internist 41, 328-331

Moss DW (1982): Alkaline phosphatase isoenzymes. Clin Chem 28, 20072016

Mouradian-Stamatiadis L, Dumortier G, Januel D, Delmas BA, Cabaret W (2002): Liver function tests during treatment with antipsychotic drugs: a case series of 23 patients. Prog Neuropsychopharmacol Biol Psychiatry 26, 1409-1411

Navarro VJ, Senior JR (2006): Drug-Related Hepatotoxicity. N Engl J Med 354, 731-739

Nelson DR, Zeldin DC, Hoffman SM, Maltais LJ, Wain HM, Nebert DW (2004): Comparison of cytochrome P450 (CYP) genes from the mouse and human genomes, including nomenclature recommendations for genes, pseudogenes and alternative-splice variants. Pharmacogenetics 14, $1-18$ 
Nomura F, Ohnishi K, Koen H, Hiyama Y, Nakayama T, Itoh Y, Shirai K, Saitoh Y, Okuda K (1986): Serum cholinesterase in patients with fatty liver. J Clin Gastroenterol 8, 599-602

Ogawa K, Minase T, Enomoto K, Onoé T (1973): Ultrastructure of Fenestrated Cells in the Sinusoidal Wall of Rat Liver after Perfusion Fixation. Tohoku J Exp Med 110, 89-101

Ohkuma S, Poole B (1978): Fluorescence probe measurement of the intralysosomal $\mathrm{pH}$ in living cells and the perturbation of $\mathrm{pH}$ by various agents. Proc Natl Acad Sci U S A 75, 3327-3331

Omura T, Sato R (1962): A New Cytochrome in Liver Microsomes. J Biol Chem 237, PC1375-PC1376

Ozcanli T, Erdogan A, Ozdemir S, Onen B, Ozmen M, Doksat K, Sonsuz A (2006): Severe liver enzyme elevations after three years of olanzapine treatment: A case report and review of olanzapine associated hepatotoxicity. Prog Neuropsychopharmacol Biol Psychiatry 30, 11631166

Pae C-U, Lim H-K, Kim T-S, Kim J-J, Lee C-U, Lee S-J, Lee C, Paik I-H (2005): Naturalistic observation on the hepatic enzyme changes in patients treated with either risperidone or olanzapine alone. Int Clin Psychopharmacol 20, 173-176

Park B, Pirmohamed M, Kitteringham N (1992): Idiosyncratic drug reactions: a mechanistic evaluation of risk factors. Br J Clin Pharmacol 34, 377395

Pauli-Magnus C, Meier PJ (2006): Hepatobiliary transporters and druginduced cholestasis. Hepatology 44 , 778-787

Pelkonen O, Mäeenpäeä J, Taavitsainen P, Rautio A, Raunio H (1998): Inhibition and induction of human cytochrome P450 (CYP) enzymes. Xenobiotica 28, 1203-1253

Penn R, Worthington DJ (1983): Is serum gamma-glutamyltransferase a misleading test? Br Med J (Clin Res Ed) 286, 531-535

Perlis R, Baker RW, Zarate CA Jr, Brown EB, Schuh LM, Jamal HH, Tohen M (2006): Olanzapine versus risperidone in the treatment of manic or mixed States in bipolar I disorder: a randomized, double-blind trial. J Clin Psychiatry 67, 1747-1753

Perrier D, Gibaldi M (1974): Clearance and Biologic Half-Life as Indices of Intrinsic Hepatic Metabolism. J Pharmacol Exp Ther 191, 17-24

Perry PJ, Sanger T, Beasley C (1997): Olanzapine plasma concentrations and clinical response in acutely ill schizophrenic patients. J Clin Psychopharmacol 17, 472-477 
Pessayre D, Mansouri A, Haouzi D, Fromenty B (1999): Hepatotoxicity due to mitochondrial dysfunction. Cell Biol Toxicol 15, 367-373

Pollock BG (1994): Recent Developments in Drug Metabolism of Relevance to Psychiatrists. Harv Rev Psychiatry 2, 204-213

Prior TI, Baker GB (2003): Interactions between the cytochrome P450 system and the second-generation antipsychotics. J Psychiatry Neurosci 28, 99-112

Rantala AO, Lilja M, Kauma H, Savolainen MJ, Reunanen A, Kesäniemi YA (2000): Gamma-glutamyl transpeptidase and the metabolic syndrome. J Intern Med 248, 230-238

Reed JC (2001): Apoptosis-regulating proteins as targets for drug discovery. Trends in Molecular Medicine 7, 314-319

Regal R, Billi J, Glazer H (1987): Phenothiazine-induced cholestatic jaundice. Clin Pharm $\underline{6}, 787-794$

Rettenbacher MA, Baumgartner S, Eder-Ischia U, Edlinger M, Graziadei I, Hofer A, Huber R, Hummer M, Kemmler G, Weiss E, Fleischhacker WW (2006): Association between antipsychotic-induced elevation of liver enzymes and weight gain: a prospective study. J Clin Psychopharmacol 26, 500-503

Reuben A, Koch DG, Lee WM (2010): Drug-Induced Acute Liver Failure: Results of a U.S. Multicenter, Prospective Study. Hepatology 52, 20652076

Reynolds GP, Kirk SL (2010): Metabolic side effects of antipsychotic drug treatment - pharmacological mechanisms. Pharmacol Ther $\underline{125}$, 169179

Riederer PF, Laux G: Grundlagen Der Neuro-Psychopharmakologie: Ein Therapiehandbuch. Springer, Wien New York 2010

Ring BJ, Binkley SN, Vandenbranden M, Wrighton SA (1996): In vitro interaction of the antipsychotic agent olanzapine with human cytochromes P450 CYP2C9, CYP2C19, CYP2D6 and CYP3A. Br J Clin Pharmacol 41, 181-186

Robin M-A, Roy ML, Descatoire V, Pessayre D (1997): Plasma membrane cytochromes P450 as neoantigens and autoimmune targets in druginduced hepatitis. J Hepatol 26, Supplement 1, 23-30

Rüther RGE: Unerwünschte Wirkungen von Psychopharmaka: Ergebnisse der AMÜP-Studie. Springer, Berlin Heidelberg 1994

Salvaggio A, Periti M, Miano L, Tavanelli M, Marzorati D (1991): Body mass index and liver enzyme activity in serum. Clin chem 37, 720-723 
Schäfer H (1997): Post-Approval Drug Research: Objectives and Methods. Pharmacopsychiatry $\underline{30,4-8}$

Schatzberg AF, Nemeroff CB: The American Psychiatric Publishing Textbook of Psychopharmacology. American Psychiatric Pub, Washington London 2009

Schimmelpfeng-Schütte VR (2004): Recht auf Behandlung und Off-LabelUse in der Gesetzlichen Krankenversicherung (GKV). MedR 22, 655659

Schmidt $\mathrm{H}$ : Pharmakologie und Toxikologie: für Studium und Praxis. Schattauer, Stuttgart 2007

Schneider K: Klinische Psychopathologie. Georg Thieme, Stuttgart New York 2007

Schott H, Tölle R: Geschichte der Psychiatrie: Krankheitslehren, Irrwege, Behandlungsformen. C.H.Beck, München 2006

Seeman MV (2004): Gender Differences in the Prescribing of Antipsychotic Drugs. Am J Psychiatry 161, 1324-1333

Sherlock S, Dooley J: Diseases of the Liver and Biliary System: Eleventh Edition. Blackwell Publishing, Oxford 2008

Shpaner A, Li W, Ankoma-Sey V, Botero RC (2008): Drug-induced liver injury: hepatotoxicity of quetiapine revisited. Eur J Gastroenterol Hepatol 20, 1106-1109

Smith S (2010): Gender differences in antipsychotic prescribing. Int Rev Psychiatry 22, 472-484

Stahl SM (2003): Describing an atypical antipsychotic: receptor binding and its role in pathophysiology. Prim Care Companion J Clin Psychiatry $\underline{5}$, 9-13

Tecott LH, Sun LM, Akana SF, Strack AM, Lowenstein DH, Dallman MF, Julius D (1995): Eating disorder and epilepsy in mice lacking 5-HT2C serotonin receptors. Nature $374,542-546$

Temple R (2006): Hy's law: predicting serious hepatotoxicity. Pharmacoepidem Drug Safe 15, 241-243

Thomas L: Labor und Diagnose: Indikation und Bewertung von Laborbefunden für die medizinische Diagnostik. TH-Books, Frankfurt 1998

Thummel KE, Kunze KL, Shen DD (1997): Enzyme-catalyzed processes of first-pass hepatic and intestinal drug extraction. Advanced Drug Delivery Reviews 27, 99-127 
Tillmann B: Anatomie; 2. Auflage. Springer, Heidelberg 2010

Toerring-Jettenbach AG zu, Issels R-D: Hepatologie, Gallenwege, Pankreas; In: Schaps K-P, Kessler O, Fetzner U (Hrsg.) Innere Medizin; Springer, Berlin Heidelberg 2007, 147-173

Tschoner A, Engl J, Laimer M, Kaser S, Rettenbacher M, Fleischhacker WW, Patsch JR, Ebenbichler CF (2007): Metabolic side effects of antipsychotic medication. International Journal of Clinical Practice 61, 1356-1370

Van Hoof VO, De Broe ME (1994): Interpretation and Clinical Significance of Alkaline Phosphatase Isoenzyme Patterns. Crit Rev Clin Lab Sci 31, 197-293

Vestal RE, Kornhauser DM, Shand DG (1980): Active uptake of propranolol by isolated rabbit alveolar macrophages and its inhibition by other basic amines. J Pharmacol Exp Ther 214, 106-111

Wachtler F: Histologie: Lehrbuch der Zytologie, Histologie und mikroskopischen Anatomie des Menschen, 7. Auflage. Facultas Maudrich, Wien 2005

Warnes TW (1972): Alkaline phosphatase. Gut 13, 926-937

Warnes TW, Hine P, Kay G (1977): Intestinal alkaline phosphatase in the diagnosis of liver disease. Gut 18, 274-278

Welsch U, Sobotta J: Lehrbuch Histologie: Zytologie, Histologie, mikroskopische Anatomie ; mit 21 Tabellen. 2. Auflage. Elsevier Urban \& Fischer, München Jena 2006

Whitfield JB, Pounder RE, Neale G, Moss DW (1972): Serum y-glutamyl transpeptidase activity in liver disease. Gut $13,702-708$

Widmann J-J, Cotran RS, Fahimi HD (1972): Mononuclear phagocytes (kupffer cells) and endothelial cells. J Cell Biol 52, 159-170

Wirshing DA, Wirshing WC, Kysar L, Andrew M, Goldstein D, Pashdag J, Mintz J, Marder SR (1999): Novel antipsychotics: Comparison of weight gain liabilities. J Clin Psychiatry 60, 358-363

Wright TM, Vandenberg AM (2007): Risperidone- and quetiapine-induced cholestasis. Ann Pharmacother 41, 1518-1523

Wroblewski DH, Schmickler M (2005): Bewertung von SUSARs. Bundesgesundheitsbl - Gesundheitsf - Gesundheitsschutz 48, 459-463

Zanger UM, Turpeinen M, Klein K, Schwab M (2008): Functional pharmacogenetics/genomics of human cytochromes P450 involved in drug biotransformation. Anal Bioanal Chem 392, 1093-1108 


\section{DANKSAGUNG}

Ich danke allen voran meinem Betreuer und Doktorvater Prof. Dr. med. Detlef Degner für die Vergabe des interessanten Promotionsthemas, die fachliche Betreuung und Unterstützung bei der Anfertigung meiner Arbeit. Besonders möchte ich mich dafür bedanken, dass er mir die Möglichkeit gab, Ergebnisse dieser Arbeit auf dem Kongress der AGNP in München im September 2015 vorzustellen.

Weiterhin möchte ich mich bei Frau Dr. med. Renate Grohmann bedanken, die als eine der Mitbegründerinnen des AMSP jederzeit für Fragen zur Verfügung stand und mir sehr bei der Aufarbeitung der Daten weiterhalf.

Bei der medizinischen Statistik der Universitätsmedizin Göttingen möchte ich mich für die fachliche Beratung bei der statistischen Aufarbeitung meiner Daten bedanken 